FÁBIO CONTE CORREIA

COPOLÍMEROS EMISSORES DE LUZ CONTENDO GRUPOS FLUORENO E QUINOLINA: PREPARAÇÃO, CARACTERIZAÇÃO E MONTAGEM DE LEDs 
FÁBIO CONTE CORREIA

\title{
COPOLÍMEROS EMISSORES DE LUZ CONTENDO GRUPOS FLUORENO E QUINOLINA: PREPARAÇÃO, CARACTERIZAÇÃO E MONTAGEM DE LEDS
}

\author{
Dissertação apresentada à Escola \\ Politécnica da Universidade de São Paulo \\ para obtenção do titulo de Mestre em \\ Engenharia.
}

SÃO PAULO 
FÁBIO CONTE CORREIA

\section{COPOLÍMEROS EMISSORES DE LUZ CONTENDO GRUPOS FLUORENO E QUINOLINA: PREPARAÇÃO, CARACTERIZAÇÃO E MONTAGEM DE LEDs}

Dissertação apresentada à Escola

Politécnica da Universidade de São Paulo

para obtenção do titulo de Mestre em

Engenharia.

Área de Concentração:

Engenharia Metalúrgica e de Materiais

Orientadora: Prof $\stackrel{a}{\text {. }}$. Dr ${ }^{\mathrm{a}}$. Wang Shu Hui

SÃO PAULO 
Este exemplar foi revisado e alterado em relação à versão original, sob responsabilidade única do autor e com a anuência de seu orientador.

São Paulo, 04 de agosto de 2009.

Assinatura do autor

Assinatura do orientador

FICHA CATALOGRÁFICA

Correia, Fábio Conte

Copolímeros emissores de luz contendo grupos fluoreno e quinolina: preparação, caracterização e montagem de LEDs /

F.C. Correia. -- ed.rev. -- São Paulo, 2009.

$122 \mathrm{p}$.

Dissertação (Mestrado) - Escola Politécnica da Universidade de São Paulo. Departamento de Engenharia Metalúrgica e de Materiais.

1. Polímeros (Materiais) 2. Dispositivos eletrônicos I. Universidade de São Paulo. Escola Politécnica. Departamento de Engenharia Metalúrgica e de Materiais II. t. 


\section{DEDICATÓRIA}

Dedico este trabalho aos meus pais José

Mario e Marisa, ao meu irmão Fernando, minhas avós Vera e Hilda e a minha namorada Géssica. 


\section{AGRADECIMENTOS}

Agradeço a todos aqueles que, de alguma forma, direta ou indiretamente, contribuíram para a realização deste trabalho, principalmente:

Aos meus pais pelo apoio incondicional, e por terem me dado a oportunidade de me dedicar exclusivamente a esse trabalho.

Á professora Dra. Wang Shu Hui, pela confiança, paciência e por todo tempo em que se dedicou a me ensinar.

Á professora Dra. Laura Oliveira Péres Philadelphi, pelos conhecimentos iniciais, dicas e conselhos.

Ao Dr. Walker Soares Drummond e a Dra Telma Moura, pela amizade, ajuda e pelos conselhos.

Á MSc. Tunísia Eufrausino Schuler, pela amizade e auxilio nas preparações iniciais dos dispositivos.

Ao Dr. Gerson dos Santos e principalmente ao Dr. Emerson Roberto Santos, pela grande ajuda nas montagens e caracterizações dos inúmeros dispositivos fabricados neste trabalho.

Ao professor Dr. Fernando Josepetti Fonseca e ao professor Dr. Roberto Koji Onmori por permitirem que eu utilizasse as estruturas do Grupo de Eletrônica Molecular (GEM) para a fabricação dos PLEDs,

Ao Técnico Marco da sala limpa do LME pela metalização dos dispositivos.

Ao CNPq pela bolsa de mestrado. 


\section{RESUMO}

Visando o crescente interesse em pesquisa de novos materiais para a fabricação de dispositivos eletrônicos a base de polímeros semicondutores, com elevado potencial para a fabricação de diodos emissores de luz poliméricos os (PLEDs - Polymer light-emitting diodes), este presente trabalho teve como objetivo a síntese de novos copolímeros através da reação de acoplamento de Suzuki e a sua fabricação de PLEDs com esses novos materiais.

É conhecido que um dos grandes problemas na fabricação desses dispositivos é propiciar um maior número de recombinações elétrons/ lacunas no interior de suas camadas ativas com a finalidade de aumentar a emissão de luz visivel. Para amenizar esse problema os copolímeros sintetizados tiveram como finalidade unir num único material, a propriedade de transporte de elétrons associada à boa emissão de luz.

O objetivo final foi elevar a injeção de elétrons contribuindo para aumentar o número de recombinações dos pares elétrons/lacunas, resultando em aumento de eletroluminescência e de eficiência dos dispositivos.

Os copolímeros inéditos foram sintetizados e caracterizados por ressonância magnética nuclear hidrogênio, termogravimetria, calorimetria diferencial exploratória, espectroscopia no UV-Vis e no infravermelho, fluorimetria no UV-vis, cromatografia de permeação em gel e voltametria cíclica.

Os copolímeros foram também utilizados como camada ativa na construção de uma série de PLEDs com arquiteturas diferentes, tanto puro como em mistura com o poli(N-vinilcarbazol) (PVK), ou, ainda, utilizando tris-8-hidroxiquinolina alumínio $\left(\mathrm{Alq}_{3}\right)$ como camada transportadora de elétrons ( $\mathrm{ETL}$ - Electron transport layer). Os dispositivos foram caracterizados quanto ao comportamento elétrico, pelas curvas de corrente por tensão $(\mathrm{IxV})$, e à sua eletroluminescência. Os PLEDS fabricados com os copolímeros sintetizados mostraram que não necessitam do uso de uma camada transportadora de elétrons, ETLs, adicional. 


\begin{abstract}
Polymer light-emitting diodes (PLEDs) have been heavily researched since their initial fabrication and utilization. In order to improve the efficiency of polymeric light-emitting devices, new materials have been studied. This present study focuses in the preparation of new copolymers by Suzuki coupling reaction and then evaluate the copolymers as active layer in PLEDs.

It is well known that the performance of PLEDs is still limited by the number of electron/hole recombination. To overcome this problem, a new material is proposed to integrate the functions of $n$ charge carrier and light emission through copolymerization.

Novel copolymers were synthesized and characterized by hydrogen nuclear magnetic resonance, thermogravimetry, and differential scanning calorimetry, UVVis, Fluorescence and IR spectroscopy, GPC and cyclic voltammetry.

Copolymers thus prepared were used as active layer in a series of PLEDs with different architectures, pure and in blends with poly(N-vinylcarbazole) (PVK), as well as with tris-8 hydroxyquinoline aluminum (Alq3) as an extra electron transport layer.

The devices were characterized concerning their electrical behavior, by the characteristic $\mathrm{J}-\mathrm{V}$ diode curves, and their electroluminescence. It was demonstrated that the PLEDs built with the synthesized copolymers do not need an extra ETL.
\end{abstract}




\section{LISTA DE ILUSTRAÇÕES}

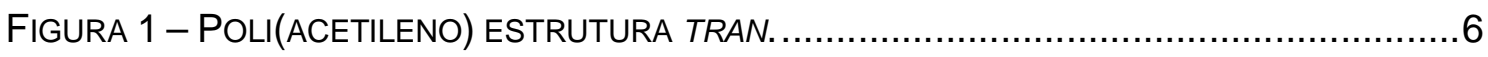

FIGURA 2 - FORMAÇÃO DE ORBITAIS EM UM POLÍMERO CONJUGADO................................7

FIGURA 3 - REPRESENTAÇÃO DOS ORBITAIS MOLECULARES $\Pi$ E $\Sigma$ FORMADOS ENTRE DOIS

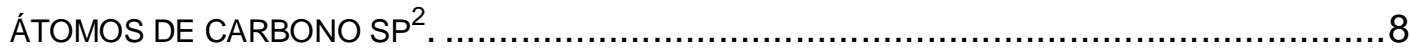

FIGURA 4 - MOLÉCULA DE BENZENO COM OS ELÉTRONS DELOCALIZADOS NA CADEIA............8

FIGURA 5 - DISTRIBUIÇÃO DE ESTADOS ELETRÔNICOS EM UMA MOLÉCULA DE BENZENO........8

FIGURA 6 - FORMAÇÃO DE BANDAS DE ENERGIA EM UMA CADEIA POLIMÉRICA DE PPV. .......9

FIGURA 7 - REPRESENTAÇÃO ESQUEMÁTICA DAS CLASSES DOS SÓLIDOS SEGUNDO AO SEU GAP ENERGÉTICO. A) MATERIAIS ISOLANTES (EG > 5EV); B) SEMICONDUTORES ( $1<$ EG $<5 \mathrm{EV})$; C) CONDUTORES (EG < 1EV) . .................................................... 10

FIGURA 8 - A) ROTA DE ACOPLAMENTO DE YAMAMOTO E B) ROTA DE ACOPLAMENTEO DE

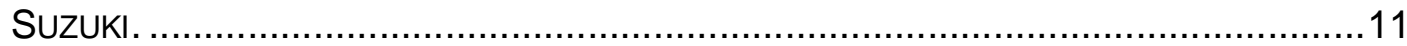

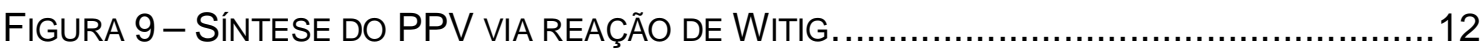

FIGURA 10 - ESQUEMA DE UMA POLIMERIZAÇÃO VIA REAÇÃO DE GILCH ${ }^{11} \ldots \ldots \ldots \ldots \ldots \ldots \ldots . . . . . . . . . .12$

FIGURA 11 - ESQUEMA DE UMA POLIMERIZAÇÃO VIA REAÇÃO DE KNOEVENAGEL ${ }^{13} \ldots \ldots \ldots . . .13$

FIGURA 12 - ESQUEMA DE ACOPLAMENTO ENTRE ARILAS HALOGENADAS E BORONADAS POR

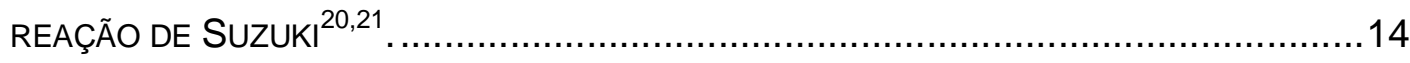

FIGURA 13 - A) POLI[2,6-(4-FENILQUINOLINA) B)5,7-DIBROMO-8-OXIOCTIL-QUINOLINA. .....16

FIGURA 14 - ESTRUTURA ESQUEMÁTICA DE UM PLED COM UM FILME FINO DE POLIQUINOLINA ${ }^{34}$.

FIGURA 15 - ESTRUTURA QUÍMICA DO FLUORENO (NUMERAÇÃO DOS CARBONOS DE ACORDO COM A IUPAC). 18

FIGURA 16 - POLI(9,9-DIHEXILFLUORENO), SINTETIZADO POR YOSHINO EM $1989^{45} \ldots \ldots \ldots . . . .19$

FIGURA 17 - ForMULA ESTRUTURAL DO: A) MONÔMERO NVK; B) POLÍMERO DE PVK........20

FIGURA 18 - PROCESSO DE ABSORÇÃO E EMISSÃO ENTRE OS ESTADOS ELETRÔNICOS FUNDAMENTAL S0 E EXCITADO S*, DE UMA MOLÉCULA ORGÂNICA. ..........................22

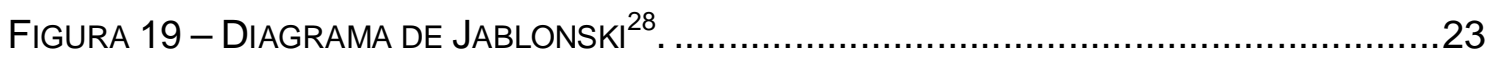

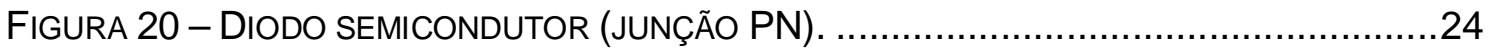

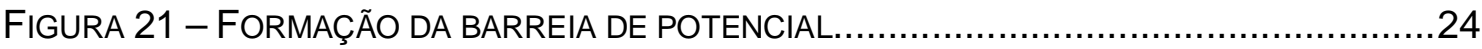

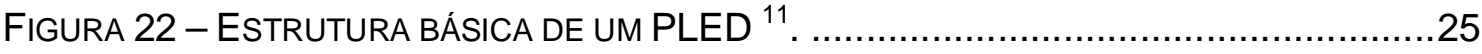


FIGURA 23 - DIAGRAMA DE BANDAS DE UM PLED DE CAMADA SIMPLES.

FIGURA 24 - ESTRUTURA QUÍMICA DO: A) POLI(3,4-ETILENODIOXITIOFENO) (PEDOT); B)

POLI(4-SULFONATO DE ESTIRENO) (PSS)

27

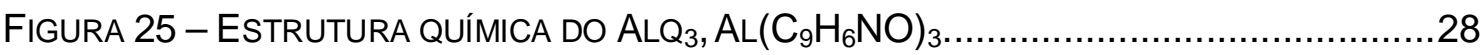

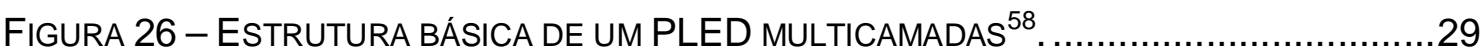

FIGURA 27 - MATERIAIS DE PARTIDA UTILIZADOS NAS SÍNTESES: A) 5,7-DIBROMO-8-

OXIOCTIL-QUINOLINA; B) 1,4-FENILENO-BISBORÔNICO; C) 9,9-DIOCTIL-2,7-

DIBROMOFLUORENO; D) 1,4 DICLOROBENZENO.

FIGURA 28 - SISTEMA DE REFLUXO UTILIZADO NAS SÍNTESES DOS COPOLÍMEROS.

FIGURA 29 - ESQUEMA DA CÉLULA ELETROQUÍMICA EM H UTILIZADA NAS MEDIDAS DE

VOLTAMETRIA CÍCLICA.

FIGURA 30 - GEOMETRIA E DISPOSIÇÕES DOS PLEDS NO SUBSTRATO.

FIGURA 31 - A) LÂMINA DE VIDRO RECOBERTA COM ITO; B) LAMINA APÓS A ETAPA DE

CORROSÃO DO ITO.

FIGURA 32 - ESQUEMA DO REATOR UTILIZADO PARA LIMPEZA SUPERFICIAL DO ITO.

FIGURA 33 - A) ESQUEMA DE DEPOSIÇÃO PELO MÉTODO SPIN-COATING; B) SPINNER

UTILIZADO

FIGURA 34 - A) LÂMINA COM A REGIÃO ATIVA DO DISPOSITIVO DEFINIDA; B) LÂMINA COM

PDOT DEPOSITADO E DACAPADO; C) ESQUEMA DA ESTRUTURA VISTA EM CORTE TRANSVERSAL.

FIGURA 35 - GEOMETRIA DA LAMINA APÓS A DEPOSIÇÃO E DECAPAGEM DO COPOLÍMERO.50

FIGURA 36 - FOTO DA EVAPORADORA DA SALA LIMPA DO LABORATÓRIO DE

MICROELETRÔNICA (LME)

FIGURA 37 - ESTRUTURA FINAL DO DISPOSITIVO APÓS A DEPOSIÇÃO DO ALUMÍNIO

FORMANDO OS ELETRODOS.

FIGURA 38 - MEDIÇÃO DE ESPESSURA POR PERFILOMETRIA................................... 52

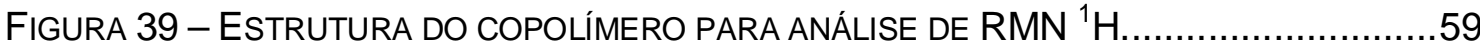

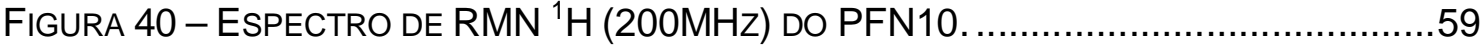

FIGURA 41 - ESPECTRO DE RMN ${ }^{1} \mathrm{H}$ (REGIÃO 1) . ..........................................60

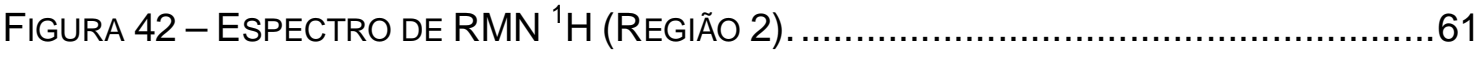

FIGURA 43 - ESPECTRO DE RMN ${ }^{1} \mathrm{H}$ SIMULADO ...........................................62

FIGURA 44 - ESPECTRO DE RMN ${ }^{1} \mathrm{H}(200 \mathrm{MHZ})$ DO MATERIAL DE PARTIDA 5,7-DIBROMO-8-

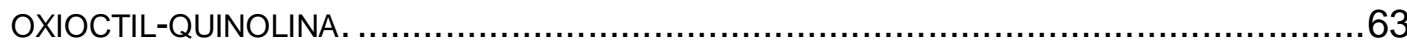

FIGURA 45 - ESPECTRO DE INFRAVERMELHO DOS COPOLÍMEROS..............................64 
FIGURA 46 - ESPECTRO DE INFRAVERMELHO DO COPOLÍMERO PFN10 (REGIÃO 1)......

FIGURA 47 - ESPECTRO DE INFRAVERMELHO DOS COPOLÍMEROS PFN01 E PFN02 (REGIÃO

2) 66

FIGURA 48 - ESPECTRO DE INFRAVERMELHO DO COPOLÍMERO PFN10 (REGIÃO 2)..........66

FIGURA 49 - IMAGEM DE EDX DO COPOLÍMERO PFN02. ....................................67

FIGURA 50 - IMAGEM DE EDX DO COPOLÍMERO PFN10 .....................................67

FIGURA 51 - TGA DOS COPOLÍMEROS PFN01, PFN02 E PFN10 .............................69

FIGURA 52 - DERIVADA DOS GRÁFICOS DE TGA dOS COPOLÍMEROS PFN01, PFN02 E

PFN10 RESPECTIVAMENTE. .................................................................... 70

FIGURA 53 - MEDIDAS DE DSC DOS COPOLÍMEROS PFN01 E PFN10 ...........................71

FIGURA 54 - ESPECTRO DE ABSORBÂNCIA NO UV-VIS DOS COPOLÍMEROS PFN1, PFN2 E

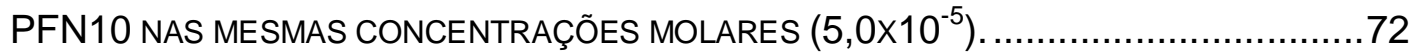

FIGURA 55 - ESPECTROS DE ABSORÇÃO NO UV-VIS DOS COPOLÍMEROS PFN2 E PFN10 EM

DIFERENTES CONCENTRAÇÕES.

FIGURA 56 - VARIAÇÃO DA INTENSIDADE DA ABSORBÂNCIA VS. VARIAÇÃO DA

CONCENTRAÇÃO MOLAR, PARA O PICO DE 314NM (PFN01 E PFN02) E PARA O PICO DE

330NM (PFN10).

FIGURA 57 - GRÁFICO COMPARATIVO E ABSORBÂNCIA NO UV-VIS DOS MATERIAIS DE

PARTIDA COM OS COPOLÍMEROS PFN02 E PFN10 .......................................... 75

FIGURA 58 - ESPECTRO DE FLUORESCÊNCIA DOS COPOLÍMEROS PFN01 E PFN02

EXCITADO EM 330NM E DO PFN10 EXCITADO EM 315NM NAS MESMAS

CONCENTRAÇÕES $\left(1,0 \times 10^{-5}\right)$.

FIGURA 59 - ESPECTRO DE FLUORESCÊNCIA DOS COPOLÍMEROS EXCITADOS EM 245NM

$\left(5,0 \times 10^{-5} \mathrm{MOL} / \mathrm{L}\right)$.

FIGURA 60 - ESPECTRO DE FLUORESCÊNCIA DO COPOLÍMERO PFN02 NUMA

CONCENTRAÇÃO DE $2,5 \times 10^{-5}$, VARIANDO O COMPRIMENTO DE ONDA DE EXCITAÇÃO. .. 77

FIGURA 61 - ESPECTRO DE FLUORESCÊNCIA DO COPOLÍMERO PFN10 NUMA

CONCENTRAÇÃO DE $1,0 \times 10^{-5}$, VARIANDO O COMPRIMENTO DE ONDA DE EXCITAÇÃO. ..78

FIGURA 62 - ESPECTRO DE FLUORESCÊNCIA DOS COPOLÍMEROS PFN02 E PFN10 EM

DIFERENTES CONCENTRAÇÕES.

FIGURA 63 - VARIAÇÃO DA INTENSIDADE DE EMISSÃO VS. VARIAÇÃO DA CONCENTRAÇÃO

PARA OS COPOLÍMEROS.

FIGURA 64 - ESPECTRO DE FLUORESCÊNCIA DOS MATERIAIS DE PARTIDA E DOS

COPOLÍMEROS. 
FIGURA 65 - ESPECTRO DE ABSORÇÃO E FLUORESCÊNCIA NO UV-VIS DOS COPOLÍMEROS.

FIGURA 66 - ESTRUTURA QUÍMICA DA QUININA.

FIGURA 67 - ESPECTRO DE FLUORESCÊNCIA DO SULFATO DE QUININA NA CONCENTRAÇÃO DE $1,0 \times 10^{-5}$.

FIGURA 68 - ESPECTRO DE FLUORESCÊNCIA DOS COPOLÍMEROS NA CONCENTRAÇÃO DE

$1,0 \times 10^{-5} \mathrm{MOL} / \mathrm{L}$, PFN01, PFN02 EXCITADO EM 314NM E PFN10 EM 330NM. .83

FIGURA 69 - VOLTAMETRIA CÍCLICA DOS COPOLÍMEROS PFN02 E PFN10. 84

FIGURA 70 - MICROSCOPIA ÓTICA DO ITO SOBRE VIDRO, COM AUMENTO DE 500X (MENOR DIVISÃO 2MM).

FIGURA 71 - MICROSCOPIA ÓPTICA DO FILME DE PEDOT SOBRE ITO, COM AUMENTO DE 500X (MENOR DIVISÃO 2MM).

FIGURA 72. MICROSCOPIA ÓPTICA DO FILME DO COPOLÍMERO PFN2 SOBRE ITO AUMENTO DE 500X (MENOR DIVISÃO 2MM).

FIGURA 73. MICROSCOPIA ÓPTICA DO FILME DO COPOLÍMERO PFN2 DOBRE

PDOT/ITO/VIDRO, AUMENTO DE 1000X (MENOR DIVISÃO 1MM).

FIGURA 74 - MICROSCOPIA ÓPTICA DO FILME DO COPOLÍMERO PFN2 COM 10\% DE PVK SOBRE PDOT/ITO/VIDRO, AUMENTO DE 1000X (MENOR DIVISÃO 1MM). .88

FIGURA 75. MICROSCOPIA ÓPTICA DO FILME DO COPOLÍMERO PFN2 COM 20\% DE PVK DOBRE PDOT/ITO/VIDRO, AUMENTO DE 500X (MENOR DIVISÃO 2MM).....................8

FIGURA 76 - ESPECTRO DE ABSORBÂNCIA NO UV-VIS EM FILME...................................90

FIGURA 77 - ESQUEMA DE TESTES ELÉTRICOS.

Figura 78 - CuRVA DE CoRRENTE VS. TENSÃO DO DISPOSITIVO SEM TRATAMENTO SOBRE O

ITO, COM O COPOLÍMERO PFN02 PURO, COM 10\% E 20\% EM MASSA DE PVK...........92

FIGURA 79 - CuRVA DE CORRENTE VS. TENSÃO DO DISPOSITIVO COM TRATAMENTO SOBRE

O ITO, COM O COPOLÍMERO PFN02 PURO, COM 10\% E 20\% EM MASSA DE PVK.......93

FIGURA 80 - CuRVA DE CORRENTE VS. TENSÃO PARA COMPARAÇÃO DA TENSÃO DE OPERAÇÃO DO COPOLÍMERO SEM TRATAMENTO DO ITO, PURO, COM 10\% E 20\% EM MASSA DE PVK

Figura 81 - CuRVA de CoRRENTE Vs. TENSÃo COM E SEM TRATAMENTO SOBRE O ITO COM ETL. 94

FIGURA 82 - ESPECTRO DE EL DO PLED - ITO/PEDOT/PFNO2/AL .95 
FIGURA 83 - ESPECTRO ELETROMAGNÉTICO MOSTRANDO AS FAIXAS DE COMPRIMENTO DE ONDA DE ALGUNS TIPOS DE ONDA ELETROMAGNÉTICA E A BANDA CORRESPONDENTE À LUZ VISÍVEL. 95

FIGURA 84 - CURVA CARACTERÍSTICA DENSIDADE DE CORRENTE VS. TENSÃO E DE LUMINÂNCIA DO PLED ITO/PEDOT/PFN10/AL. ............................................. 96

FIGURA 85 - REGISTRO FOTOGRÁFICO DO DISPOSITIVO ITO/PDOT/PFN10/AL. ..............97

FIGURA 86 - ESPECTRO DE EL DO PLED - ITO/PEDOT/PFN10/AL...........................97

FIGURA 87 - DIAGRAMA DE CROMATICIDADE COM AS COORDENADAS X E Y DA EL DO DISPOSITIVO ITO/PEDOT/PFN10/AL. ........................................................... 98 


\section{LISTA DE TABELAS}

TABELA 1 - ESTRUTURA E SUA ENERGIA E $\mathrm{G}_{\mathrm{G}}$ DE ALGUNS POLÍMEROS SEMICONDUTORES.....10

TABELA 2 - MASSA MOLAR E MASSAS DO REAGENTES UTILIZADAS NAS SÍNTESES.

TABELA 3. COMPARAÇÃO ENTRE AS DIFERENTES ROTAS SINTÉTICAS, OS RENDIMENTOS OBTIDOS E AS MASSAS MOLARES CALCULADAS

TABELA 4 - MASSAS MOLARES DOS POLÍMEROS DETERMINADAS POR GPC UTILIZANDO-SE

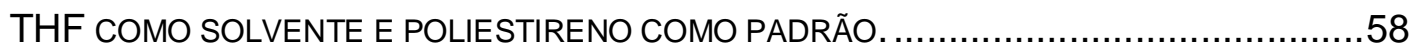

TABELA 5 - IDENTIFICAÇÃO DOS DESLOCAMENTOS QUÍMICOS DO COPOLÍMERO. 62

TABELA 6 - IDENTIFICAÇÃO DOS DESLOCAMENTOS QUÍMICOS DO 5,7-DIBROMO-8-OXIOCTILQUINOLINA. 63

TABELA 7 - QUANTIFICAÇÃO DOS ELEMENTOS QUÍMICOS NA ESTRUTURA DOS COPOLÍMEROS.

TABELA 8 - TABELA DE VALORES DOS RENDIMENTOS QUÂNTICOS CALCULADOS. .83

TABELA 9 - VALORES DE HOMO, LUMO E GAP CALCULADOS ATRAVÉS DOS DADOS DE VOLTAMETRIA CÍCLICA. .85

TABELA 10 - TABELA COM AS MEDIDAS DE ESPESSURAS DOS FILMES FINOS. 89

TABELA 11 - VARIAÇÃO DAS TENSÕES DE LIMIAR DO DISPOSITIVO SEM TRATAMENTO, VARIANDO A QUANTIDADE DE PVK. 92

TABELA 12 - VARIAÇÃO DAS TENSÕES DE LIMIAR DO DISPOSITIVO COM TRATAMENTO, VARIANDO A QUANTIDADE DE PVK. 


\section{LISTA DE ABREVIATURAS E SIGLAS}

\begin{tabular}{|c|c|}
\hline $\mathrm{Alq}_{3}$ & 8-hidroxiquinolina alumínio \\
\hline $\mathrm{CDCl}_{3}$ & clorofórmio deuterado \\
\hline CIE & Coordenadas do diagrama de cromaticidade \\
\hline DSC & Calorimetria Diferencial Exploratória \\
\hline$E_{A E}$ & afinidade eletrônica \\
\hline $\mathrm{E}_{\mathrm{g}}$ & Energia de gap \\
\hline EL & Eletroluminescência \\
\hline $\mathrm{E}_{\mathrm{PI}}$ & potencial de ionização \\
\hline ETLs & Electrons transport layers - Camada transportadora de elétrons \\
\hline eV & Elétron-volt \\
\hline $\mathrm{F}$ & Fluorescência \\
\hline gap & Banda de energia \\
\hline GPC & Cromatografia de permeação em gel \\
\hline HOMO & $\begin{array}{l}\text { Highest Occupied Molecular Orbital - Mais alto orbital molecular } \\
\text { ocupado }\end{array}$ \\
\hline HTLs & Hole transport layers - camada transportadora de buracos \\
\hline IC & internal convertion - conversão interna \\
\hline ITO & Indium Tin Oxide - Oxido de Índio e Estanho \\
\hline IV & Infravermelho \\
\hline LED & light-emitting diode - Diodo emissor de Luz. \\
\hline LUMO & $\begin{array}{l}\text { Lowest Unoccupied Molecular Orbital- Mais baixo orbital } \\
\text { molecular }\end{array}$ \\
\hline MEV & Microscópio eletrônico de varredura \\
\hline mmol & Milemol \\
\hline $\mathrm{nm}$ & Nanômetro \\
\hline NVK & N-vinilcarbazol \\
\hline OFET & $\begin{array}{l}\text { Organic Field-Effect Transistor - Transistores de efeito de campo } \\
\text { orgânicos }\end{array}$ \\
\hline
\end{tabular}




$\begin{array}{ll}\text { OLEDs } & \text { organic light-emitting diode - Diodos orgânicos emissores de luz } \\ \text { PDOT/PSS } & \text { poli(3,4-etilenodioxitiofeno):poli(4-sulfonato de estireno) } \\ \text { PET } & \text { Polietileno teraftalato } \\ \text { PL } & \text { Fotoluminescência } \\ \text { PLEDS } & \begin{array}{l}\text { Polymer light-emitting diodes - Diodos emissores de luz } \\ \text { poliméricos }\end{array} \\ \text { ppm } & \text { partes por milhão } \\ \text { PPV } & \text { poli(p-fenilenovinileno) } \\ \text { PS } & \text { Poliestireno } \\ \text { PVK } & \text { poli(N-vinil-carbazol) } \\ \text { PVK } & \text { poli(N-vinil-carbazol) } \\ \text { r } & \text { distância interatômica (Å) } \\ \text { RPM } & \text { Rotações por minuto } \\ \text { SCE } & \text { saturated calomel electrode-eletrodo de calomelano saturado } \\ T_{g} & \text { Transição vítrea } \\ \text { TGA } & \text { Análise Termogravimétrica } \\ \text { THF } & \text { tetra-hidrofurano } \\ \text { TMS } & \text { Tetrametilsilano } \\ \text { UV-O } & \text { Ultra-violeta-ozônio } \\ \text { UV-Vis } & \text { Ultravioleta-visível } \\ \text { VC } & \text { Voltametria Cíclica }\end{array}$




\section{LISTA DE SÍMBOLOS}

$\begin{array}{ll}\mathrm{Al} & \text { Alumínio } \\ \mathrm{Au} & \text { Ouro } \\ \mathrm{Ca} & \text { Cálcio } \\ \mathrm{GaAs} & \text { Arseneto de Gálio } \\ \mathrm{h} & \text { constante de Planck }\left(\mathrm{m}^{2} \cdot \mathrm{kg} / \mathrm{s}\right) \\ \mathrm{HCl} & \text { Ácido clorídrico } \\ \lambda & \text { Comprimento de onda }(\mathrm{nm}) \\ \mathrm{Si} & \text { Silício } \\ \Delta_{\mathrm{e}} & \text { Barreira de potencial para injeção de elétrons } \\ \pi & \text { orbital molecular ligante } \\ \Pi^{*} & \text { orbital molecular anti-ligante } \\ \sigma & \text { orbital molecular ligante } \\ \sigma^{*} & \text { orbital molecular anti-ligante } \\ \phi_{\mathrm{a}} & \text { Função trabalho do ânodo } \\ \phi_{\mathrm{c}} & \text { função trabalho do cátodo } \\ \phi_{\text {HOMO }} & \text { nível de energia do HOMO } \\ \phi_{\text {LUMO }} & \text { nível de energia do LUMO }\end{array}$




\section{SUMÁRIO}

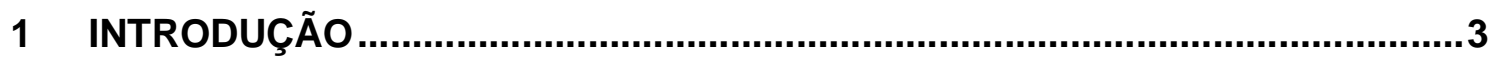

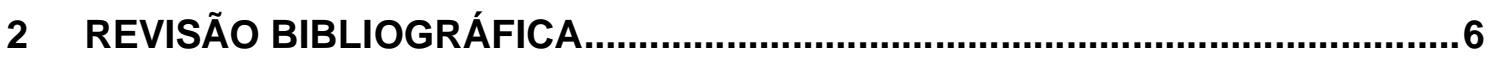

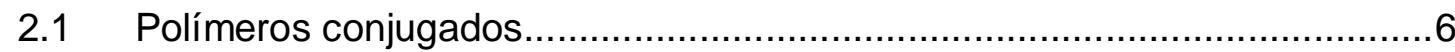

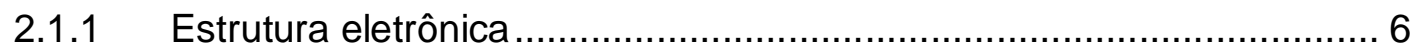

2.1.2 Rotas Sintéticas para obtenção de polímeros conjugados ................. 11

2.1.2.1 Reação por acoplamento de Suzuki .............................................13

2.1.3 Polímeros emissores de luz .................................................... 15

2.1.3.1 Polímeros contendo grupos quinolina ........................................16

2.1.3.2 Polímeros contendo grupos fluoreno ……………………........18

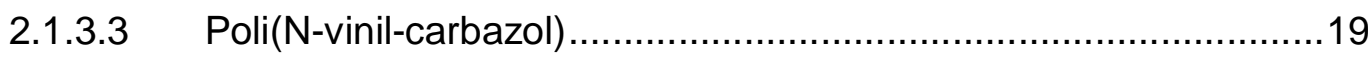

2.1.4 Fotofísica dos polímeros emissores de luz .................................... 20

2.1.4.1 Princípios de absorção e emissão de energia ................................20

2.2 Diodos emissores de Luz Poliméricos (PLEDS) ……...............................24

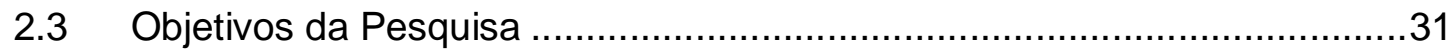

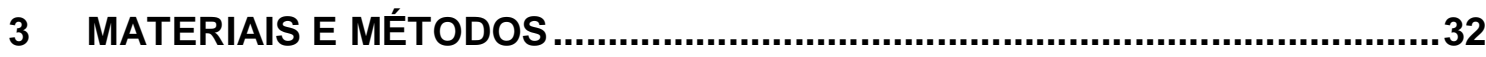

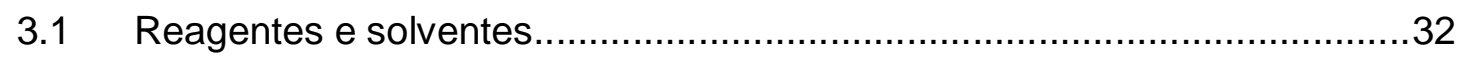

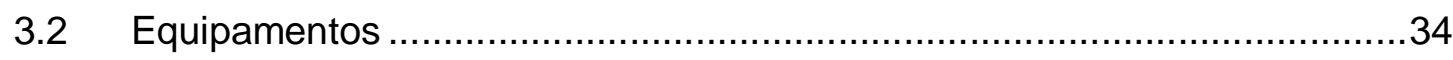

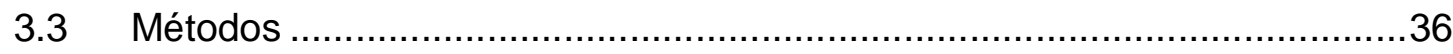

3.3.1 Síntese dos copolímeros emissores de luz ........................................ 36

3.3.2 Caracterização dos copolímeros emissores de luz ............................. 41

3.3.2.1 Espectroscopia de absorção no UV-Vis...................................... 41

3.3.2.2 Espectroscopia de fluorescência ........................................... 42

3.3.2.3 Espectroscopia de ressonância magnética nuclear de hidrogênio (HNMR) 42

3.3.2.4 Espectroscopia no infravermelho (FTIR) …............................. 42

3.3.2.5 Analisador termogravimétrico (TG) ........................................... 43

3.3.2.6 Calorimetria diferencia exploratória (DSC) ............................... 43

3.3.2.7 Cromatografia de permeação em gel (GPC) ...............................4 43

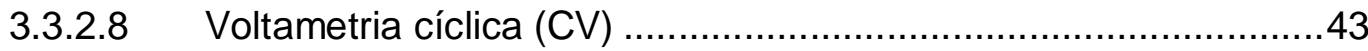

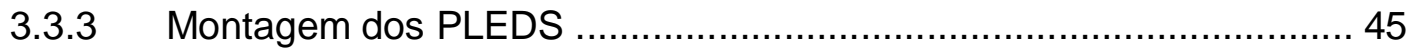

3.3.3.1 Preparo das soluções poliméricas ..............................................46 


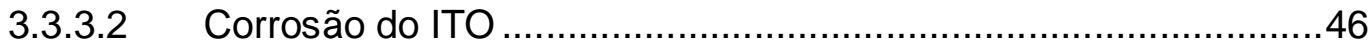

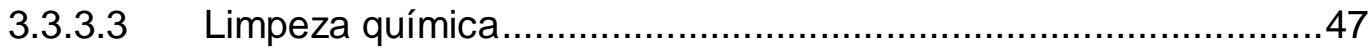

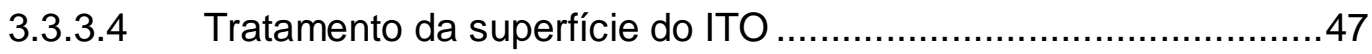

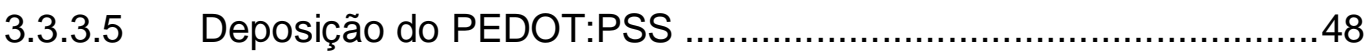

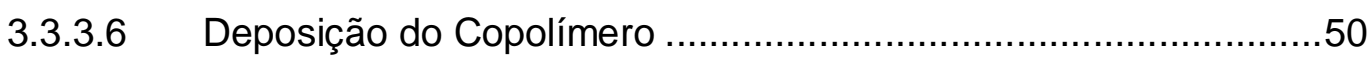

3.3.3.7 Metalização dos eletrodos ........................................................

3.3.3.8 Aplicação de Cola de Prata .......................................................

3.3.4 Caracterização dos PLEDS ………………................................ 52

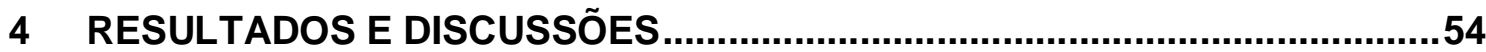

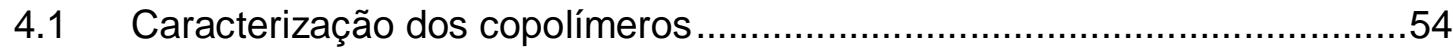

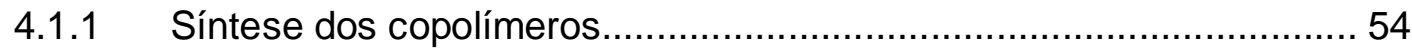

4.1.2 Cromatografia de permeação em gel.............................................. 58

4.1.3 Espectroscopia de ressonância magnética nuclear de hidrogênio ..... 59

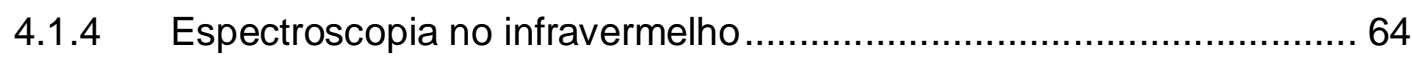

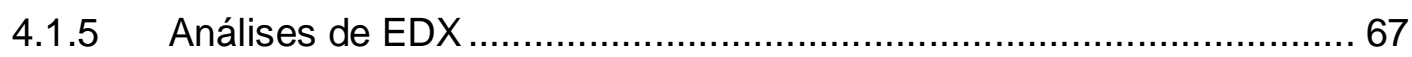

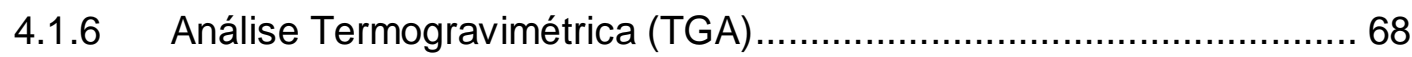

4.1.7 Análise de Calorimetria diferencial exploratória (DSC) ...................... 70

4.1.8 Espectroscopia de absorção no UV-Vis.......................................... 71

4.1.9 Espectroscopia de fluorescência ..................................................... 75

4.1.9.1 Rendimento Quântico .......................................................... 81

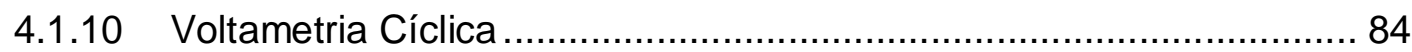

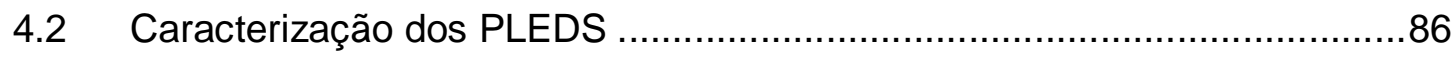

4.2.1 Microscopia óptica do filmes ...................................................... 86

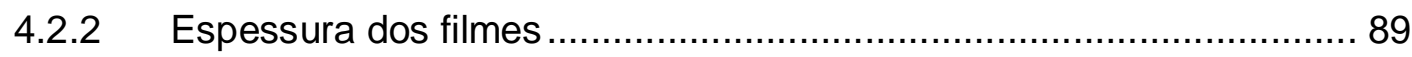

4.2.3 Espectroscopia de absorção no UV-Vis em filme ............................. 90

4.2.4 Caracterização elétrica dos PLEDS …………................................. 91

4.2.4.1 PLED com o copolímero PFN02 como camada ativa....................91

4.2.4.2 PLED com o copolímero PFN10 como camada ativa....................96

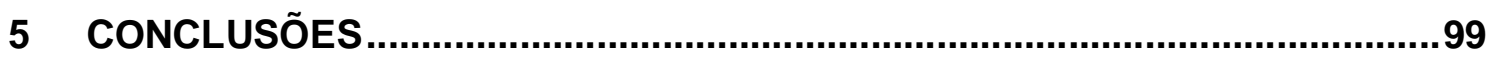

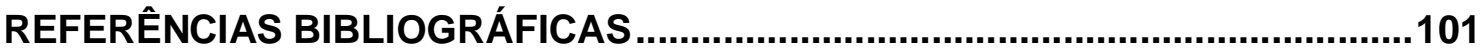




\section{INTRODUÇÃO}

Os primeiros trabalhos explorando as propriedades condutoras de moléculas orgânicas datam de 1962 quando Pope et al descobriram a eletroluminescência em cristais de antraceno, porém devido a necessidade de altas tensões de operação e a baixa eficiência quântica, esse tipo de material acabou não despertando maiores interesses.

Entretanto, o interesse em pesquisas relacionado às propriedade de condução elétrica dos polímeros voltou em 1977, quando Shirakawa, Heeger e McDiarmid $^{2,3}$ doparam quimicamente o poliacetileno (polímeros conjugado mais simples) com iodo, produzindo um filme com a aparência de uma folha metálica dourada, cuja condutividade elétrica era significativamente aumentada cerca de doze vezes chegando a valores superiores a $10^{3}\left(\mathrm{~S} \mathrm{~cm}^{-1}\right)$.

Com o surgimento dessa nova classe de materiais relacionada aos polímeros conjugados foi, então, relatado pela primeira vez, no final da década de 800 fenômeno de eletroluminescência $(E L)^{4}$.

O fenômeno de EL, então novo para os materiais poliméricos já era bem conhecido para os materiais inorgânicos como o Silício (Si) e o Arseneto de Gálio (GaAs) desde a década de 30. Após alguns anos de pesquisa e desenvolvimento resultou na tecnologia comercial de diodos emissores de luz de operação em corrente contínua do tipo junção p-n (light-emitting diode - LED) e no protótipo de visor eletrônico feito de filme fino eletroluminescente.

Apenas em 1987 C. Tang e S. VanSlyke apresentaram, pela Eastman Kodak, o primeiro dispositivo emissor de luz eficiente baseado em materiais orgânicos funcionando a baixas tensões (menores que $10 \mathrm{~V})^{5}$.

Esse dispositivo eletrônico foi construído com moléculas montadas basicamente em duas camadas: uma camada responsável pelo transporte de lacunas formado por moléculas aromáticas derivadas de diaminas e outra camada responsável pelo transporte de elétrons e emissão de luz do dispositivo, uma molécula fluorescente pertencente à classe de complexos metálicos, o tris-(8hidroxiquinoline) alumínio $\left(\mathrm{Alq}_{3}\right)$. 
A partir daí novos materiais e novos dispositivos baseados em polímeros semicondutores passaram a ser intensamente pesquisados ${ }^{6}$, até que em 1990 Burroughes et $a l^{7}$ apresentaram o primeiro dispositivo emissor de luz eficiente baseado em polímeros conjugados, utilizando-se para isso o poli( $p$-fenilenovinileno) (PPV), que funcionava a uma tensão próxima de $20 \mathrm{~V}$.

Os polímeros que sempre foram amplamente utilizados como materiais isolantes elétricos por possuírem elevada resistividade elétrica e de fácil processabilidade, agora com o surgimento dessa nova classe de materiais (polímeros semicondutores) começam a ganhar um novo espaço no mercado, despertando assim grandes interesses científicos, tecnológicos e industriais, devido ao seu potencial na construção de diodos orgânicos emissores de luz (OLEDs) ${ }^{8}$, transistores de efeito de campo orgânicos (OFET) ${ }^{9}$, fotodiodos, possibilitando assim a utilização desses materiais em mostradores luminosos, tais como telas de vídeo, computadores, painéis de controle, entre outros.

Esses novos materiais possuem diversas vantagens em relação aos sistemas convencionais a base de semicondutores inorgânicos, pois podem ser flexíveis, leves, permitem uma deposição em grandes áreas com baixos custos, além de terem a possibilidade de emissão em praticamente todo o espectro visível.

Entretanto esses materiais não se restringem apenas a esse tipo de tecnologia, eles podem ser empregados também em novas tecnologias de células solares, emissores tipo lasers, sistemas de armazenamento de dados numéricos e circuitos integrados poliméricos ${ }^{10}$. Várias empresas como IBM, Sony, Epson e Philips estão estudando-os e desenvolvendo-os.

Atualmente diversos polímeros conjugados vêem sendo empregados como materiais eletroluminescente entre eles os mais estudados e utilizados são os poli( $p$ vinilenofenileno)s, poli(fluoreno)s, poli(tiofeno)s, poli(N-vinilcarbazol) e seus derivados, polímeros derivados das fenotiazinas, derivados das triazinas, entre outros $^{11}$.

O principal motivo para que essa tecnologia continue evoluindo, consiste ainda na melhoria de seu desempenho e no aumento significativo do tempo de vida útil desses dispositivos ${ }^{12}$ e para isso, diversos polímeros conjugados estão sendo modificados e intensamente estudados ${ }^{11,13}$, bem como a síntese de novos copolímeros com propriedades características. 
Uma contribuição dos polímeros semicondutores na melhoria da eficiência desses dispositivos consiste em promover um aumento do número de recombinações elétrons-lacunas com a finalidade de se obter assim decaimentos radiativos para emissão de fótons, luz visível. Para isso os dispositivos são atualmente montados com a presença de camadas transportadoras de lacunas os HTLs (Hole transport layers) e com camadas transportadoras de elétrons os ETL (Electron transports layers), formando uma estrutura tipo multicamadas onde entre os eletrodos (ITO/AL) há uma camada de HLT, o polímero eletroluminescente e o ETL.

Outra forma também que pode ser utilizada e que foi estudada nesse trabalho é a inserção de componentes doadores e/ou receptores de elétrons na camada ativa polimérica, seja pela mistura de outros polímeros, promovendo a formação de blendas ou mesmo pela própria modificação da estrutura química polimérica através da síntese de novos polímeros e copolímeros.

Pode-se então, através deste trabalho, traçar comparações entre dispositivos fabricados com estruturas multicamadas utilizando um ETL como forma de auxiliar no processo de injeção de elétrons e uma nova estrutura de polímero eletroluminescente, formado através da síntese de um novo copolímero, capaz de agregar em sua estrutura propriedades injetora de elétrons e emissoras de luz. 


\section{REVISÃO BIBLIOGRÁFICA}

\subsection{Polímeros conjugados}

Os polímeros por definição são macromoléculas que apresentam uma seqüência de unidades repetitivas denominadas meros ${ }^{14}$. Polímeros conjugados são aqueles que apresentam em suas cadeias intercalação de ligações simples $\sigma$ e duplas $\pi$, sendo a alternância dessas ligações ao longo das cadeias responsáveis pelas propriedades semicondutoras particulares desse tipo de material ${ }^{15}$. Ficando as ligações $\pi$ responsáveis pelas propriedades elétricas e as ligações $\sigma$ responsáveis principalmente pelas propriedades mecânicas das moléculas.

A estrutura polimérica conjugada mais simples é a do poli(acetileno) $(-\mathrm{C}=\mathrm{C}-)_{\mathrm{n}}$, mostrada na Figura 1.

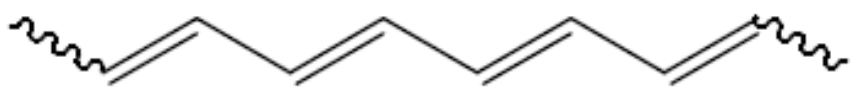

Figura 1 - Poli(acetileno) estrutura tran.

\subsubsection{Estrutura eletrônica}

Os materiais poliméricos são normalmente formados por longas cadeias de carbonos e esses átomos de carbono em seu estado fundamental possuem a configuração eletrônica $1 s^{2} 2 s^{2} 2 p^{2}$, onde os elétrons de valência são referentes aos orbitais mais externos $2 s$ e $2 p$, que participam das ligações químicas. Esses elétrons de valência em seu estado excitado podem sofrer hibridizações do tipo $\mathrm{sp}^{3}, \mathrm{sp}^{2}$ ou $\mathrm{sp}$. A mais comum é a $\mathrm{sp}^{3}$ onde todos os elétrons de valência participam de ligações 
covalentes simples, nesta configuração, o átomo de carbono possui quatro átomos vizinhos e as ligações são denominadas ligações " $\sigma$ ".

Em sistemas conjugados a configuração eletrônica de menor energia é aquela em que o átomo de carbono apresenta três orbitais $\mathrm{sp}^{2}$ (que acomoda três elétrons ligação $\sigma$ ) e um orbital remanescente $p_{z}$, que se localiza perpendicularmente ao plano que contém os três orbitais híbridos $\mathrm{sp}^{2}$. A sobreposição entre dois orbitais $\mathrm{p}_{z}$ de átomos de carbono adjacentes leva a criação de uma ligação $\pi$. A Figura 2 mostra de forma esquemática a sobreposição desses orbitais.

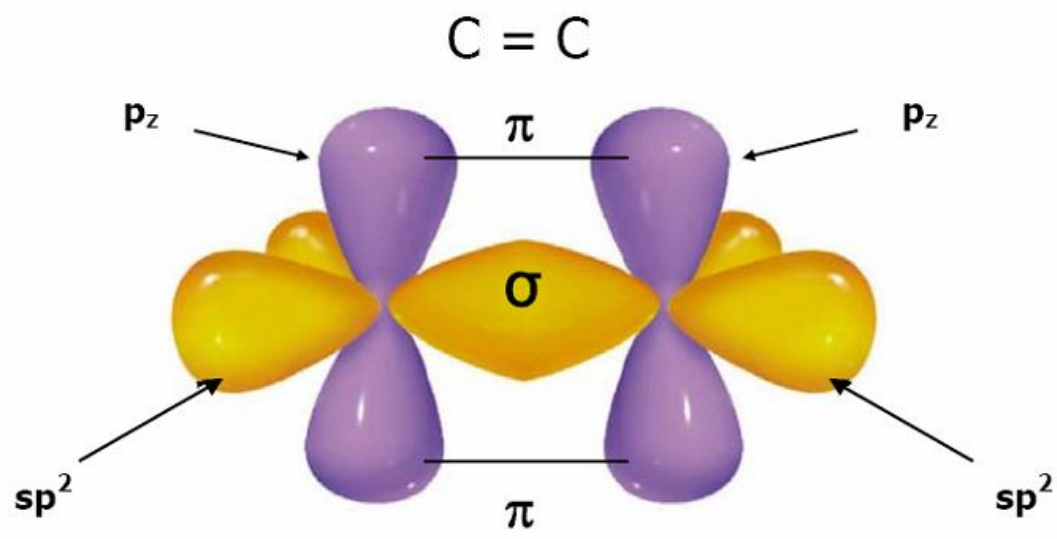

Figura 2 - Formação de orbitais em um polímero conjugado

A superposição das funções de onda dos orbitais que participam de uma ligação pode ser construtiva ou destrutiva e o resultado então é a formação de um orbital ligante ou antiligante, esta denotada através do símbolo *.

O orbital ligante no seu estado fundamental é ocupado por dois elétrons, enquanto que o orbital antiligante permanece vazio ${ }^{16}$, como pode ser observado na Figura 3. As propriedades ópticas e elétricas dos polímeros são essencialmente governadas pelos orbitais $\pi$ e $\pi^{*}$ visto que a diferença energética entre os orbitais $\sigma$ e $\sigma^{*}$ é muito maior do que as dos orbitais $\pi$ e $\pi^{*}$. 


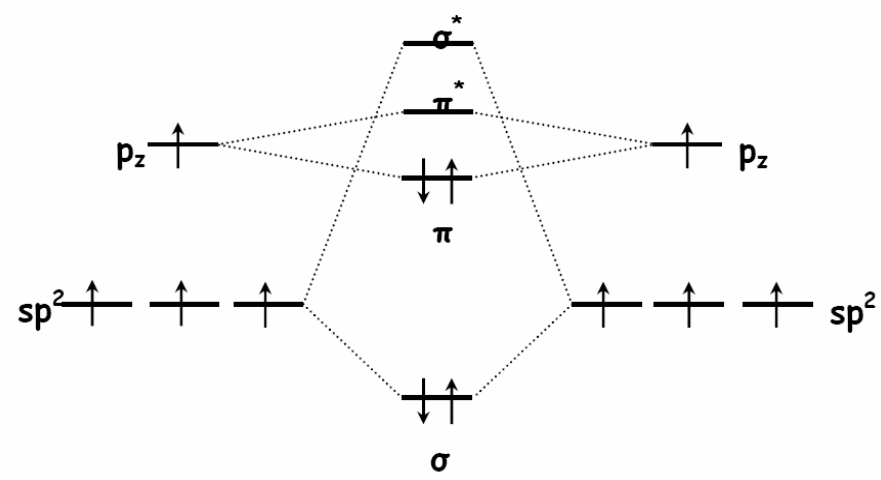

Figura 3 - Representação dos orbitais moleculares $\pi$ e $\sigma$ formados entre dois átomos de carbono $s p^{2}$.

Um sistema conjugado simples pode ser exemplificado pela molécula de benzeno apresentada na Figura 4, essa molécula possui três ligações simples e três ligações duplas.

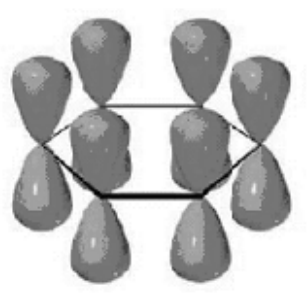

Molécula de benzeno

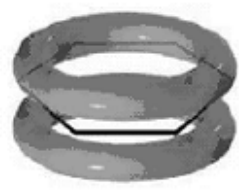

Elétrons $\pi$ delocalizados

Figura 4 - Molécula de benzeno com os elétrons delocalizados na cadeia.

Os orbitais dos elétrons $\pi$ de cada átomo de carbono presente na molécula de benzeno interagem e produzem uma distribuição de estados eletrônicos que se assemelha a uma estrutura de bandas (Figura 5).

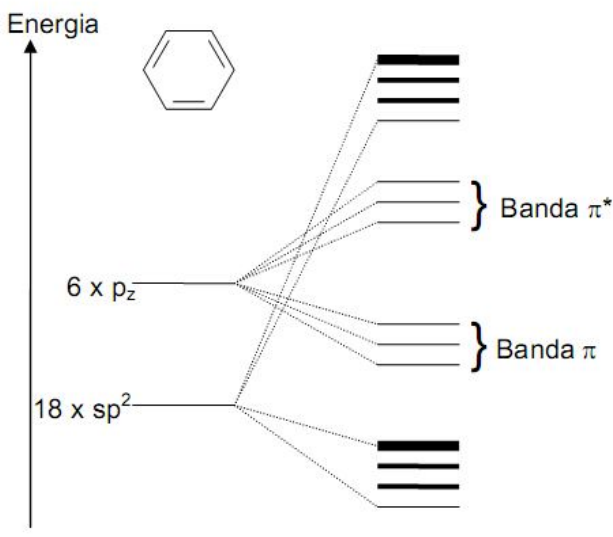

Figura 5 - Distribuição de estados eletrônicos em uma molécula de benzeno. 
A interação entre orbitais $\pi$ ligantes (ocupados) produzirá uma banda denominada de HOMO (highest occupied molecular orbital) e a interação entre orbitais $\pi^{*}$ antiligantes (desocupados) irá produzir a banda LUMO (lowest unoccupied molecular orbital).

Em uma cadeia polimérica infinita, a interação coulombiana entre os orbitais $\pi$ irá fazer com que os elétrons fiquem totalmente delocalizados na cadeia, ou seja, a probabilidade de encontrar os elétrons é igual em qualquer ponto da cadeia, surgindo uma distribuição aproximadamente contínua de estados energéticos, ficando assim, em analogia aos semicondutores inorgânicos a banda HOMO sendo representada pela banda de valência e a banda LUMO pela banda de condução.

A Figura 6 apresenta um sistema idealizado para uma cadeia infinita do PPV.

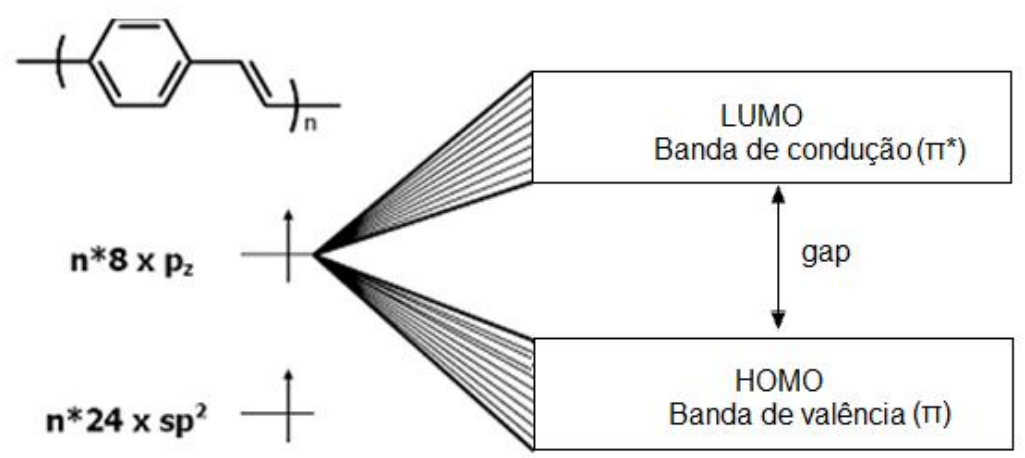

Figura 6 - Formação de bandas de energia em uma cadeia polimérica de PPV ${ }^{17}$.

A diferença entre os valores do topo da banda de valência (HOMO) e o fundo da banda de condução (LUMO) irá fornecer o valor de energia proibida do material $\mathrm{E}_{\mathrm{g}}$ (gap), indicando também a natureza elétrica do sólido (Figura 7), essa diferença energética entre os estados $\pi^{*}$ e $\pi$ para o carbono normalmente encontra-se mais favorável para a absorção óptica na região visível do espectro eletromagnético (400 $-700 \mathrm{~nm})$.

A maior parte dos polímeros conjugados possui essa diferença de energia $\left(E_{g}\right)$ entre 1,5 eV e 3,5 eV, (376 a $886 \mathrm{~nm}$ ), valores cujos comprimentos de ondas correspondem ao espectro visível. Este valor pode ser alterado variando a estrutura polimérica $^{18}$. A Tabela 1, exemplifica alguns polímeros conjugados, bem como suas energias de gap, $E_{g}$. 


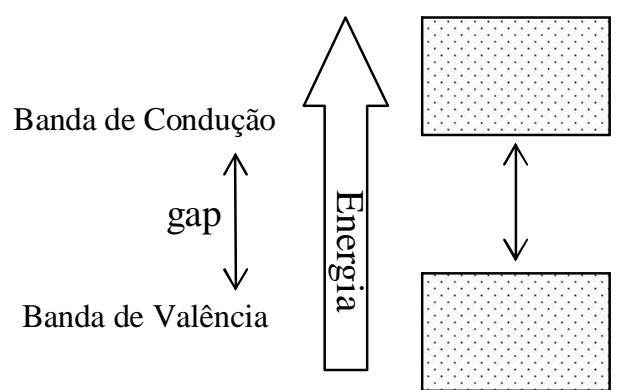

a)

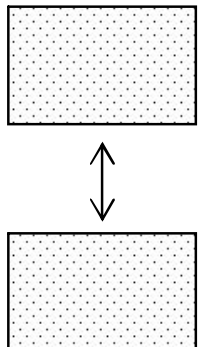

b)

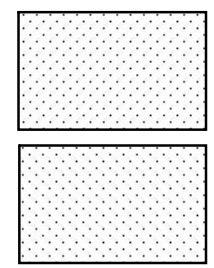

c)

Figura 7 - Representação esquemática das classes dos sólidos segundo ao seu gap energético. a) materiais isolantes $(\mathrm{Eg}>5 \mathrm{eV})$; b) semicondutores $(1<\mathrm{Eg}<5 \mathrm{eV})$; c) condutores $(\mathrm{Eg}<1 \mathrm{eV})$.

Tabela 1 - Estrutura e sua energia $E_{g}$ de alguns polímeros semicondutores ${ }^{19}$.

\begin{tabular}{|c|c|c|}
\hline Polímero & Estrutura & $E_{g}(e V)$ \\
\hline $\begin{array}{l}\text { polianilina } \\
\text { (PANI) }\end{array}$ & & 3,2 \\
\hline $\begin{array}{l}\text { poli( } p \text {-fenileno) } \\
\text { (PPP) }\end{array}$ & & 3,0 \\
\hline $\begin{array}{l}\text { poli( } p \text {-fenileno vinileno) } \\
\text { (PPV) }\end{array}$ & & $2,3 \sim 2,5$ \\
\hline Politiofeno & & 2,0 \\
\hline trans-poliacetileno & & 1,5 \\
\hline
\end{tabular}

O intervalo de energia (bandgap) $\left(E_{g}\right)$ desses semicondutores orgânicos é determinado única e exclusivamente pela estrutura da unidade mero do polímero, sendo, portanto, as propriedades eletrônicas dependentes da estrutura resultante da rota de síntese química escolhida. Desta maneira, pode-se modificar o espectro de emissão e, como conseqüência, a cor da luz emitida, promovendo alterações na molécula, como adição de grupos laterais.

Uma característica fundamental destes semicondutores orgânicos do ponto de vista físico e/ou químico é a facilidade que apresentam em transferir energia 
absorvida de um sítio específico para outro sítio onde esta energia é usada para aumentar a probabilidade de induzir processos energéticos, como: luminescência, reações fotoquímicas, transporte de portadores e outros.

\subsubsection{Rotas Sintéticas para obtenção de polímeros conjugados}

Existem basicamente dois tipos de rotas para o acoplamento de carbonos (C-C) para a produção de polímeros conjugados emissores de luz e, são divididas segundo o tipo de acoplamento gerado.

Um dos tipos de rotas englobam as reações de acoplamento de Suzuki ${ }^{20,21,22}$ e de Yamamoto $^{23}$ onde a polimerização acontece por acoplamento de aromáticos mediante ligações simples $\sigma$ (ligações covalentes) entre os carbonos aromáticos na presença de um catalisador.

A reação de acoplamento de Suzuki ocorre entre uma arila boronada e uma arila halogenada podendo ser iguais ou diferentes na presença de um catalisador a base de paládio. $O$ acoplamento de Yamamoto é feito a através da reação entre duas arilas halogenadas na presença de complexos de Níquel como catalisador ${ }^{13}$, se os monômeros forem iguais (Arila 1 = Arila 2 ) a reação de acoplamento fornecerá um homopolímero, se foram diferentes, será formado um copolímero estatístico (Figura 8).

$$
\begin{aligned}
& \mathrm{Ni}\left(\mathrm{COD}_{2}\right)
\end{aligned}
$$

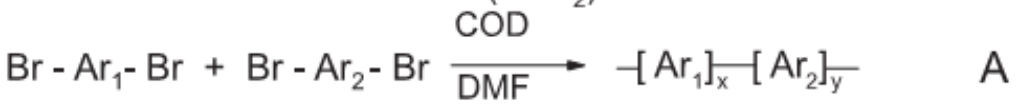

$$
\begin{aligned}
& \text { Bipiridilo } \\
& \left(\mathrm{RO}_{2}\right) \mathrm{B}-\mathrm{Ar}_{1}-\mathrm{B}\left(\mathrm{RO}_{2}\right)+\mathrm{X}-\mathrm{Ar}_{2}-\mathrm{X} \underset{\mathrm{H}_{2} \mathrm{O} / \text { tolueno }}{\stackrel{\mathrm{Pd}(0)}{\stackrel{\mathrm{Na}_{2} \mathrm{CO}_{3}}{\longrightarrow}}}-\left[\mathrm{Ar}_{1}-\mathrm{Ar}_{2}\right]_{\mathrm{n}} \\
& \mathrm{R}=\mathrm{H} \text {, alquila } \quad \mathrm{X}=\mathrm{Br}, \mathrm{I}
\end{aligned}
$$

Figura 8 - A) rota de acoplamento de Yamamoto e B) rota de acoplamenteo de Suzuki. 
O outro tipo notável de rota de acoplamento engloba as reações de Wittig, Horner, Knoevenagel e Gilch, onde no processo de polimerização há a formação de unidade de vinileno entre os carbonos aromáticos.

As polimerizações via reações de Wittig ${ }^{24}$, Horner, Gilch e Knoevenagel ${ }^{13,25}$ possibilitam o acoplamento carbono-carbono por meio de duplas ligações. A reação de Horner é considerada uma modificação da reação de Wittig, pois utiliza uma ilida diferente.

A reação de Wittig pode ser brevemente descrita como sendo uma reação química entre um aldeído ou uma cetona com um ileto de fósforo formando um alceno. A Figura 9 mostra o esquema da rota sintética do PPV via ração de Wittig.

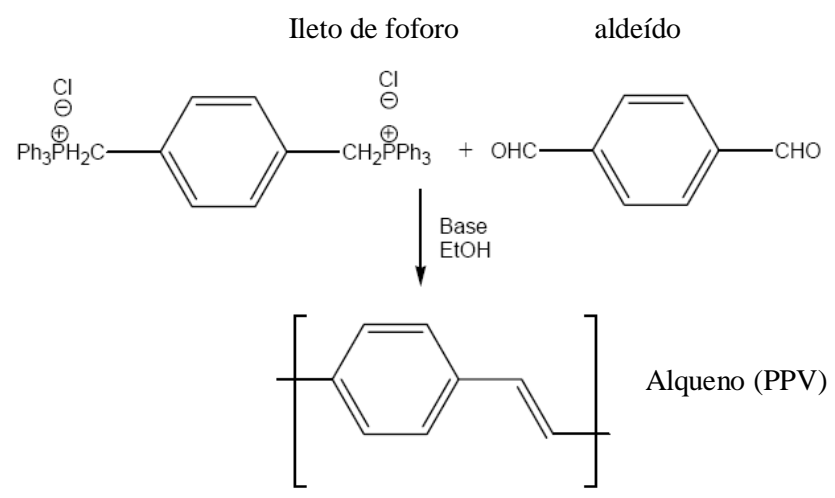

Figura 9 - Síntese do PPV via reação de Witig.

A reação de Horner é uma modificação da reação de Wittig, pois utiliza um óxido de fosfina como carbânion ${ }^{13}$.

A Figura 10 exemplifica a reação de Gilch que se forma entre di-haletos metilados. A reação de Knoevenagel mostrada na Figura 11 ocorre entre um aromático diacetonitrila e um dialdeido aromático correspondente ${ }^{25}$.

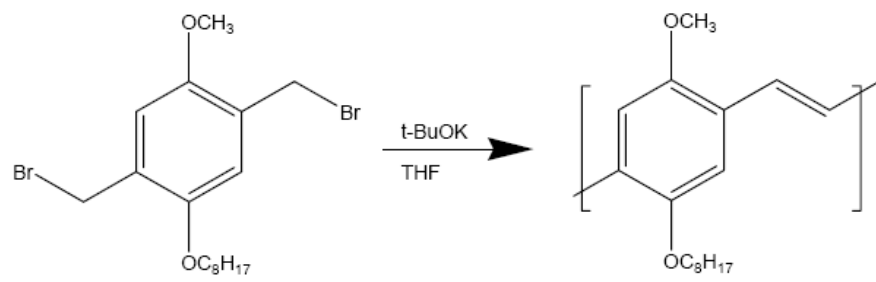

Figura 10 - Esquema de uma polimerização via reação de Gilch ${ }^{11}$ 


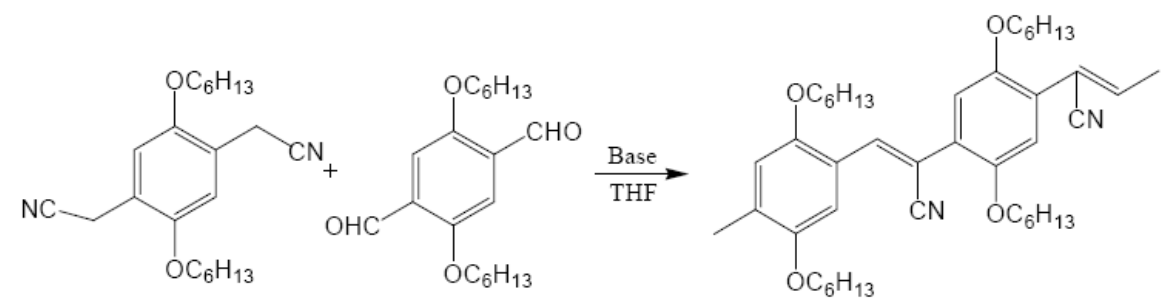

Figura 11 - Esquema de uma polimerização via reação de Knoevenagel ${ }^{13}$.

\subsubsection{Reação por acoplamento de Suzuki}

A reação de acoplamento de Suzuki ${ }^{20,21,22}$ representa um dos métodos mais amplamente utilizados em síntese orgânica ${ }^{26,22}$. Essa síntese ocorre na presença de um complexo de paládio ${ }^{20,27}$ como catalisador, sendo uma forma de se obter ligações C-C, promovendo acoplamento entre os grupos organo-borônico e organohalogenado. Se as arilas di-halogenadas e diboronadas forem iguais, o acoplamento fornecerá um homopolímero e se forem diferentes, será obtido um copolímero perfeitamente alternado (Esquema 1), porque as arilas di-halogenadas ou diboronadas não se homopolimerizam. Esse tipo de reação tem diversas vantagens, entre as quais podem ser citadas: não ser afetada pela presença de água, possuir uma grande faixa de tolerância a grupos funcionais e apresenta régio e estereosseletividade. Além disso, os subprodutos inorgânicos da reação não são tóxicos e são facilmente removidos ${ }^{21}$.

$\mathrm{R}-\mathrm{X}+\mathrm{R}^{\prime}-\mathrm{B}(\mathrm{OH})_{2} \quad \rightarrow \quad \mathrm{R}-\mathrm{R}^{\prime}$
$\mathrm{R}, \mathrm{R}^{\prime} \rightarrow$ arila
$\mathrm{X} \rightarrow$ haleto

Esquema 1 - Esquema de um acoplamento entre duas arila R e R' via reação de Suzuki.

A Figura 12 descreve como ocorre o processo de acoplamento entre a arilas na presença do paládio como catalisador. Primeiramente o complexo de paládio 
sofre oxidação e entra entre a arila e o halogênio ( $\operatorname{Ar}-\mathrm{Pd}(\mathrm{II})-\mathrm{X})$, na presença de uma solução básica o halogênio da estrutura é substituído por uma hidroxila, essa hidroxila ira reagir com o composto boronado da outra arila (arila boronada) formando o composto $\mathrm{B}(\mathrm{OH})_{4}$, e ligando assim essa nova arila a estrutura (Ar-(Pd(II)-Ar'), após esse processo o complexo de paládio sofre a redução e é eliminado, acoplando assim as duas arilas (Ar-Ar').

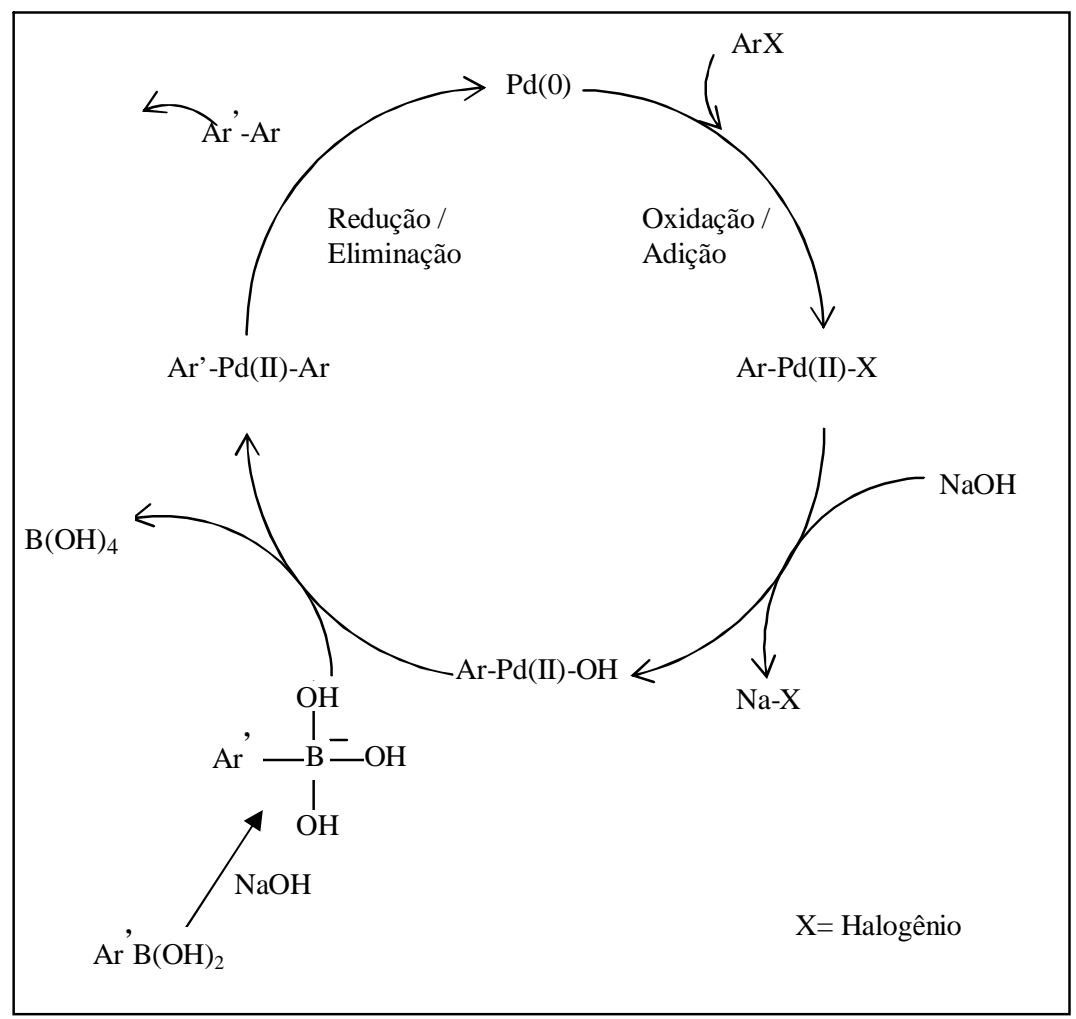

Figura 12 - Esquema de acoplamento entre arilas halogenadas e boronadas por reação de Suzuki ${ }^{20,21}$.

Atualmente essa síntese vem sendo freqüentemente empregada na formação de novos polímeros e copolímeros conjugados, com grande interesse na área de síntese de polímeros semicondutores ${ }^{11,28,29}$.

Rendimentos melhores dessas sínteses foram observados em sistemas reacionais hermeticamente fechados com a adição de um agente transferidor de fases; comumente, é utilizado o Aliquat $336^{\circledR}$, um sal quaternário de amônio, que atua como surfactante, facilitando a migração dos reagentes de uma fase aquosa para a outra orgânica $28,30,31$. 


\subsubsection{Polímeros emissores de luz}

Toda forma de emissão de luz é chamada de luminescência exceto quando a emissão de luz ocorre pelo aquecimento do material a altas temperaturas, gerando assim a incandescência.

A emissão de luz de um material semicondutor quando ele é submetido a um campo elétrico, é conhecido como eletroluminescência ( $E L)$ e quando a energia é fornecida por meio de absorção de luz visível temos a fotoluminescência (PL) sendo essa, subdividida em fosforescência e fluorescência, de acordo com as etapas intermediárias nos processos de decaimento energético (radiativo). Assim, a diferença entre a eletroluminescência e a fotoluminescência é apenas a natureza da fonte de excitação dos elétrons ${ }^{32}$.

O uso de materiais orgânicos, poliméricos ou não, nos vários tipos de dispositivos emissores de luz tem, entre suas principais vantagens, a imensa possibilidade de preparação de estruturas químicas diferentes, além de poderem ser misturados, formando sistemas com outras propriedades.

O primeiro material orgânico utilizado na construção de um diodo (OLED organic light emitting diode) foi um hidrocarboneto aromático policíclico, os cristais de antraceno, em 1965, que logo foi deixado de ser utilizado por apresentar baixa eficiência. Em meados dos anos 80, um novo LED foi apresentado, fabricado com 8hidroxiquinolina de alumínio $\left(\mathrm{Alq}_{3}\right)^{5}$ que sob tensão elétrica emitiu uma luz verde. No final da década de 80 surgiu o poli( $p$-fenileno-vinileno) (PPV), sendo o primeiro polímero com estrutura completamente conjugada, abrindo um novo rumo na fabricação dos dispositivos eletrônicos baseados em polímeros eletroluminescentes.

Após o surgimento desse material, um grande número de polímeros eletroluminescentes derivados do PPV e outros novos polímeros vêm sendo sintetizados através de diversas rotas sintéticas, a fim de se obter propriedades específicas com o intuito de melhorar sua solubilidade e suas propriedades elétricas e ópticas.

Há também a possibilidade de mistura física (blendas poliméricas) entre componentes permitindo a obtenção de sistemas com diferentes e novas propriedades características, se tornando assim uma forma atraente e de custo reduzido na preparação de novos materiais. 
Essa facilidade na preparação de novos materiais é particularmente interessante no caso de polímeros eletroluminescentes para os quais pequenas alterações nas rotas de síntese podem levar a materiais com diferentes estruturas e, tomando possível a preparação de novos materiais que emitem em diferentes regiões do espectro. As diferenças nos processos sintéticos podem, também, envolver reações de copolimerização, permitindo a geração de materiais com propriedades projetadas para fornecer dispositivos mais eficientes.

Através dessas inúmeras possibilidades novos materiais poliméricos com propriedades eletroluminescentes surgiram e vem sendo intensamente estudados nos últimos anos, como é o caso de polímeros derivados de poli( $p$-vinilenofenilenos), poli(fluorenos), poli(N-vinilcarbazóis), poli(tiofenos), polímeros derivados das fenotiazinas, derivados das triazinas ${ }^{13}$, entre outros bem como a síntese de novos copolímeros com propriedades características.

\subsubsection{Polímeros contendo grupos quinolina}

As quinolinas ou poliquinolinas são compostos conjugados aromáticos contendo o heteroátomo nitrogênio ${ }^{33}$ (Figura 13). Os polímeros contendo o grupo quinolina na cadeia principal possuem alta resistência mecânica devido à rigidez pelas ligações conjugadas, alta estabilidade térmica e química e podem ser processados formando filmes finos com alta qualidade, apresentando-se como materiais promissores na construção de PLEDS. No entanto suas propriedades de EL e fotofísicas ainda não foram sistematicamente investigadas ${ }^{34}$.

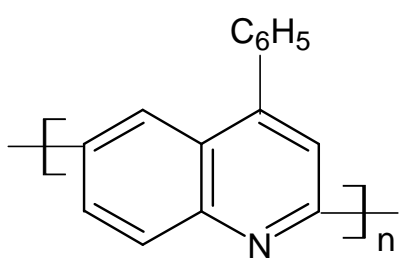

a)<smiles>[GaH]Oc1c(Br)cc(Br)c2cccnc12</smiles>

b)

Figura 13 - a) poli[2,6-(4-fenilquinolina) b)5,7-dibromo-8-oxioctil-quinolina. 
Poliquinolinas são conhecidas também como polímeros do tipo $\mathrm{n}$, ou seja, materiais com predominância de portadores de elétrons ${ }^{13,34}$ sendo, então, de grande interesse na construção de PLEDS em conjunto com materiais já muito estudados do tipo $\mathrm{p}$ (predominância de portadores de lacunas).

PLEDS contendo poliquinolina possuem geralmente tensões de limiar acima de $7 \mathrm{~V}$, e esses dispositivos, normalmente, emitem no comprimento de onda de 589 $\mathrm{nm}$, montados em uma estrutura onde a poliquinolina é depositada na forma de filme como mostrado na Figura 14.

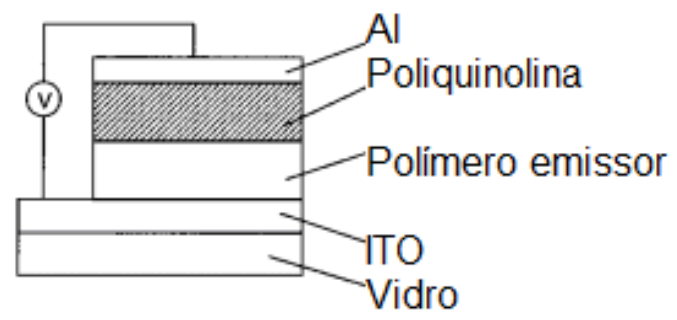

Figura 14 - Estrutura esquemática de um PLED com um filme fino de poliquinolina ${ }^{34}$.

Polímeros derivados de quinolina são obtidos a partir da reação de Friedlander, que consiste na condensação de um diahaleto aromático com um bisfenol em meio ácido e foram primeiramente estudados por Stille em $1976^{35}$, sendo que o mesmo também sintetizou uma série de poliquinolinas com diferentes solubilidades em diversos solventes orgânicos, diferentes propriedades térmicas e mecânicas ${ }^{36}$.

Neste trabalho, um novo copolímero contendo grupos quinolina foi preparado, utilizando um método já empregado anteriormente pelo grupo ${ }^{37,38}$, sendo possível efetuar a síntese do monômero 5,7-dibromo-8-oxioctila-quinolina a partir de 5,7dibromo-8-oxioctil-quinolina e 1-bromooctano (Figura 12b). O monômero assim obtido foi polimerizado através da reação de Suzuki, possibilitando a composição de estruturas poliméricas contendo segmentos com diferentes propriedades emissivas e elétricas, e apresentando os copolímeros obtidos estruturas químicas inéditas na literatura. 


\subsubsection{Polímeros contendo grupos fluoreno}

Os polímeros e oligômeros derivados do fluoreno estão sendo muito utilizados na construção e no desenvolvimento de novos dispositivos eletroluminescentes por apresentarem uma grande versatilidade na emissão de cores, emitindo especialmente na região azul do espectro da radiação eletromagnética, além de apresentarem alta eficiência quântica, tanto em solução quanto no estado sólido e, por fim, grande estabilidade química, térmica e oxidativa $a^{39,40,41,42}$.

A Figura 15 mostra a estrutura química do fluoreno, onde a facilidade na substituição dos hidrogênios ligados ao carbono 9 por grupos de radicais orgânicos $\left(\mathrm{C}_{n} \mathrm{H}_{2 n+1}\right)$-(alquilas) não afetam significativamente as interações eletrônicas existentes entre os anéis aromáticos, e promovem um significativo aumento na solubilidade em vários solventes orgânicos ${ }^{43,44}$ e na resistência aos ataques oxidativo $^{42,43}$. Além disso, quando funcionalizadas nas posições 2 e 7 , por meio de reações de substituição eletrofílica aromática, podem facilitar o controle do crescimento da cadeia polimérica.

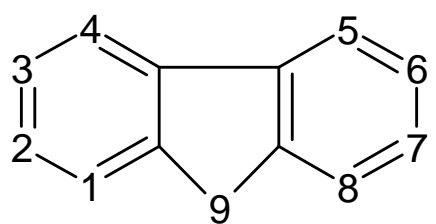

Figura 15 - Estrutura química do fluoreno (numeração dos carbonos de acordo com a IUPAC).

Yoshino et al. $(1989)^{45,46}$, foram os pioneiros na tentativa de sintetizar os polifluorenos, sintetizando o poli(2,7-fluoreno), utilizando reações de oxidação com $\mathrm{FeCl}_{3}$ para acoplar os monômeros de 9,9-dihexiffluoreno, representado na Figura 16.

Atualmente os métodos de acoplamento de Suzuki ${ }^{21}$ e de Yamamoto ${ }^{23}$ são as técnicas mais utilizadas para a síntese de novos polímeros de fluoreno e seus derivados, devido à especificidade destas reações que conduzem a elevado controle das estruturas dos produtos. 


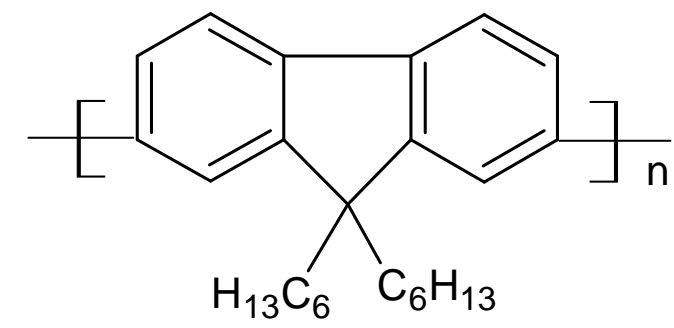

Figura 16 - Poli(9,9-dihexilfluoreno), sintetizado por Yoshino em $1989^{45}$.

Essa classe de polímeros tem despertado o interesse dos cientistas por suas propriedades elétricas e ópticas, com grande potencial de aplicação para fabricação de dispositivos emissores de luz (LEDs). Estes polímeros apresentam algumas propriedades interessantes para essa finalidade, destacando-se, entre elas, a possibilidade de formarem materiais líquido-cristalinos com altos parâmetros de ordem e temperaturas de transição termotrópica na faixa entre 100 a $170{ }^{\circ} \mathrm{C}$, ocorrendo entre as temperaturas de amolecimento e de decomposição térmica ${ }^{13}$.

Nesta pesquisa foi utilizado o monômero 9,9-dioctil-2,7-dibromofluoreno para a preparação do copolímero, devido a sua elevada emissividade.

\subsubsection{Poli(N-vinil-carbazol)}

O poli(N-vinil-carbazol) (PVK) é um polímero vinílico aromático preparado através da polimerização do monômero N-vinilcarbazol (NVK) (Figura 17), sendo um dos primeiros polímeros fotocondutores mais amplamente estudado.

Foi sintetizado pela primeira vez por Reppe e colaboradores em 1934. Ele pode ser sintetizado por polimerização via radicais livres, polimerização catiônica e por polimerização no estado sólido ${ }^{47}$.

A Figura 17 mostra a estrutura do monômero NVK e do polímero PVK. 


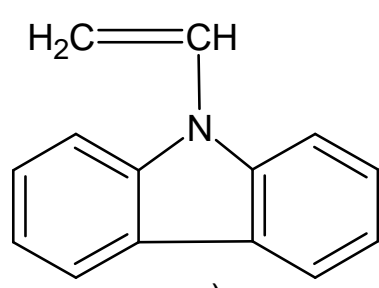

a)

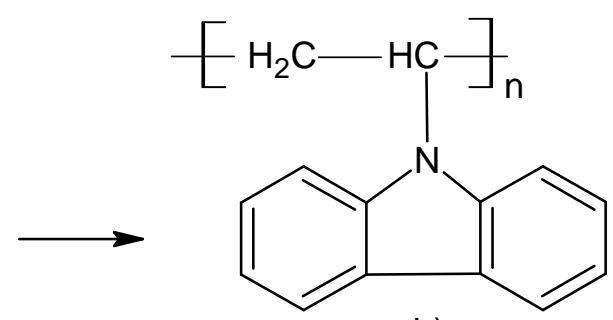

b)

Figura 17 - Formula estrutural do: a) monômero NVK; b) polímero de PVK.

Este polímero possui sua transição vítrea $\left(T_{g}\right)$ por volta de $227^{\circ} \mathrm{C}$ sendo um dos polímeros vinílicos com maior $\mathrm{T}_{\mathrm{g}}^{48}$.

Quanto às suas características elétrica é um polímero que possui um número de lacunas muito maior que o número de elétrons sendo, portanto considerado um material transportador de lacunas ${ }^{49}$, devido principalmente ao comportamento do nitrogênio na estrutura da unidade NVK, que por ser mais eletronegativo acaba capturando os elétrons da dupla ligação ${ }^{38}$. É um material que exibe eletroluminescência intrínseca na região do azul, sendo, portanto atualmente bastante utilizado na fabricação de PLEDS dessa cor ${ }^{50}$.

Um PLED com estrutura ITO/PVK/AI possui pico no espectro de EL em aproximadamente em $480 \mathrm{~nm}^{50,51}$, já sua tensão de limiar, tensão na qual o diodo passa a conduzir é superior a $10 \mathrm{~V}^{50}$. Em geral, os dispositivos poliméricos a base de PVK, ou com ele presente na sua estrutura, também possuem essas tensões por volta de $10 \mathrm{~V}^{52}$.

\subsubsection{Fotofísica dos polímeros emissores de luz}

\subsubsection{Princípios de absorção e emissão de energia}

As moléculas em seu estado fundamental, ou seja, o estado de menor energia vibracional assim que absorvem um fóton, são excitadas para um estado vibracional de maior energia e de não-equilíbrio com a vizinhança, estando, então sujeita aos diversos níveis vibracionais e rotacionais desse novo estado eletrônico. 
Essa mudança de estado vibracional recebe o nome de transição eletrônica, sendo, portanto seu espectro de absorção um conjunto de bandas associadas a essas diversas transições vibracionais e rotacionais possíveis entre esses dois estados eletrônicos envolvidos na transição.

As transições de menor energia correspondem às transições entre os orbitais $\Pi \rightarrow \pi^{*}$, que em geral são observadas pela espectroscopia no UV-Vis. As moléculas ou partes das moléculas responsáveis por esse tipo de absorção são conhecidas como cromóforos.

Essas transições eletrônicas são obtidas através de várias combinações de energia cinética e potencial e são regidas pelo principio de Franck-Condon, que postula que a transição mais provável será aquela na qual não há alteração na posição ou no momento nuclear, isto é, as configurações nucleares do estado excitado devem ser idênticas àquelas do estado fundamental. A Figura 18 mostra um gráfico de energia potencial por distância interatômica $r$, onde esse princípio é representado por uma linha vertical que relaciona um nível do estado fundamental ao seu respectivo estado excitado, possibilitando a previsão das transições permitidas $^{53,28}$.

Pela Figura 18, pode-se ver também o espectro de absorção característico dessas transições, que pode ser interpretado quando nesse processo de absorção de luz, um fóton de menor energia se torna responsável pela transição entre o primeiro nível vibracional do estado fundamental (SO) para o primeiro nível vibracional do estado excitado $\left(S^{*} 1\right)$, dando origem à banda (0-1) correspondente ao maior comprimento de onda, e, conseqüentemente, quando há a absorção de outros fótons com energias maiores ha formação de outras bandas em comprimentos de ondas menores, (S0) $\rightarrow$ (S2) e (S0) $\rightarrow$ (S3).

Quando o elétron excitado no primeiro nível vibracional do primeiro nível eletrônico excitado $\left(\mathrm{S}^{*} 0\right)$ decai para o nível fundamental (S1), fenômeno esse conhecido como decaimento radiativo, ele libera energia na forma de luz, como a energia desse decaimento é a maior possível, ele emitirá em um comprimento de onda menor, e os outros decaimentos energéticos, respectivamente, de menor energia ocorrerão com emissão em comprimentos de onda maiores.

Esses decaimentos são resultados devido aos elétrons nos estados excitados não estarem em equilíbrio com a sua "vizinhança", tendo assim um tempo de vida 
muito curto, devido ao grande número de processos químicos e físicos que podem contribuir para a sua desativação ao estado fundamental.

As diferenças de energia entre as transições $S 0 \rightarrow S^{*} 0$ e $S^{*} 0 \rightarrow S 0$ no espectro de absorção e fluorescência são conhecidas como deslocamento de Stokes e estão relacionadas às perdas por transições não-radiativas dos portadores de cargas e pares excitados, devido às características químicas, morfológicas e estruturais dos polímeros. Podem também ocorrer devido ao processo de reorientação das moléculas de solvente ao redor da molécula excitada, e essa reorientação dissipa energia na forma de calor, fazendo com que a emissão nessa banda apresente energia menor.

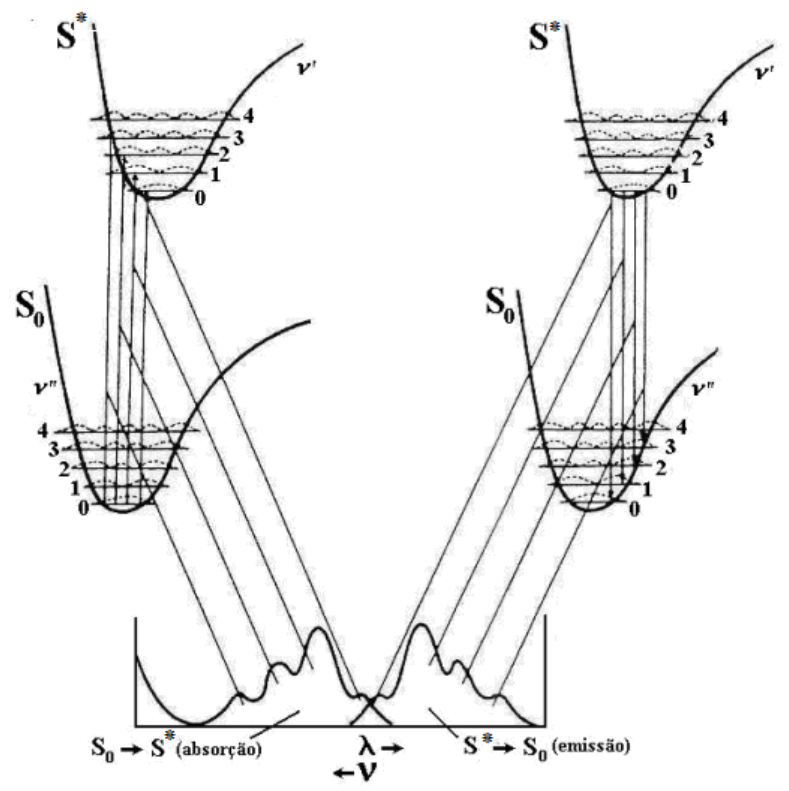

Figura 18 - processo de absorção e emissão entre os estados eletrônicos fundamental S0 e excitado $\mathrm{S}^{*}$, de uma molécula orgânica ${ }^{54}$.

Há também outras formas de dissipação de energia desses estados excitados, podendo ser eles radiativos ou não radiativos, que serão brevemente descritos a seguir e que são exemplificados pelo diagrama de Jablonski, apresentado na Figura 19. 


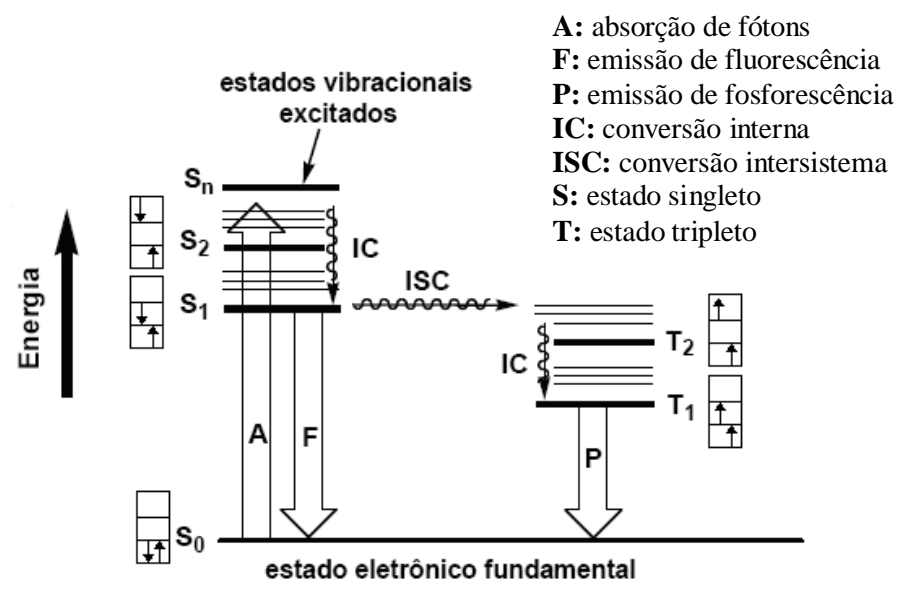

Figura 19 - Diagrama de Jablonski ${ }^{28}$.

$\mathrm{Na}$ maioria dos sistemas moleculares, os elétrons das moléculas em seu estado fundamental (de menor energia) estão em um mesmo orbital e possuem spins opostos, ou seja, estados nos quais todos os elétrons encontram-se emparelhados. Quando um elétron dessa molécula é excitado (A) e elevado para um orbital de maior energia, seu spin pode permanecer na mesma posição ficando no estado singleto $(\downarrow \uparrow)$ ou em direção oposta, estado tripleto $(\uparrow \uparrow)$, em relação ao outro elétron que permaneceu em sua orbita original.

Do nível excitado de menor energia $S_{1}$, a molécula pode retornar a qualquer um dos níveis vibracionais/rotacionais do estado fundamental de mesma multiplicidade, emitindo assim fluorescência $(F)$.

A conversão interna (IC - internal convertion) ocorre quando a molécula passa de um baixo nível vibracional de um estado excitado superior para um alto nível vibracional de um estado excitado inferior. Em solução, este processo é seguido por uma relaxação vibracional até o mais baixo nível vibracional do estado eletrônico final. Essa relaxação vibracional ocorre quando a molécula excitada perde rapidamente seu excesso de energia vibracional devido às colisões com outras moléculas.

A conversão intersistema (intersystem crossing), é uma conversão isoenergética que ocorre entre estados de multiplicidades diferentes. Um elétron não pode ser diretamente excitado para o estado tripleto, mas pode atingir o estado tripleto mediante a inversão do spin do elétron singleto (cerca de 75\% dos elétrons excitados singletos tem a probabilidade de migrar para o estado tripleto,que é mais estável por possuir menor energia ${ }^{53}$. 


\subsection{Diodos emissores de Luz Poliméricos (PLEDS)}

O diodo é um dispositivo eletrônico que se forma através da união física de um semicondutor do tipo $p$ com um semicondutor do tipo $n$, formando uma junção PN (Figura 20).

E possível conseguir um semicondutor do tipo $p$ (lacunas) dopando o silício ou germânio que são semicondutores intrínsecos com átomos trivalentes como boro, formando dessa forma três ligações covalente e um buraco, tornando-se assim um material, cujos portadores de cargas majoritários serão as lacunas e os minoritários os elétrons. Já no semicondutor do tipo $n$, temos que ter o inverso, com os portadores majoritários sendo os elétrons e os minoritários os buracos, para que isso ocorra o silício ou o germânio são dopados com impurezas ou átomos pentavalentes como o fósforo, obtendo-se assim quatro ligações covalentes e um elétron livre ${ }^{55}$.

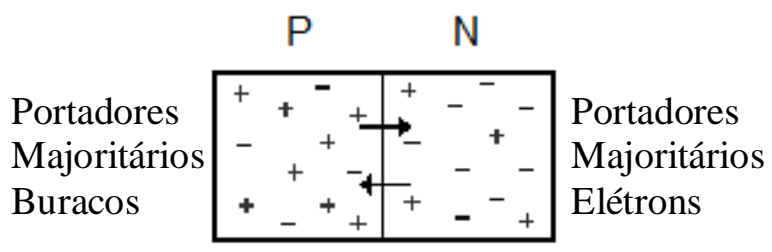

Figura 20 - Diodo semicondutor (junção PN).

$\mathrm{Na}$ formação da junção $\mathrm{PN}$ ocorre o processo de recombinação ou balanceamento de cargas no qual os elétrons do lado $n$ mais próximos a junção $P N$ migram para $\circ$ lado $p$, com esse processo ocorrendo até atingir o equilíbrio eletrônico e químico. Durante o processo de recombinação, forma-se próximo a junção uma região conhecida como camada de depleção, e quando a recombinação termina essa camada de depleção fica ionizada formando a região de depleção mostrada na Figura 21.

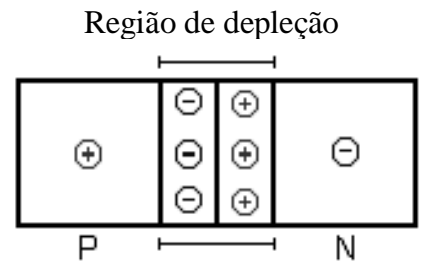

Figura 21 - Formação da barreia de potencial. 
Quando uma diferença de potencial entre eles é aplicada, as forças elétricas podem superar essa barreira de potencial, então se diz que o potencial foi maior do que o potencial de barreira, e a partir deste valor ocorre à condução elétrica. Se o terminal positivo de uma bateria for conectado ao lado $p$ e o negativo ao lado $n$, chamamos de polarização direta, o oposto é chamado de polarização reversa.

Para que haja passagem de corrente, é necessário que ocorra uma interação entre os elétrons livres e as lacunas com decaimento energético, e, em um LED, este decaimento se dá na forma de emissão de luz no espectro visível.

A forma tradicional de um LED polimérico (PLED) constitui-se de um substrato transparente de vidro (PLED rígido) ou um filme de PET (PLED flexível), recoberto por um filme fino também transparente de um oxido metálico, normalmente, o ITO (Indium Tin Oxide) que é o óxido de índio dopado com estanho, 90\% de $\operatorname{lnO}_{3}$ e $10 \%$ de $\mathrm{SnO}_{2}$ (de aproximadamente $100 \mathrm{~nm}$ de espessura), uma camada emissiva formada pelo polímero eletroluminescente, que geralmente é depositado sobre o ITO por vazamento ou por rotação, formando filmes entre 30 e $100 \mathrm{~nm}$, e um filme metálico de alumínio, cálcio, ouro ou magnésio como cátodo ${ }^{5,13}$, depositado por evaporação sobre o polímero eletroluminescente.

Uma possível estrutura de um PLED pode ser exemplificada pela Figura 22.

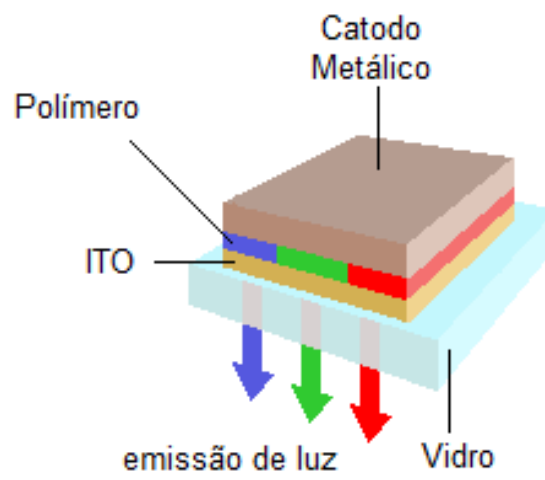

Figura 22 - Estrutura básica de um PLED ${ }^{11}$.

Em analogia aos semicondutores inorgânicos, a energia liberada em semicondutores orgânicos corresponde à diferença energética entre o nível menos energético desocupado LUMO, referente à banda de condução, e o nível mais 
energético ocupado, $\mathrm{HOMO}$, referente à banda de valência. A diferença entre esses dois níveis é conhecida como banda proibida (band-gap) ou simplesmente gap.

Para que haja a emissão de luz o processo de operação do PLED tem que seguir três etapas básicas: injeção, transporte e recombinação de cargas ${ }^{56}$.

Os PLEDS operam mediante a aplicação de uma diferença de potencial (Figura 23), sendo que o cátodo injeta portadores negativos (elétrons) na banda de condução, (LUMO - orbital $\Pi^{*}$ ) de acordo com a diferença de energia $\Delta_{e}$ entre a função de trabalho do cátodo $\left(\phi_{c}\right)$ e o nível de energia do LUMO (фLUMO), e o ânodo, por sua vez, injeta portadores positivos (lacunas) na banda de valência (HOMO orbital $\pi$ ) do polímero, de acordo com a diferença de energia entre a função trabalho do ânodo $\left(\phi_{\mathrm{a}}\right)$ e o nível de energia do HOMO (фномо); essa injeção de cargas é representada por (1) na Figura 23. Essas cargas, n (2) e p (3), caminham pelo semicondutor (polímeros eletroluminescentes) até que se encontram, ocorrendo a recombinação (4), que pode originar decaimento via processo radiativo (transição $\pi^{*}$ - $\left.\pi\right)$ com emissão de um fóton de energia equivalente ao gap (4) $)^{56,57,58}$.

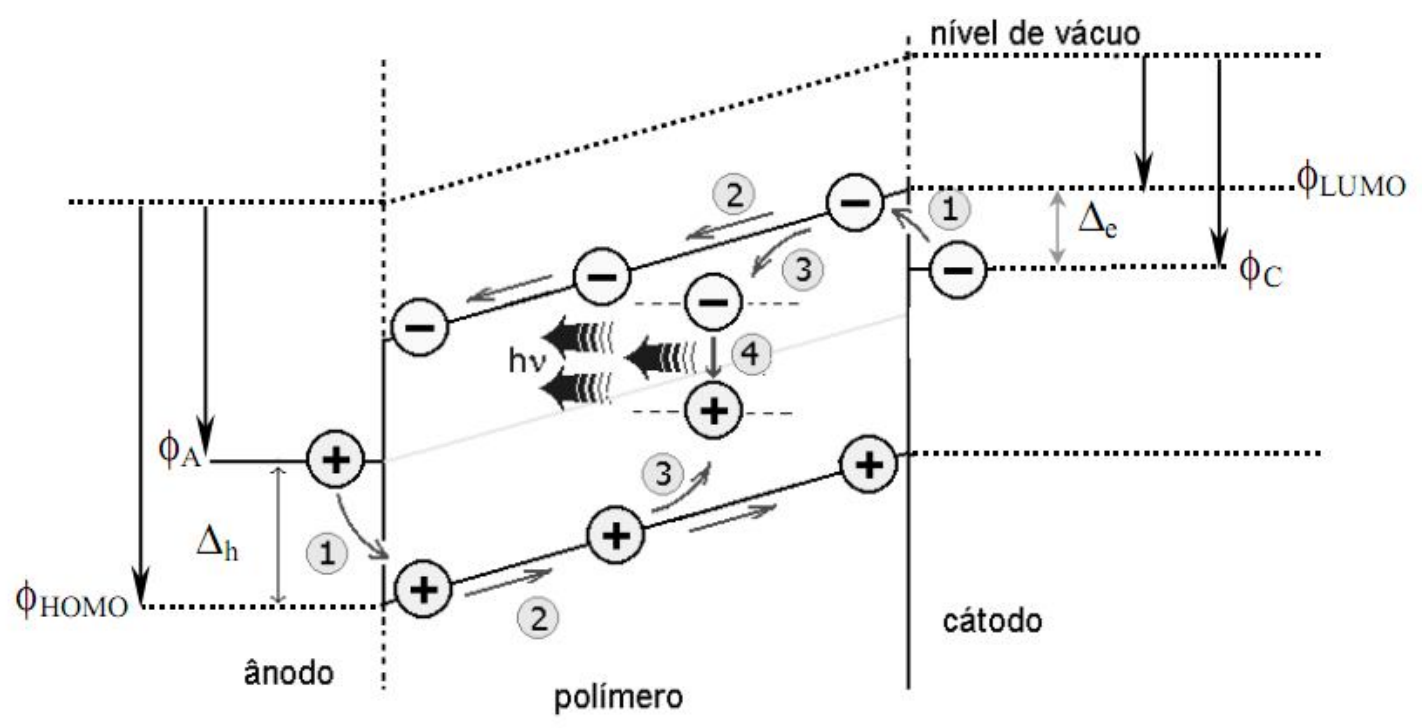

Figura 23 - Diagrama de bandas de um PLED de camada simples.

O bom desempenho de um PLED está diretamente relacionado à injeção de portadores de cargas, assim, um ótimo balanço da taxa de recombinação depende muitas vezes das energias interfaciais metal/substância orgânico ${ }^{58}$.

Para isso é necessário, então, utilizarmos como ânodo materiais com alta função trabalho para injeção de buracos, sendo o ITO o material mais usado, pois 
além de transparente, possui baixa resistência elétrica e tem função trabalho próxima a energia do $\mathrm{HOMO}$ da maioria dos polímeros semicondutores $(4,2 \sim 5,3$ eV $)^{59}$, e como cátodo, materiais com baixa função trabalho para injeção de elétrons. Neste o cálcio $(\mathrm{Ca})$ é o material mais indicado, pois possui função trabalho de aproximadamente $2,87 \mathrm{eV}^{59}$, sendo do ponto de vista eletrônico, o melhor injetor de elétrons que existe atualmente, entretanto, o cálcio é muito reativo na presença de água e oxigênio, o que acaba limitando o seu uso, já o Alumínio (Al) apesar de possuir uma função trabalho de aproximadamente $4,1 \mathrm{eV}$, e, portanto, maior que a do cálcio, é interessante e muito utilizado na fabricação de PLEDS, devido, principalmente, a sua estabilidade, fácil deposição e elevada pureza.

Outras propriedades também devem ser levadas em conta no polímero eletroluminescente, a fim de se obter PLEDs mais eficientes, como estabilidade química e boa resistência à degradação térmica.

Apesar de o ITO ser atualmente o material mais utilizado como ânodo, ele apresenta um problema de interface com os polímeros emissores, onde o oxigênio presente no ITO faz com que ocorra a foto-oxidação do polímero emissor de luz, degradando-o. Para se resolver esse problema fez-se necessário então a utilização de uma camada transportadora de buracos, os HTL (Hole transport layers), essa camada, além de resolver o problema da interface auxilia também na injeção de buracos no polímero emissor ${ }^{60}$.

O polímero mais utilizado como HTL é o poli(3,4-etilenodioxitiofeno) dopado com poli(4-sulfonato de estireno) conhecido como PEDOT/PSS, que tem sua estrutura mostrada na Figura 24.

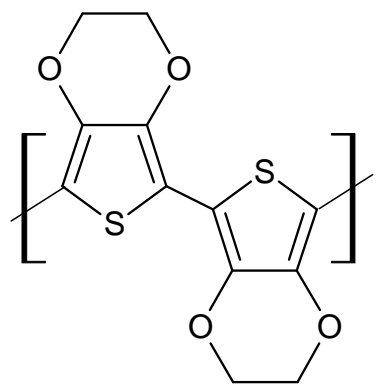

a) PEDOT<smiles>CCC(C)c1ccc(S(=O)(=O)O)cc1</smiles>

b) PSS

Figura 24 - Estrutura química do: a) poli(3,4-etilenodioxitiofeno) (PEDOT); b) poli(4-sulfonato de estireno) (PSS). 
O PDOT/PSS é um material muito interessante e de fácil processamento e tem a vantagem de ser solúvel em água, e, por não utilizar solventes orgânicos, permite a sua deposição sem que ocorra corrosão de outros polímeros.

Além dos processos de injeção de portadores, outro fator que deve ser levado em consideração é o balanceamento das correntes de elétrons e de buracos ${ }^{18}$, e visto que a maioria dos polímeros eletroluminescente tem como preferência o transporte de buracos, sendo, portando, semicondutores do tipo $p$, o processo de transporte de elétrons é mais raro e difícil, e a mobilidade dos elétrons em um PLED é da ordem de $10^{-6}$ a $10^{-8} 61$.

Para tentar amenizar esse problema, promovendo um maior balanceamento de cargas, são comumente depositados entre o cátodo e 0 polímero eletroluminescente uma camada transportadora de elétrons conhecidos como ETL (electron-transport layer). O intuito dessas camadas é aumentar o número de elétrons fazendo um balanceamento de $\operatorname{cargas}^{60} \mathrm{e}$, consequentemente, aumentar a probabilidade de recombinação elétron-lacuna, aumentando assim a eficiência luminosa ${ }^{57}$.

O polímero mais utilizado como ETL é o tris-8-hidroxiquinolina alumínio $\left(\mathrm{Alq}_{3}\right)$, cuja estrutura química aparece na Figura 25.

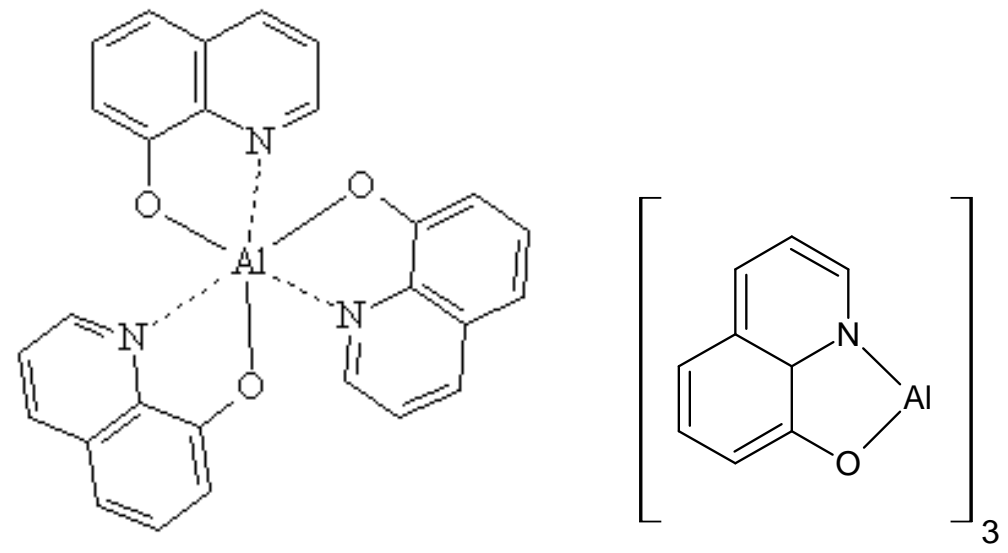

Figura 25 - Estrutura química do $\mathrm{Alq}_{3}, \mathrm{Al}\left(\mathrm{C}_{9} \mathrm{H}_{6} \mathrm{NO}\right)_{3}$.

A Figura 26 exemplifica a estrutura multicamada de um PLED com o ETL e o HTL, contendo o polímero eletroluminescente (EL) inserido entre as duas camadas. 


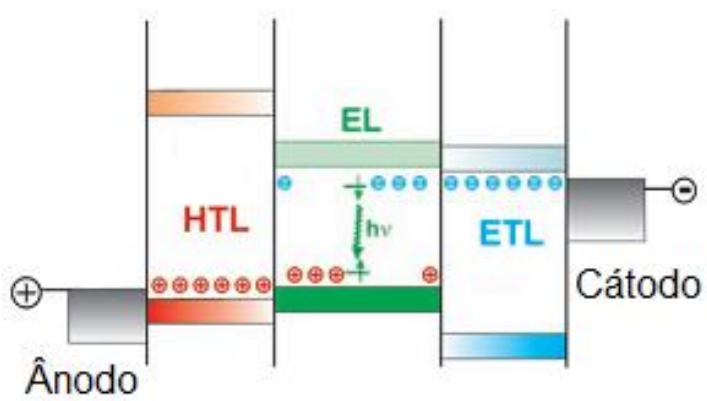

Figura 26 - Estrutura básica de um PLED multicamadas ${ }^{58}$.

Outro fator que também tem influência na eficiência de um dispositivo PLED é a ocorrência de emissões energéticas não radioativas, como a emissão de fônons e a transferência de energia para os defeitos estruturais ${ }^{57}$. Estudos mostram que a eficiência quântica é da ordem de $5 \%$ a $25 \%{ }^{18}$.

Outros fatos que diminuem a eficiência do dispositivo são as ocorrências de recombinações em áreas próximas ao eletrodo. Para minimizar tal fato, é necessário aumentar a afinidade/compatibilidade nas interfaces e também uma melhoria nas técnicas de deposição. Outro problema é a foto-oxidegradação, que apesar de ser conhecido, ainda não é completamente esclarecido, embora possa ser minimizada mantendo-se o polímero ao abrigo da luz ${ }^{62}$.

Atualmente, intensos estudos vêm sendo realizados a fim de se obter materiais poliméricos semicondutores com boa estabilidade térmica, oxidativa e elétrica para a construção desses dispositivos eletrônicos.

O emprego de polímeros intrinsecamente emissores representa a maneira mais apropriada para o aperfeiçoamento da estabilidade física dos PLEDs.

Os polímeros conjugados são os mais apropriados e têm sido largamente aplicados como camadas emissoras em PLEDs, porque os elétrons $\pi$ podem ser facilmente delocalizados formando íons-radicais (polarons), sem comprometer as ligações $\sigma$, responsáveis pela integridade física das macromoléculas.

Além de todas as vantagens que os PLEDs oferecem o fácil processamento dos polímeros semicondutores através de técnicas convencionais de formação de filme polimérico, tais como vazamento da solução, rotação (spin coating) ou imersão (dip-coating), consiste em uma das principais vantagens sobre os diodos fabricados com materiais inorgânicos.

Aliando essa fácil processabilidade dos polímeros com as imensas possibilidades de se obter estruturas diferentes a partir de síntese, assim como 
através de mistura de polímeros diferentes, produzindo materiais novos com propriedades características. Os polímeros apresentam, portanto, muitos atrativos para novas pesquisas e desenvolvimentos tanto de estrutura químicas novas como processos de fabricação dos PLEDS. 


\subsection{Objetivos da Pesquisa}

Conhecendo os principais fatores que interferem na eficiência dos PLEDs, esse trabalho apresenta os seguintes objetivos:

1. Síntese de copolímeros contendo segmentos do tipo $n$, injetores de elétrons contendo grupos 8-oxioctil-quinolina, juntamente com segmentos emissores de luz, partindo do 9,9-dioctil-2,7-dibromofluoreno, em diferentes concentrações, sendo essas reações de copolimerização feitas através da reação de acoplamento de Suzuki.

2. Construção de PLEDs utilizando como camada ativa os copolímeros sintetizados.

Esses copolímeros sintetizados têm, como principal finalidade, aumentar o número de recombinações entre pares elétron-lacuna obtendo assim um maior número de decaimentos radiativos com emissão de luz visível na estrutura polimérica da parte ativa dos PLEDs, podendo até mesmo deixar de usar camadas adicionais de ETL. 


\section{MATERIAIS E MÉTODOS}

\subsection{Reagentes e solventes}

Os seguintes reagentes e solventes foram utilizados como recebidos, exceto quando indicada purificação adicional prévia:

- $\quad 1,4$ dicloro benzeno (Vetec $99 \%$ )

- $\quad$ 5,7-dibromo-8-hidroxi-quinolina (Sintetizado pela Prof ${ }^{a}$. Dr ${ }^{a}$. Wang Shu Hui).

- $\quad$ 9,9-dioctil-2,7-dibromofluoreno (Aldrich $99 \%$ )

- $\quad$ Acetona (Casa Americana, Synth 99,5\%)

- Ácido 1,4 fenilenobisborônico (Aldrich 97\%)

- $\quad$ Ácido fenilborônico (Aldrich $97 \%$ )

- $\quad$ Alq3 (Aldrich)

- $\quad$ Brometo de tetraetilamônio (Et4NBr) (Merck 99 \%) foi secado em uma estufa a $120^{\circ} \mathrm{C}$ por 12 horas, e utilizado como eletrólito de suporte nas medidas eletroquímicas a uma concentração de 0,1 molL-1.

- $\quad$ Carbonato de Cálcio (Casa Americana P.A).

- Carbonato de Potássio (Casa Americana P.A).

- $\quad$ Cloreto benzalcônico (Synth)

- Clorofórmio (VETEC - Química Fina Ltda 99,8\%.).

- $\quad$ Clorofórmio espectrométrico (Tédia)

- $\quad$ Clorofórmio Deuterado (Merck 99,8 \%)

- Diclorometano: o solvente foi deixado sob refluxo por 6 horas e destilado a pressão ambiente.

- Metanol (Casa Americana, Synth 99,8\%).

- $\quad$ PEDOT:PSS 1:6 (p) 1,3 - 1,7\% (Baytron PVPAI 4083 - H.C.Starck)

- Peróxido de hidrogênio (CAAL $35 \%$ )

- $\quad$ PVK (Aldrich, $99 \%)$

- $\quad$ THF (Aldrich, $99 \%$ )

- Tolueno (Synth 99,5\%) 
- $\quad$ Vidro com ITO com resistência de folha $30-60$ ohm/ $\square$ (DELTA)

- $\quad$ Vidro com ITO com resistência de folha de aproximadamente 15 ohms/ $\square$ (Chinês)

- $\quad$ Xileno (Synth 98,5\%) 


\subsection{Equipamentos}

- Analisador de Parâmetros Semicondutores:

Source Meter modelo 2420-C 3A da Keithley.

- Analisador termogravimétrico (TG):

Analisador termogravimétrico TG-51, Shimadzu.

- Calorimetria diferencia exploratória (DSC):

DSC modelo Q100 da TA instruments.

- Câmara "Glove-box.

- Calorímetro modelo SC100A da Konica-Minolta.

- Cromatografia de permeação em gel (GPC):

Agilent 1100 do instituto de física de São Carlos (IFSC-USP).

- Espectrofotômetro de Fluorescência:

Fluorímetro modelo Eclypse da Varian.

- Espectrofotômetro de Infravermelho (FTIR):

Espectrômetro Modelo Vector 22 da Bruker,

Espectrômetro Modelo Magna IR 560 ESP da Nicolet.

- Espectrofotômetro ultravioleta-visível (UV-Vis):

UV-Vis modelo Cary 50 Conc da Varian.

UV-Vis modelo UV-1650 PC da Shimadzu, pertencente ao Grupo de Eletrônica Molecular (GEM). 
- Espectrômetro de ressonância magnética nuclear (RMN):

Espectrômetro Bruker AC-200, operando a 200 MHz para hidrogênio, Instituto de Química da USP.

- Evaporadora:

Evaporadora da Varian do laboratório de microeletrônica da escola politécnica da USP.

- Microscópio Eletrônico de Varredura (MEV):

Microscópio eletrônico Modelo XL-30 da Phillips.

- Microscópio Óptico:

Microscópio modelo Polyvar Met da Reichert Jung.

- Perfilômetro: Medida de espessura

Afpha Step 500.

- Spectroradiômetro HR 2000+ da Ocean Optics.

- Spin coating:

Modelo P 6024 da Specialty Coating System Incorporation.

- Voltametria Cíclica (VC):

Equipamento potenciostato/galvanostato da PalmSens.

Célula Eletroquímica: Foi utilizada uma célula em "H". O seu corpo é constituído de vidro, sendo as tampas de teflon. Apresenta uma placa porosa de vidro, um eletrodo de referência de $\mathrm{Ag} / \mathrm{AgBr}$, um eletrodo de trabalho de Au e um contra-eletrodo de grafite. 


\subsection{Métodos}

\subsubsection{Síntese dos copolímeros emissores de luz}

A Figura 27 mostra e estrutura molecular dos compostos envolvidos nas sínteses realizadas.

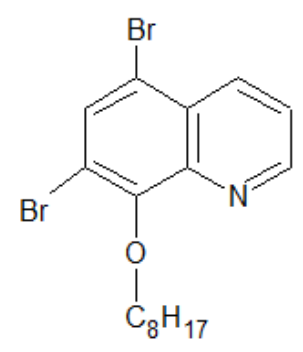

Quinolina<smiles>COc1ccc(O)cc1</smiles>

Bisborônio

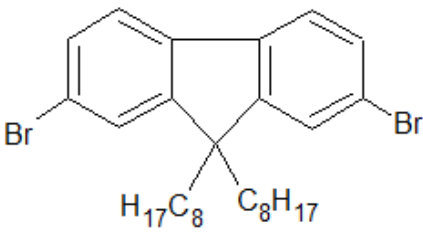

Fluoreno<smiles>Clc1ccc(Cl)cc1</smiles>

Diclorobenzeno

Figura 27 - Materiais de partida utilizados nas sínteses: a) 5,7-dibromo-8-oxioctil-quinolina; b) 1,4fenileno-bisborônico; c) 9,9-Dioctil-2,7-dibromofluoreno; d) 1,4 diclorobenzeno.

As composições dos copolímeros obtidos foram selecionadas com base em resultados anteriores do grupo que indicaram maximização da fluorescência com concentração do grupo emissor ao redor de $10 \%$, tendo sido estabelecidas as seguintes composições:

Copolímeros PFN01, PFN02, PFN10:

$70 \%$ molar de grupos quinolina: $10 \%$ molar de grupos fluoreno e $20 \%$ molar de diclorobenzeno.

\section{Copolímero PFNO3:}

$50 \%$ molar de grupos quinolina: $10 \%$ molar de grupos fluoreno e $40 \%$ molar de diclorobenzeno

Como a síntese de Suzuki ocorre entre grupos boronados e grupos halogenados, o balanço estequiométrico é obtido com $100 \%$ molar do composto 
bisborônico, já que ele reagirá com os demais reagentes. Partindo-se então de 2 mmol do ácido fenilenobisbôronico, foram feitos os cálculos para os demais reagentes, ficando assim:

PFN01, PFN02 e PFN10 $\rightarrow 1,4 \mathrm{mmol}$ de quinolina: $0,2 \mathrm{mmol}$ de fluoreno: 0,4 mmol de diclorobenzeno.

PFN03 $\rightarrow 1 \mathrm{mmol}$ de quinolina: $0,2 \mathrm{mmol}$ de fluoreno: $0,8 \mathrm{mmol}$ de diclorobenzeno

A Tabela 2 mostra a massa molar e a massa pesada dos reagentes para cada síntese.

Tabela 2 - Massa molar e massas do reagentes utilizadas nas sínteses.

\begin{tabular}{|l|c|c|c|c|c|}
\hline \multicolumn{1}{|c|}{ Reagente } & Massa molar & PFN01 (g) & PFN02(g) & PFN03(g) & PFN10(g) \\
\hline Quinolina & $415,0 \mathrm{~g} / \mathrm{mol}$ & 0,5860 & 0,5813 & 0,4141 & 0,5814 \\
\hline Fluoreno & $548,0 \mathrm{~g} / \mathrm{mol}$ & 0,1080 & 0,1130 & 0,1106 & 0,1120 \\
\hline Diclorobenzeno & $147,0 \mathrm{~g} / \mathrm{mol}$ & 0,0581 & 0,0597 & 0,1141 & 0,0583 \\
\hline Bisborônio & $165,6 \mathrm{~g} / \mathrm{mol}$ & 0,3342 & 0,3300 & 0,3339 & 0,3301 \\
\hline
\end{tabular}

Inicialmente foi montado o condensador para a reação ser processada sob refluxo e o banho de silicone foi posto sobre a placa aquecida para atingir a temperatura desejada para cada síntese. Os reagentes pesados foram colocados dentro do balão de três bocas e em uma das bocas desse balão foi acoplado um adaptador para o fluxo de nitrogênio, pois a reação tem que ocorrer em atmosfera inerte. $\mathrm{Na}$ "glove-box", foi pesado o catalisador tetrakis(triphenylphosphine) palladium $\left(\mathrm{P}\left(\mathrm{Ph}_{3}\right)_{4} \mathrm{Pd}\right)$ que já se encontrava a temperatura ambiente (pesado em ambiente de baixa umidade para evitar a contaminação do restante do próprio material, que logo em seguida foi fechado, guardado ao abrigo da luz e armazenado novamente na geladeira). A quantidade de catalisador utilizada foi de 1,5\% a 5,0\% da massa total do sistema. A Figura 28 mostra o sistema de refluxo onde foram processadas as sínteses. 


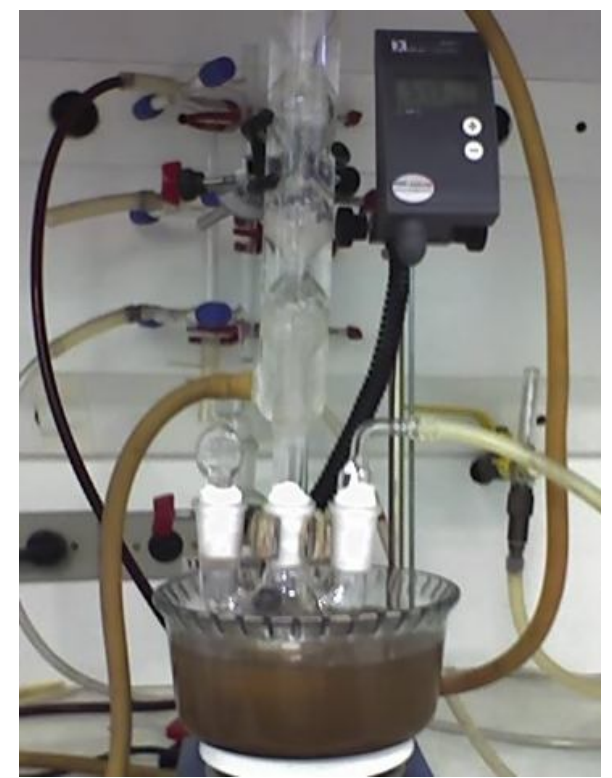

Figura 28 - Sistema de refluxo utilizado nas sínteses dos copolímeros.

\section{Síntese do copolímero PFN01}

A síntese do copolímero PFN01 teve como base o procedimento usual ${ }^{63}$ da reação de acoplamento de Suzuki, utilizando-se tolueno como solvente e uma solução de carbonato de cálcio.

Com o balão acoplado no condensador, em banho de silicone a uma temperatura de $65^{\circ} \mathrm{C}$, e com fluxo de nitrogênio constante para manter a atmosfera inerte, foram adicionados então $15 \mathrm{~mL}$ de tolueno, 0,0162 $\mathrm{g}$ do catalisador $\left(\mathrm{P}\left(\mathrm{Ph}_{3}\right)_{4} \mathrm{Pd}\right)$ e $10 \mathrm{~mL}$ de solução de carbonato de sódio dissolvido em água destilada, sob agitação. Após 24 horas de reação foram adicionados mais $10 \mathrm{~mL}$ de tolueno e 0,055 g, cerca de 5 \% em massa, de ácido fenil-borônico, responsável por completar a reação e eliminar grupos halogenados terminais da cadeia polimérica e após mais 3 hs a reação foi terminada. Foram adicionados $10 \mathrm{~mL}$ de água oxigenada, e a mistura mantida em agitação por mais 24 hs para desativar os compostos boronados não reagidos e remover também possível excedente de catalisador.

O Esquema 2 mostra a rota sintética da reação com os respectivos compostos utilizados e o copolímero PFN01 obtido. 


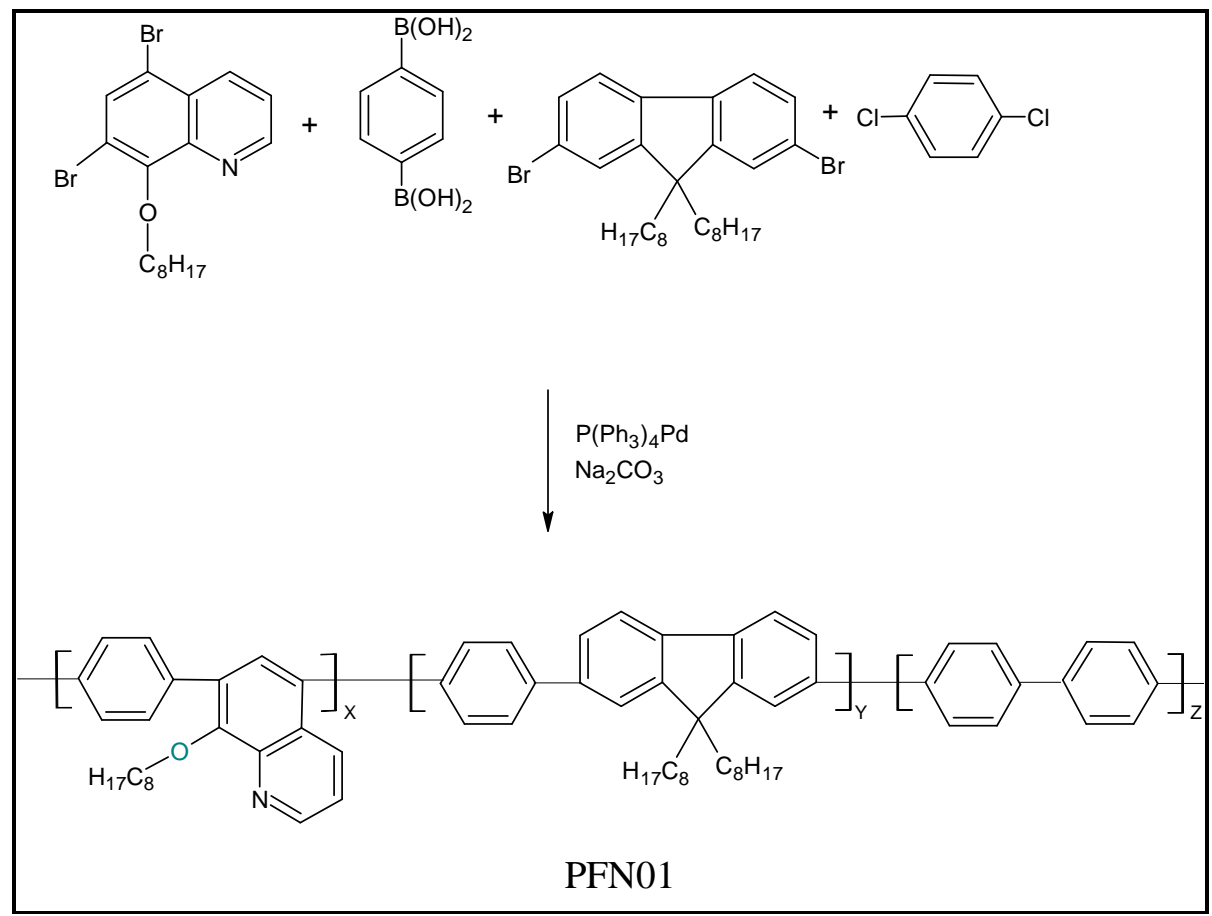

Esquema 2 - Rota sintética para a obtenção do copolímero PFN01.

Em um balão de adição separou-se a fase orgânica da fase aquosa. Para essa separação a solução foi sendo lavada com água destilada até a neutralização da solução. Feita a separação, a fase orgânica foi seca em $\mathrm{Na}_{2} \mathrm{SO}_{4}$ e o solvente foi retirado com o auxilio de um evaporador rotativo e em estufa a vácuo até que o material tivesse peso constante, quando foi purificado, para isso foi dissolvido em clorofórmio e precipitado em metanol.

O rendimento dessa síntese foi de 59\%.

\section{Síntese do copolímero PFN02}

A síntese do copolímero PFN02 foi realizada utilizando o mesmo procedimento descrito para a síntese do PFN01, entretanto, utilizou-se um agente transferidor de fases, que poderia melhorar o resultado da síntese, de acordo com Inbasekaran e colaboradores ${ }^{30}$. Essa patente descreve e sugere a utilização de um agente transferidor de fases que atua facilitando a migração dos reagentes de uma fase para outra ${ }^{28,31}$. No caso dessa síntese foi utilizado o cloreto de benzalcônio 
$\left(\mathrm{C}_{12} \mathrm{H}_{25} \mathrm{n}\left(\mathrm{CH}_{3}\right)_{2} \mathrm{C}_{7} \mathrm{H}_{7} \mathrm{Cl}\right)$. O solvente foi também trocado, usando-se então o xileno, além da solução alcalina de carbonato de potássio.

Com o balão acoplado ao condensador, em banho de silicone com fluxo de nitrogênio constante foram adicionados $15 \mathrm{~mL}$ de xileno, $0,0140 \mathrm{~g}$ do catalisador $\left(\mathrm{P}\left(\mathrm{Ph}_{3}\right)_{4} \mathrm{Pd}\right)$ e uma solução contendo carbonato de potássio $(3 \mathrm{~g})$ e cloreto de benzalcônio $\left(\mathrm{C}_{12} \mathrm{H}_{25} \mathrm{~N}\left(\mathrm{CH}_{3}\right)_{2} \mathrm{C}_{7} \mathrm{H}_{7} \mathrm{Cl}\right) \quad(0,1791 \mathrm{~g})$, dissolvidos em $10 \mathrm{~mL}$ água destilada. Após 48 hs, com a solução já se encontrando bem viscosa, foi adicionado mais $15 \mathrm{~mL}$ de xileno e também 0,0626 g de ácido fenil-borônico, e após mais 24 hs a reação foi terminada pelo resfriamento até a temperatura ambiente e pela adição de $10 \mathrm{~mL}$ de $\mathrm{H}_{2} \mathrm{O}_{2}$ por 2 horas.

Em um balão de adição separou-se a fase orgânica da fase aquosa. Para essa separação a solução foi sendo lavada com água destilada até a neutralização da solução. O solvente foi retirado a vácuo.

O copolímero seco foi purificado, sendo dissolvido em clorofórmio e precipitado em metanol.

O rendimento dessa síntese foi de $88,5 \%$ e o copolímero final após a purificação apresentou-se como um sólido pastoso amarelado.

O Esquema 3 mostra a rota sintética da reação da síntese do copolímero PFN02, com os respectivos compostos utilizados e o copolímero obtido.

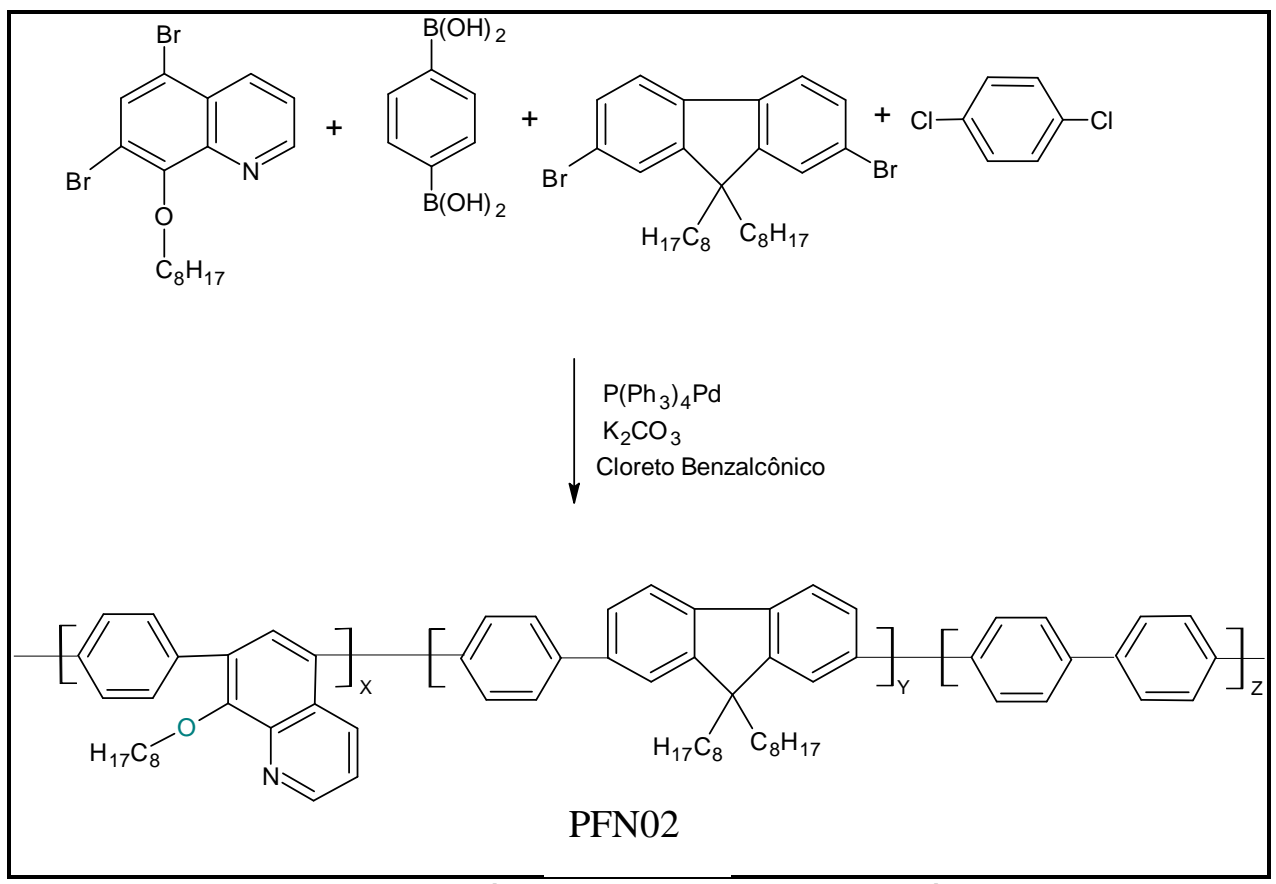

Esquema 3 - Rota sintética para a obtenção do copolímero PFN02. 


\section{Síntese do copolímero PFNO3}

A síntese do copolímero PFN03 seguiu o procedimento sintético descrito para a obtenção do copolímero PFN02, porém com outra composição relativa dos monômeros, sendo $50 \%$ de quinolina, $10 \%$ de fluoreno e $40 \%$ de diclorobenzeno.

Essa síntese teve um rendimento de $23 \%$ e o copolímero final após a purificação apresentou-se como um sólido pastoso amarelado.

\section{Síntese do copolímero PFN10}

A síntese do copolímero PFN10 seguiu o procedimento sintético descrito para a obtenção do copolímero PFN02, porém com um maior controle do sistema de refluxo (mantendo em até $1 / 3$ do condensador).

Essa síntese teve um rendimento de $89 \%$ e o copolímero final após a purificação apresentou-se como um sólido amarelado.

\subsubsection{Caracterização dos copolímeros emissores de luz}

\subsubsection{Espectroscopia de absorção no UV-Vis}

Para obter os espectros de absorção no UV-Vis foram feitos dois tipos de análises:

Em solução, onde as amostras foram dissolvidas em clorofórmio espectrométrico, dentro de uma célula quadrada de quartzo de $1 \mathrm{~cm}$.

Em filme, onde o copolímero é depositado pelo método de spin-coating sobre uma placa de vidro recoberta por ITO.

Os espectros de transmissão tanto em solução quanto em filme foram coletados de $\lambda=200$ a $800 \mathrm{~nm}$. 


\subsubsection{Espectroscopia de fluorescência}

As amostras foram dissolvidas em clorofórmio, dentro de uma célula quadrada de quartzo e submetidas à irradiação no comprimento de onda correspondente ao máximo de absorção observado no espectro de UV-Vis e os espectros de emissão foram coletados na faixa de comprimento de onda $250 \mathrm{~nm}$ $800 \mathrm{~nm}$.

\subsubsection{Espectroscopia de ressonância magnética nuclear de hidrogênio (HNMR)}

O solvente utilizado foi clorofórmio deuterado $\left(\mathrm{CDCl}_{3}\right)$. Os sinais de absorção do clorofórmio e/ou do tetrametilsilano (TMS) foram usados como padrões de referência interna.

\subsubsection{Espectroscopia no infravermelho (FTIR)}

As medidas dos copolímeros obtidas da análise do Infravermelho para os copolímeros PFN01 e PFN02 foram realizadas com colaboração da Dra. Shirley Possidônio e do Prof. Dr. Omar Abou El Seoud no prédio do Instituto de Química da Universidade de São Paulo, através de filmes finos sobre pastilhas de $\mathrm{NaCl}$.

Para o copolímero PFN10 as análises foram realizadas com o aúxilio do aluno de doutorado Douglas Morais no laboratório de Materiais Cerâmicos do departamento de Engenharia Metalúrgica e de Matérias da escola Politécnica da USP, também através de filmes finos sobre pastilhas de $\mathrm{NaCl}$. 


\subsubsection{Analisador termogravimétrico (TG)}

As amostras foram submetidas a uma variação de temperatura de $25^{\circ} \mathrm{C}$ a $800^{\circ} \mathrm{C}$ e a uma taxa de aquecimento de $10^{\circ} \mathrm{C} / \mathrm{min}$ sob fluxo de nitrogênio.

\subsubsection{Calorimetria diferencia exploratória (DSC)}

As análises foram realizadas em atmosfera inerte $\left(\mathrm{N}_{2}\right)$ a uma variação de temperatura de $-80^{\circ} \mathrm{C}$ a $180^{\circ} \mathrm{C}$ e a uma taxa de aquecimento de $10^{\circ} \mathrm{C} / \mathrm{min}$.

\subsubsection{Cromatografia de permeação em gel (GPC)}

As amostras foram dissolvidas em tetra-hidrofurano (THF) e analisadas num equipamento Agilent 1100 com colunas de GPC PLgel mixed C e PLgel mixed B em série, detector de índice de refração a $35{ }^{\circ} \mathrm{C}$, usando THF como solvente, a 1 $\mathrm{mL} / \mathrm{min}$. O equipamento foi calibrado com padrões de poliestireno (PS).

\subsubsection{Voltametria cíclica (CV)}

Nos experimentos foi utilizada uma célula eletroquímica em " $\mathrm{H}$ " como mostrada na Figura 29, o seu corpo é construído em vidro, sendo as tampas de teflon e apresenta uma placa porosa de vidro.

Nesta célula utilizou-se um contra-eletrodo de grafite, e os potenciais foram medidos contra um eletrodo de referência de $\mathrm{Ag} / \mathrm{AgBr}$ e um eletrodo de trabalho de $\mathrm{Au}$.

As medidas foram realizadas em solução do copolímero em diclorometano em atmosfera de nitrogênio. 
O potencial de ionização (nível HOMO) $\mathrm{E}_{\mathrm{Pl}}$, e a afinidade eletrônica (nível de LUMO) $E_{A E}$, foram estimados pelos pontos onde se começa a se observar uma alteração na passagem de corrente de início dos picos das curvas de oxidação e redução.

O potencial do eletrodo de referência $\mathrm{Ag} / \mathrm{AgBr}$ foi tomado tendo como referência um contra eletrodo de calomelano saturado $(\mathrm{SCE})^{64}$.

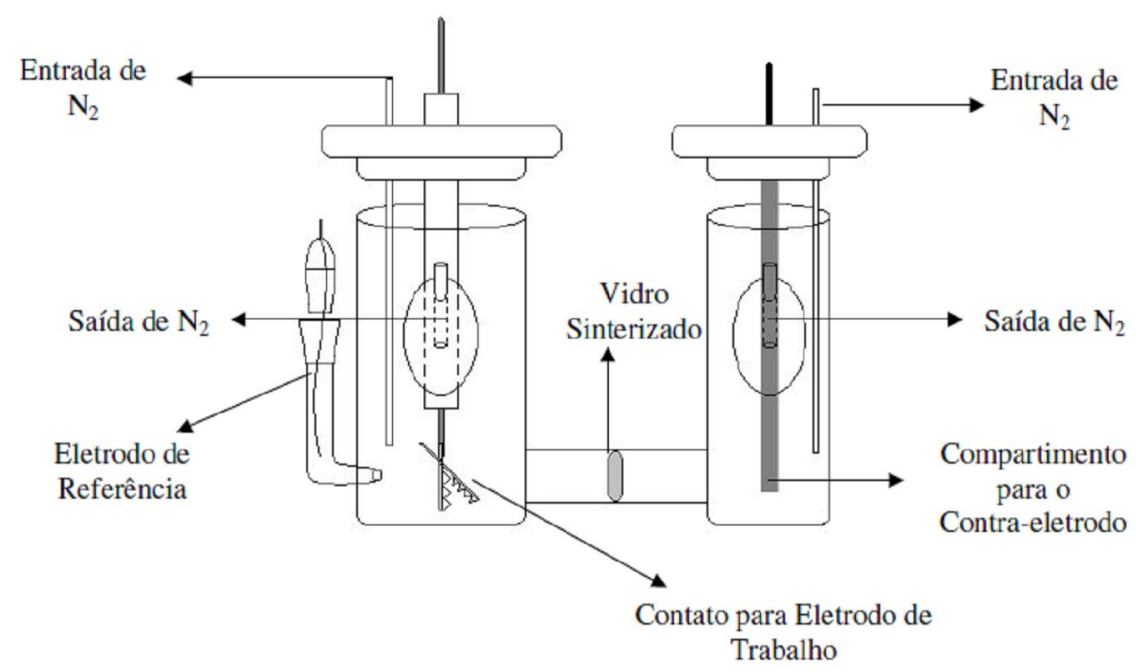

Figura 29 - Esquema da célula eletroquímica em H utilizada nas medidas de voltametria cíclica. 


\subsubsection{Montagem dos PLEDS}

As fabricações de PLEDs foram divididas principalmente em quatro etapas distintas: (1) corte dos substratos com ITO em tamanho de $25 \times 25 \mathrm{~mm}^{2}$, (2) preparo do substrato, que engloba a corrosão do ITO para formação da geometria da área ativa e eletrodo ânodo do dispositivo e pré-limpeza química para retirar particulados da superfície, (3) deposição da camada de PEDOT:PSS que atua no dispositivo como HTL (Hole Transport Layer - camada transportadora de buracos), preparação e deposição da solução do copolímero emissivo sobre o PEDOT:PSS e por fim (4) a metalização por evaporação térmica do alumínio para a formação do eletrodo cátodo.

Foram utilizados dois tipos de máscaras mecânicas contendo geometrias diferentes, em uma das máscara é possível construir seis dispositivos com a área ativa de $13 \mathrm{~mm}^{2}$ cada (Figura 30a) e na outra, quatro dispositivos com área ativa de $9 \mathrm{~mm}^{2}$ cada (Figura 30b).

A Figura 30 mostra a estrutura final dos PLEDs sobre o substrato de vidro parcialmente recoberto com ITO.

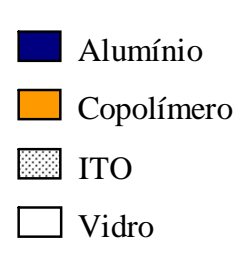

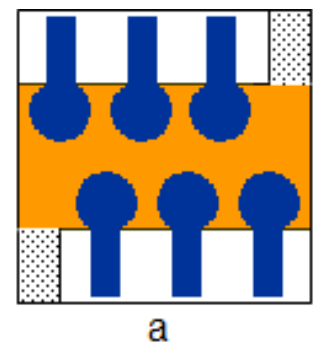

a

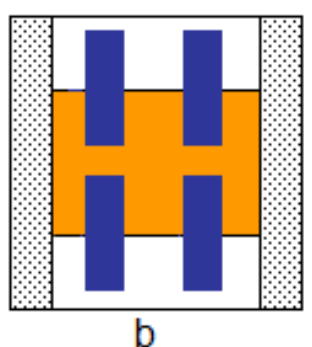

Figura 30 - Geometria e disposições dos PLEDS no substrato.

Para se obter a estrutura Figura 30, fez se necessário à execução de algumas etapas de processos, que serão discutidas mais detalhadamente nos itens a seguir. 


\subsubsection{Preparo das soluções poliméricas}

As soluções foram preparadas em concentrações de $1 \%$ em clorofórmio, grau espectroscópico, visto que essa concentração foi considerada ideal em trabalhos realizados anteriormente no laboratório ${ }^{65}$.

O cálculo da quantidade de material utilizado foi determinado pelo volume de solução que se necessitaria fazer para a deposição nas lâminas, utilizou-se, então, um padrão de $250 \mu \mathrm{L}$ por lâmina, valor esse que se notou mais do que suficiente.

Preparada a solução, a mesma foi filtrada em membranas da marca Millipore de $0,25 \mu \mathrm{m}$ e guardadas em ambiente isolado e longe de umidade e ao abrigo da luz até o momento da deposição.

\subsubsection{Corrosão do ITO}

Essa corrosão é responsável pela formação da região ativa do dispositivo e também da formação do eletrodo ânodo.

Para se delimitar a região ativa desse dispositivo foi utilizada uma fita adesiva (fita mágica marca $3 M$ ) como máscara protetora, então, a região ativa e o eletrodo foram pintados com esmalte acrílico. Após a secagem do esmalte, foi retirada da fita adesiva, deixando uma região do ITO exposta que foi logo em seguida corroída. Foi feita uma corrosão úmida, friccionando o ITO exposto, com algodão (cotonete) umedecido com uma solução de $\mathrm{HCl}$ e pó de zinco, este usado como catalisador. Logo após a corrosão, o esmalte que protegia a área ativa do dispositivo e a região do ânodo foram removidos com acetona. A geometria do substrato Vidro/ITO após essa etapa é mostrada na Figura 31 b). 
a)

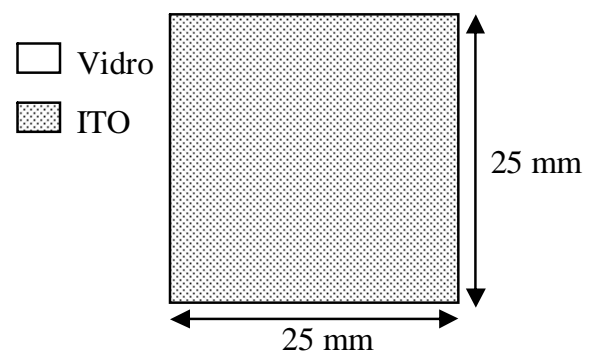

b)

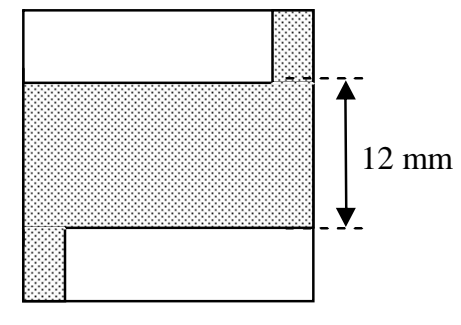

Figura 31 - a) Lâmina de vidro recoberta com ITO; b) Lamina após a etapa de corrosão do ITO.

\subsubsection{Limpeza química}

A limpeza química ou pré-limpeza das lâminas é uma das etapas mais importantes do processo de fabricação dos dispositivos, pois é nela que as impurezas, pó, particulados sobre o ITO são removidos juntamente com possíveis gorduras aderidas.

As lâminas já com as geometrias definidas foram carregadas no portaamostras e imersas em uma solução de acetona onde permaneceram em banho ultrassônico por 30 min, em seguida elas foram retiradas e imersas numa outra solução de álcool isopropílico, também em ultrassom por $30 \mathrm{~min}$. Após esses procedimentos, as lâminas foram secas com jato de nitrogênio.

\subsubsection{Tratamento da superfície do ITO}

Após o procedimento de pré-limpeza as lâminas com Vidro/ITO foram submetidas a um outro tratamento de limpeza superficial para remoção de outros possíveis contaminantes como carbonos e hidrocarbonetos com radiação ultravioleta e formação de ozônio (UV-O ${ }_{3}$ ), utilizando um reator montado, a partir do tubo de ignição de uma lâmpada de vapor de mercúrio sob pressão, cujo bulbo externo foi removido. O equipamento foi montado utilizando além do tubo de ignição, um refletor 
com porta-lâmpada, ventiladores, reator e uma base de madeira coberta com folha de papel alumínio (Figura 32). O projeto e a construção deste reator foram parte integrante do trabalho de doutorado do Dr. Emerson Roberto Santos, do Laboratório de Microeletrônica da Escola Politécnica da Universidade de São Paulo ${ }^{66}$.

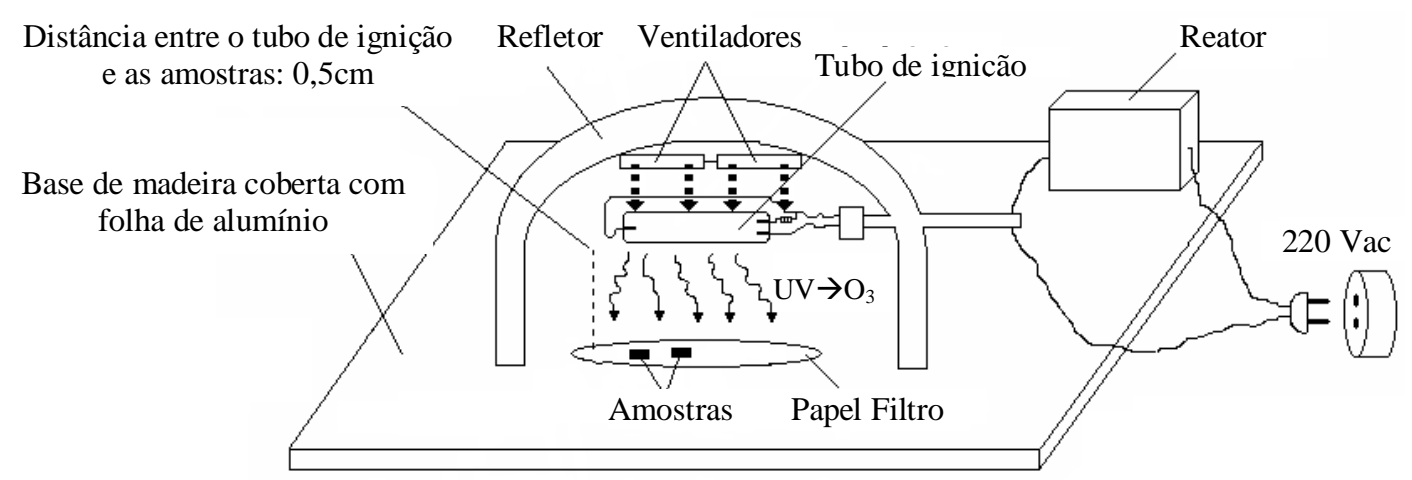

Figura 32 - Esquema do reator utilizado para limpeza superficial do ITO.

\subsubsection{Deposição do PEDOT:PSS}

O PEDOT:PSS foi depositado sobre o ITO pelo método de Spin-Coating (espalhamento rotativo).

Com o Spinner programado para uma rotação de 1500 RPM por um tempo de 60 segundos, a lâmina de ITO/Vidro é presa por vácuo em um suporte do Spinner chamado Chuck e com o auxílio de um pipetador de $500 \mu \mathrm{L}$, a solução aquosa de PEDOT:PSS foi distribuída recobrindo totalmente a lâmina e, então, iniciou-se o processo de rotação causando o espalhamento da solução pela força de centrifugação, formando assim o filme fino. 


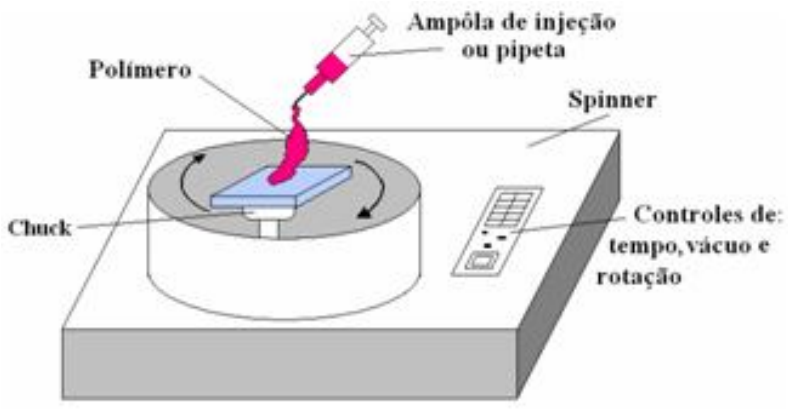

a)

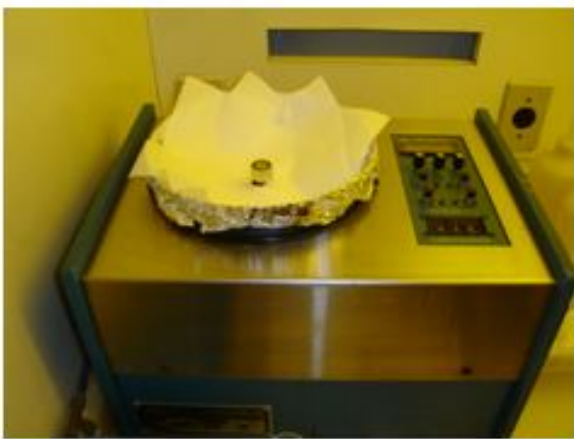

b)

Figura 33 - a) esquema de deposição pelo método Spin-coating; b) Spinner utilizado.

Terminado os 60 segundos de rotação, as lâminas foram retiradas do spinner e submetidas ao processo de decapagem para liberar o excesso de PEDOT:PSS sobre a área de contato do cátodo. Essa decapagem é feita cuidadosamente (para não tocar a área ativa do dispositivo), utilizando-se um cotonete molhado com água para retirar parte do filme depositado. A Figura 34 mostra a geometria do substrato após a deposição e a decapagem do PEDOT:PSS.

a)

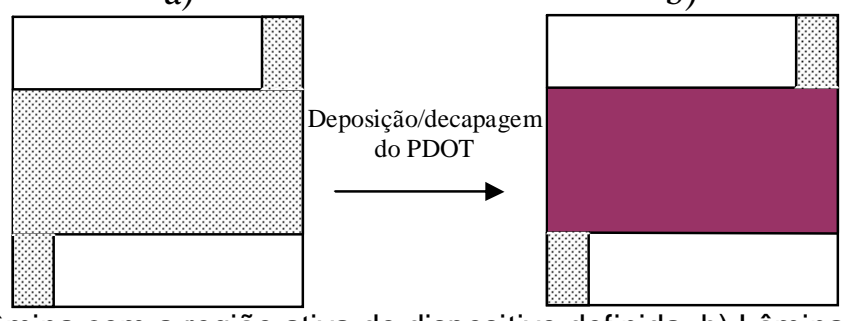

c)

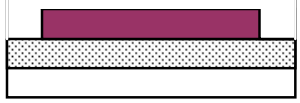

Figura 34 - a) Lâmina com a região ativa do dispositivo definida; b) Lâmina com PDOT depositado e dacapado; c) esquema da estrutura vista em corte transversal.

Após a decapagem as lâminas foram levadas à estufa a vácuo que já se encontrava a uma temperatura de $100^{\circ} \mathrm{C}$, por onde permaneceram por aproximadamente 24 horas, para que tudo o que sobrou do solvente, no caso a água, fosse removido. 


\subsubsection{Deposição do Copolímero}

Para a deposição do copolímero PFN02 utilizou-se o mesmo processo da deposição do PEDOT:PSS, com a mesma rotação e o mesmo tempo. A única diferença foi à utilização de uma microseringa de $250 \mu \mathrm{L}$ e deposição de cerca de $200 \mu \mathrm{L}$ de solução do copolímero sobre cada substrato Vidro/ITO/PEDOT. Após o processo de deposição, passou-se então para a decapagem com clorofórmio, formando então a geometria do substrato mostrado na Figura 35.

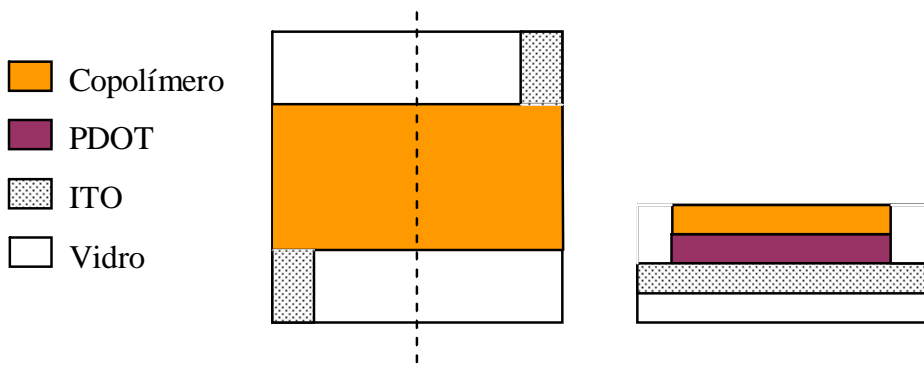

Figura 35 - Geometria da lamina após a deposição e decapagem do copolímero.

Após a deposição e a decapagem as lâminas foram colocadas na estufa a vácuo a aproximadamente $50^{\circ} \mathrm{C}$ onde permaneceram por 24 horas para evaporação total do solvente.

\subsubsection{Metalização dos eletrodos}

Os eletrodos de alumínio (cátodo) foram depositados na sala limpa do Laboratório de Microeletrônica, utilizando a evaporadora térmica mostrada na Figura 36.

No interior de um cadinho foram colocados cerca de $400 \mathrm{mg}$ de alumínio e esse cadinho foi fixado entre dois eletrodos. O alumínio evaporado se depositou sobre as lâminas formando um filme com espessura de $\approx 500 \mathrm{~nm}$, com uma taxa de evaporação de $\approx 1 \mathrm{~nm} / \mathrm{s}$, sob uma pressão de $1,5 \mathrm{mbar}$. 


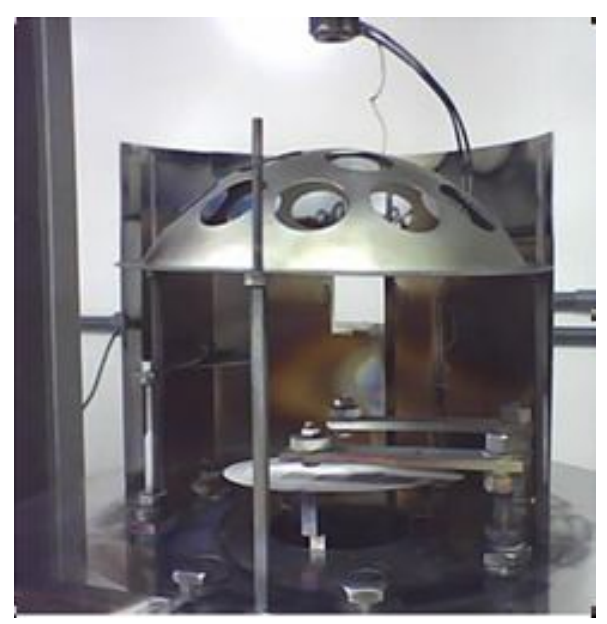

Figura 36 - Foto da evaporadora da sala limpa do Laboratório de Microeletrônica (LME).

Para formar os eletrodos de Al foi utilizada uma máscara mecânica de cobre de 0,3 $\mathrm{mm}$ de espessura sobre o copolímero, formando assim, a estrutura do dispositivo mostrado na Figura 37.
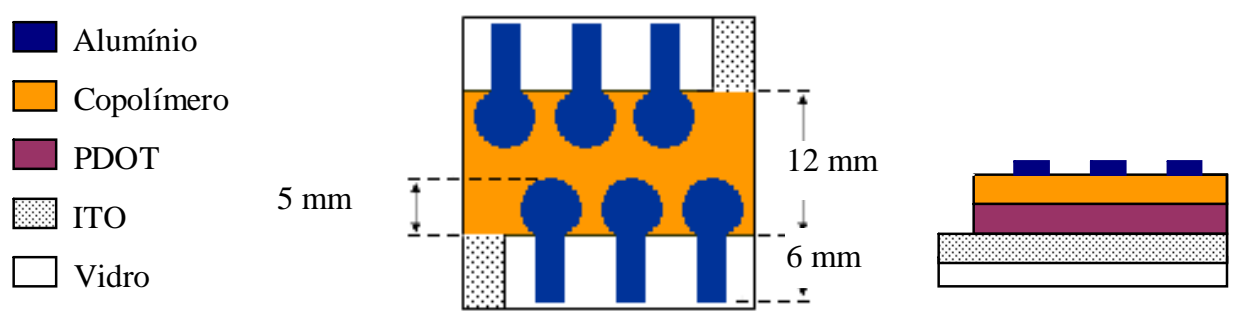

Figura 37 - Estrutura final do dispositivo após a deposição do Alumínio formando os eletrodos.

\subsubsection{Aplicação de Cola de Prata}

Para não causar nenhum dano aos eletrodos tanto cátodo de alumínio quanto ânodo de ITO, sobre estes foi depositado uma camada de cola de prata condutora protegendo ambos de ruptura do condutor pelo esforço mecânico do próprio manuseio ou pelas pontas de contato dos equipamentos durante a caracterização elétrica, melhorando também o contato elétrico. 


\subsubsection{Caracterização dos PLEDS}

\section{Microscopia ótica do filmes}

As microscopias ópticas do ITO e dos filmes poliméricos (PDOT:PSS e Copolímeros) foram realizadas assim que esses filmes acabaram de serem depositados, para verificar a uniformidade das deposições pela inspeção visual.

\section{Perfilometria}

As medidas de espessura dos filmes foram feitas pelo método de perfilometria, onde o filme foi depositado sobre o ITO e corroído deixando apenas uma região para ser feira a medida, que consiste em uma agulha que varre o substrato, e detecta a diferença de profundidade dos degraus (Figura 38).

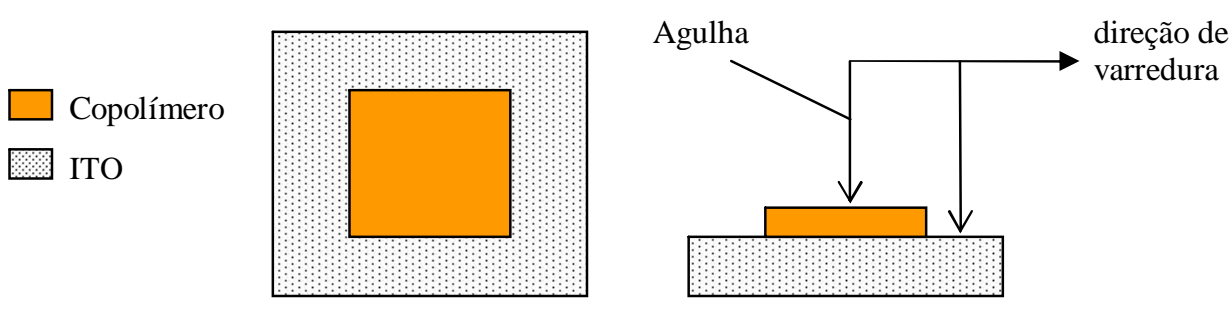

Figura 38 - Medição de espessura por perfilometria.

\section{Caracterização elétrica}

Para a caracterização elétrica, pontas de prova de uma fonte de corrente/tensão foram conectados aos eletrodos dos PLEDs. Nos dispositivos, o ITO atua como ânodo e o filme de alumínio atua como cátodo. Para esse procedimento foi utilizado o equipamento Source Meter Keithley Série 2420 conectado a um micro computador e através de um software chamado EvalDisplay desenvolvido por alunos de graduação da própria Escola Politécnica, os dispositivos foram submetidos a uma 
variação de tensão de 0 a $20 \mathrm{~V}$ com intervalos de $0,5 \mathrm{~V}$ medindo-se a corrente elétrica.

A partir desses dados foram obtidas as curvas dos dispositivos, representadas pelos gráficos de corrente (I) vs. tensão (V).

\section{Caracterização óptica}

Foi utilizado um espectroradiômetro da marca Ocean Optics, modelo HR $2000_{+}$, conectado a um cabo de fibra óptica, o qual foi posicionado sobre a área ativa do dispositivo (vidro), fazendo-se a detecção da intensidade luminosa em função do comprimento de onda da emissão do PLED. 


\section{RESULtADOS E DISCUSSÕES}

Esta seção está dividida em duas partes, a primeira relaciona as caracterizações dos copolímeros sintetizados e a segunda parte trata das caracterizações dos dispositivos PLEDS.

\subsection{Caracterização dos copolímeros}

\subsubsection{Síntese dos copolímeros}

O rendimento foi calculado tomando como rendimento teórico a soma das massas relativas dos meros constituintes do polímero obtido.

Mero 1

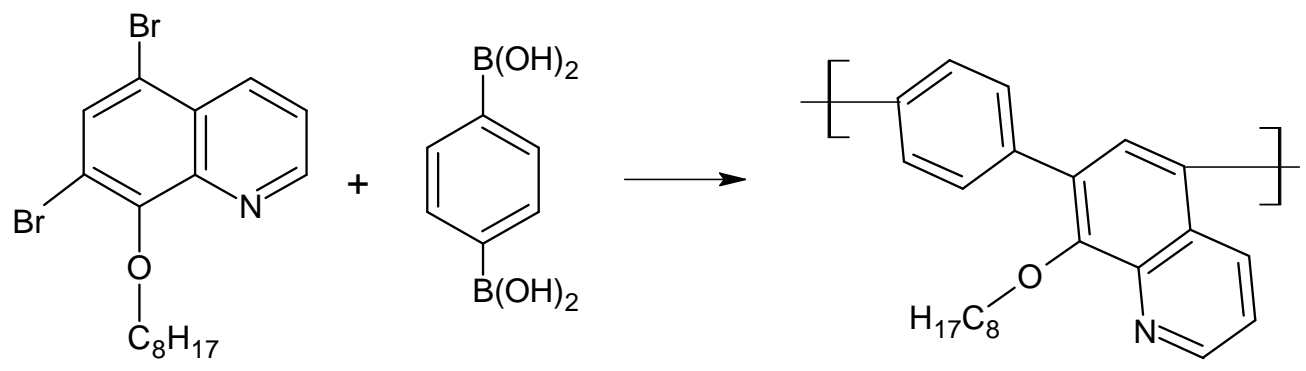

$\mathrm{MM}=331 \mathrm{~g} / \mathrm{mol}$

Mero 2<smiles>CCCCC1([13CH])c2cc(Br)ccc2-c2ccc([Se]c3ccc(O)cc3)cc21</smiles>

$\mathrm{MM}=464 \mathrm{~g} / \mathrm{mol}$ 
Mero 3

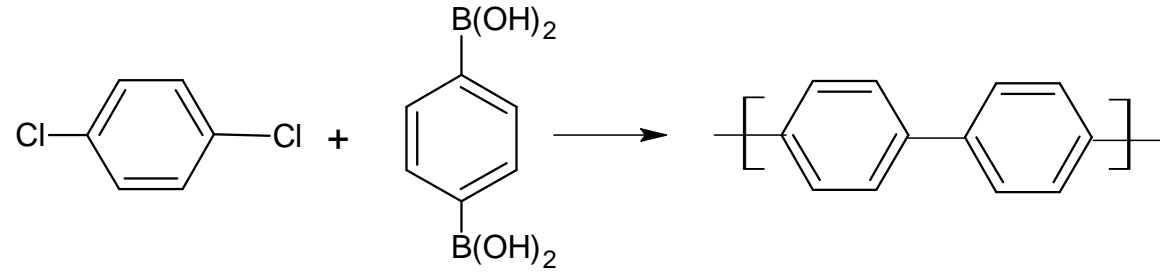

$\mathrm{MM}=152 \mathrm{~g} / \mathrm{mol}$

Como mencionado anteriormente na seção 3.3.1, as proporções dos reagentes foram:

\section{Para as Sínteses do PFN01, PFN02 e PFN10.}

$\mathrm{M}_{\mathrm{m}}=70 \%$ do mero $1+10 \%$ do mero $2+20 \%$ do mero 3

$M_{m}=0,7^{*} 331+0,1^{*} 464+0,2 * 152$

$M_{m}=231,7+46,4+30,4=308,5 \mathrm{~g} / \mathrm{mol}$

Usando-se $2 \mathrm{mmol}$ de cada tipo de reagentes $(2 \mathrm{mmol}$ de grupos halogenados e $2 \mathrm{mmol}$ de ácido fenilenobisborônico), temos então que obter em 100 $\%$ de rendimento da reação $617 \mathrm{mg}$ do polímero.

Para a síntese do PFN01 seria necessário obter 620 mg e foi obtido 364 mg, ou seja, um rendimento de aproximadamente $59 \%$.

Para a síntese do PFN02 seria necessário obter 618 mg e foi obtido 547,2 $\mathrm{mg}$, ou seja, um rendimento de aproximadamente $88,5 \%$.

Para a síntese do PFN10 seria necessário obter 617 mg e foi obtido 550,2 mg, ou seja, um rendimento de aproximadamente $89,2 \%$.

\section{Para a Síntese do PFN03.}

$\mathrm{M}_{\mathrm{m}}=50 \%$ do mero $1+10 \%$ do mero $2+40 \%$ do mero 3

$\mathrm{M}_{\mathrm{m}}=0,5^{\star} 331+0,1^{*} 464+0,4^{*} 152$

$M_{m}=165,5+46,4+60,8=272,7 \mathrm{~g} / \mathrm{mol}$ 
Para a síntese do PFN03 seria necessário obter em 100\% de rendimento $545,4 \mathrm{mg}$ e foi obtido $125,4 \mathrm{mg}$, um rendimento de aproximadamente $22,9 \%$.

Cálculo das massas molares dos copolímeros pela equação de Carothers.

$\mathrm{x}_{\mathrm{n}}=\frac{1+\mathrm{r}}{(1+\mathrm{r})-(2 * \mathrm{r} * \mathrm{P})}$, onde $\mathrm{r}$ é a relação entre o número de mols dos diferentes grupos de reagente e $\mathrm{P}$ é o fator de conversão.

$\mathrm{M}_{\mathrm{m}}{ }^{*} \mathrm{x}_{\mathrm{n}}=$ massa molar do polímero.

\section{PFN01:}

$r=\frac{2,010}{2,017}=0,996$

$\mathrm{P}=0,6 \rightarrow \quad \mathrm{x}_{\mathrm{n}}=2,49$

$308,6^{\star} 2,49=768,41 \mathrm{~g} / \mathrm{mol}$

PFN02:

$r=\frac{1,994}{2,013}=0,990$

$\mathrm{P}=0,885 \rightarrow \mathrm{x}_{\mathrm{n}}=8,40$

$308,6^{\star} 8,4=2592,24 \mathrm{~g} / \mathrm{mol}$

PFN03:

$r=\frac{1,975}{2,015}=0,981$

$\mathrm{P}=0,230 \rightarrow \mathrm{x}_{\mathrm{n}}=1,85$

$272,7^{*} 1,85=504,49 \mathrm{~g} / \mathrm{mol}$

PFN10:

$r=\frac{1,993}{2,001}=0,996$

$\mathrm{P}=0,892 \rightarrow \mathrm{x}_{\mathrm{n}}=9,11$

$308,6^{*} 9,11=2811,35 \mathrm{~g} / \mathrm{mol}$ 
A Tabela 3 apresenta uma comparação entre as sínteses realizadas bem como os rendimentos e suas massas molares obtidas.

Tabela 3. Comparação entre as diferentes rotas sintéticas, os rendimentos obtidos e as massas molares calculadas

\begin{tabular}{ccccc} 
Copolímero & Solvente & $\begin{array}{c}\text { Cloreto de } \\
\text { benzalcônio }\end{array}$ & Rendimento & $\begin{array}{c}\text { Massa molar } \\
\text { (equação de Carothers) }\end{array}$ \\
\hline PFN01 & Tuloeno & Não & 59,0 & $768,41 \mathrm{~g} / \mathrm{mol}$ \\
\hline PFN02 & Xileno & Sim & 88,5 & $2592,24 \mathrm{~g} / \mathrm{mol}$ \\
\hline PFN03 & Xileno & Sim & 22,9 & $504,49 \mathrm{~g} / \mathrm{mol}$ \\
\hline PFN10 & Xileno & Sim & 89,2 & $2811,35 \mathrm{~g} / \mathrm{mol}$ \\
\hline
\end{tabular}

Comparando os valores calculados utilizando a equação de Carothers, é possível afirmar que a síntese dos copolímeros PFN02 e PFN10 que obtiveram um rendimento maior produziram copolímeros com massas molares superiores do que a das sínteses do PFN01 e PFN03, podendo também ser comprovado pelo aspecto dos copolímeros obtidos, sendo o PFN10 único sólido de todos.

Essa diferença de rendimento pode ser creditada a adição do cloreto de benzalcônio, já que ele teve como finalidade promover uma maior probabilidade de choque dos monômeros na interface entre a fase aquosa e a fase orgânica, aumentando assim a reação de polimerização e também a um melhor controle do sistema de refluxo não permitindo a perda do solvente durante a reação. Da mesma forma, o tempo de reação maior para as sínteses do PFN02 e PFN10 em relação à síntese do PFN01 também favoreceu o aumento do rendimento.

Já para a síntese do PFN03, que teve a mesma rota sintética dos copolímeros de maiores rendimentos (PFN02 e PFN10) e apenas a proporção dos reagentes foi alterada, apresentou um rendimento de 22,9 \%, bem abaixo do esperado sendo, portanto, uma rota sintética descartada nas análises seguintes, já que o intuito deste trabalho era obter um copolímero com massa suficiente para as caracterizações e as montagens dos PLEDs. 


\subsubsection{Cromatografia de permeação em gel}

Os resultados das análises por cromatografia de permeação em gel estão apresentados na Tabela 4.

Tabela 4 - Massas molares dos polímeros determinadas por GPC utilizando-se THF como solvente e poliestireno como padrão.

\begin{tabular}{|c|c|c|c|c|}
\hline Copolímero & $\mathbf{M}_{\mathbf{n}}$ & $\mathbf{M}_{\mathbf{w}}$ & $\mathbf{M}_{\mathbf{z}}$ & $\mathbf{M}_{\mathbf{w}} / \mathbf{M}_{\mathbf{n}}$ \\
\hline PFN02 & 489 & 662 & 880 & 1,35 \\
\hline PFN10 & 1470 & 2778 & 4372 & 1,89 \\
\hline
\end{tabular}

Os resultados mostram que realmente o copolímero PFN10 possui uma massa molar maior do que o copolímero PFN02, o que já era de se esperar visto os seus aspectos físicos, sendo o PFN10 sólido e o PFN02 pastoso. 


\subsubsection{Espectroscopia de ressonância magnética nuclear de hidrogênio}

A estrutura do copolímero utilizada para as análises de $\mathrm{RMN}{ }^{1} \mathrm{H}$ está representada na Figura 39.

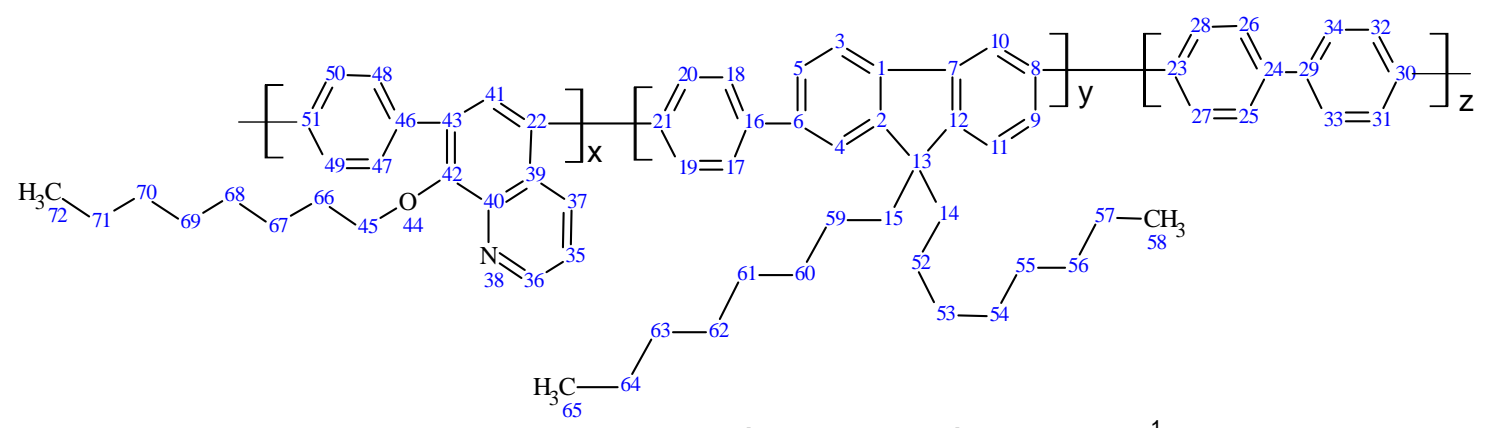

Figura 39 - Estrutura do copolímero para análise de RMN ${ }^{1} \mathrm{H}$.

O espectro de RMN ${ }^{1} \mathrm{H}$ do copolímero PFN10 (Figura 40) foi separado em duas regiões para melhor atribuição dos picos.

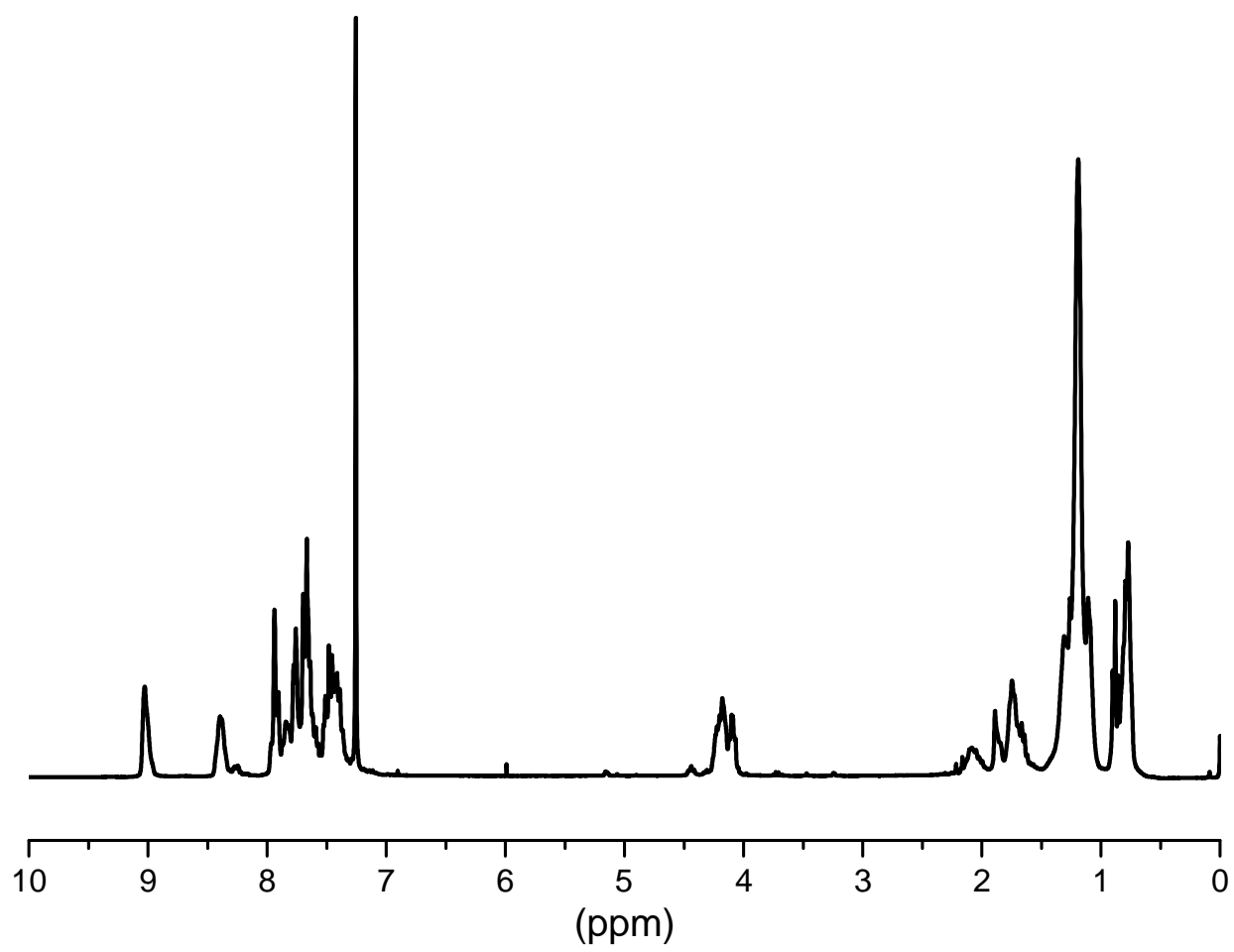

Figura 40 - Espectro de $\mathrm{RMN}^{1} \mathrm{H}(200 \mathrm{MHz})$ do PFN10. 
A região 1 (Figura 41) apresenta os prótons referentes aos hidrogênios alifáticos, sendo a região de prótons mais blindados. A região de deslocamento químico entre 0,90 - 0,77 ppm é referente ao final das cadeias laterais $\mathrm{CH}_{3}$ (prótons 58, 65 e 72), a região entre 1,72 - 1,09 ppm se refere aos grupos $\mathrm{CH}_{2}$ (prótons 52 a $57 ; 59$ a 64; 66 a 71) a região entre 2,09 - 1,82 ppm aos prótons 14 e 15 e a região entre 4,12 - 4,01 ppm representa o próton de $\mathrm{CH}_{2}$ próximo ao oxigênio da quinolina (próton 45).

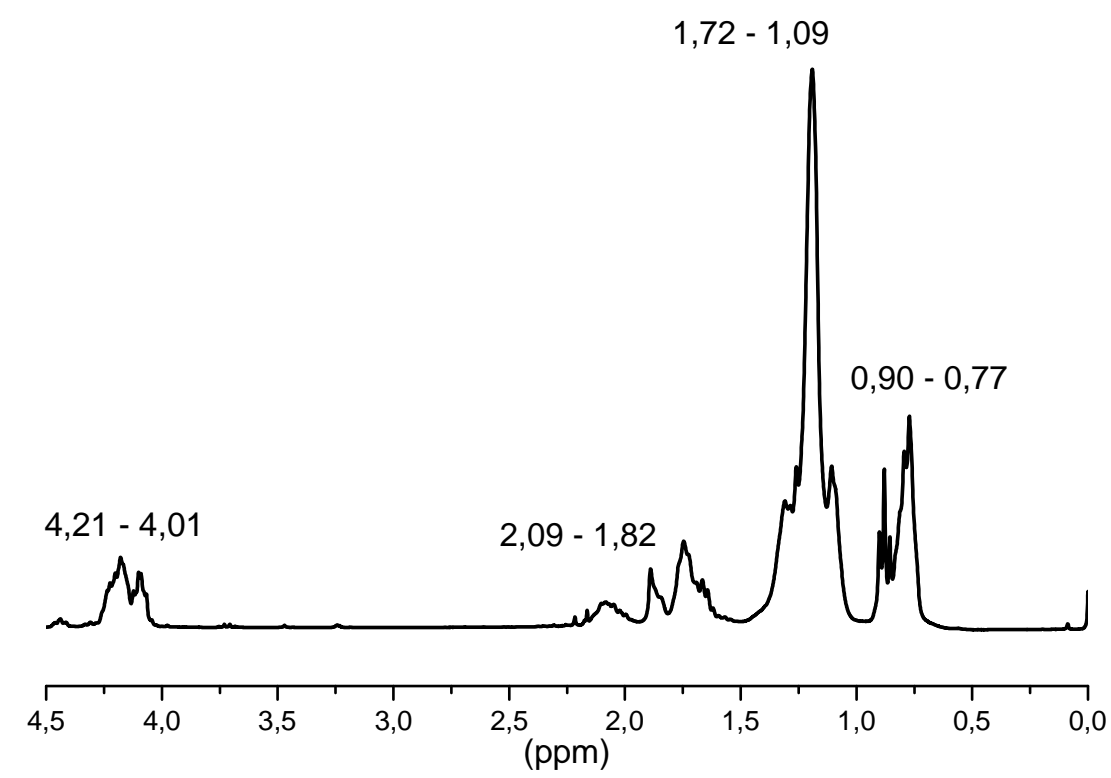

Figura 41 - Espectro de $\mathrm{RMN}^{1} \mathrm{H}$ (Região 1).

A Região 2 (Figura 42) apresenta os deslocamentos químicos referentes aos hidrogênios aromáticos, sendo os prótons menos blindados. A região entre os deslocamentos químicos 8,39 - 7,25 ppm representam os prótons ligados aos anéis benzênicos, e o pico a 9,02 ppm, representa o próton do anel benzênico próximo ao nitrogênio da quinolina (próton 36), o qual devido à proximidade do nitrogênio é o próton mais desblindado de todos. 


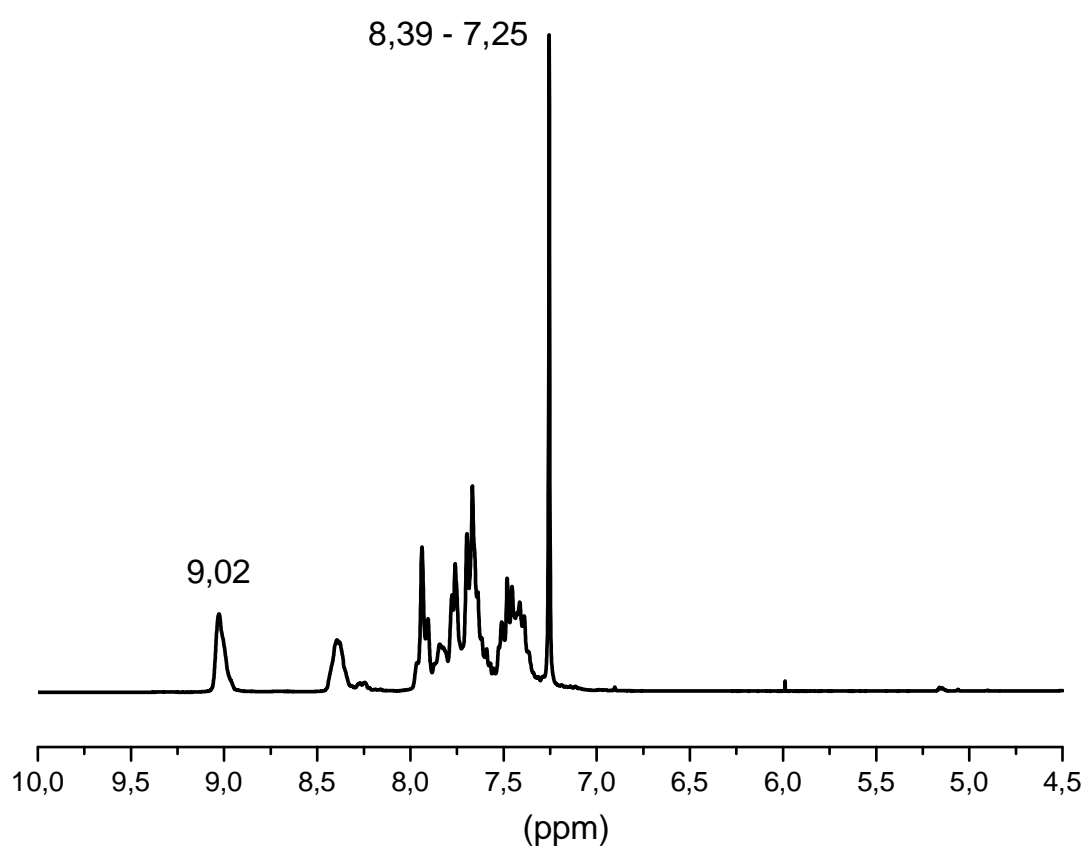

Figura 42 - Espectro de RMN ${ }^{1} \mathrm{H}$ (Região 2).

Com o objetivo de confirmar as atribuições descritas, foi realizado, utilizando programa ACDLABS 10.0, um espectro de $\mathrm{RMN}^{1} \mathrm{H}$ da estrutura química mostrada na Figura 39.

A Figura 43 mostra o espectro simulado no programa ACDLabs/ChemSktch. A identificação dos picos foi feita e comparada com o espectro gerado pelo programa, através desses espectros os prótons foram localizados em regiões e organizados na Tabela 5. 


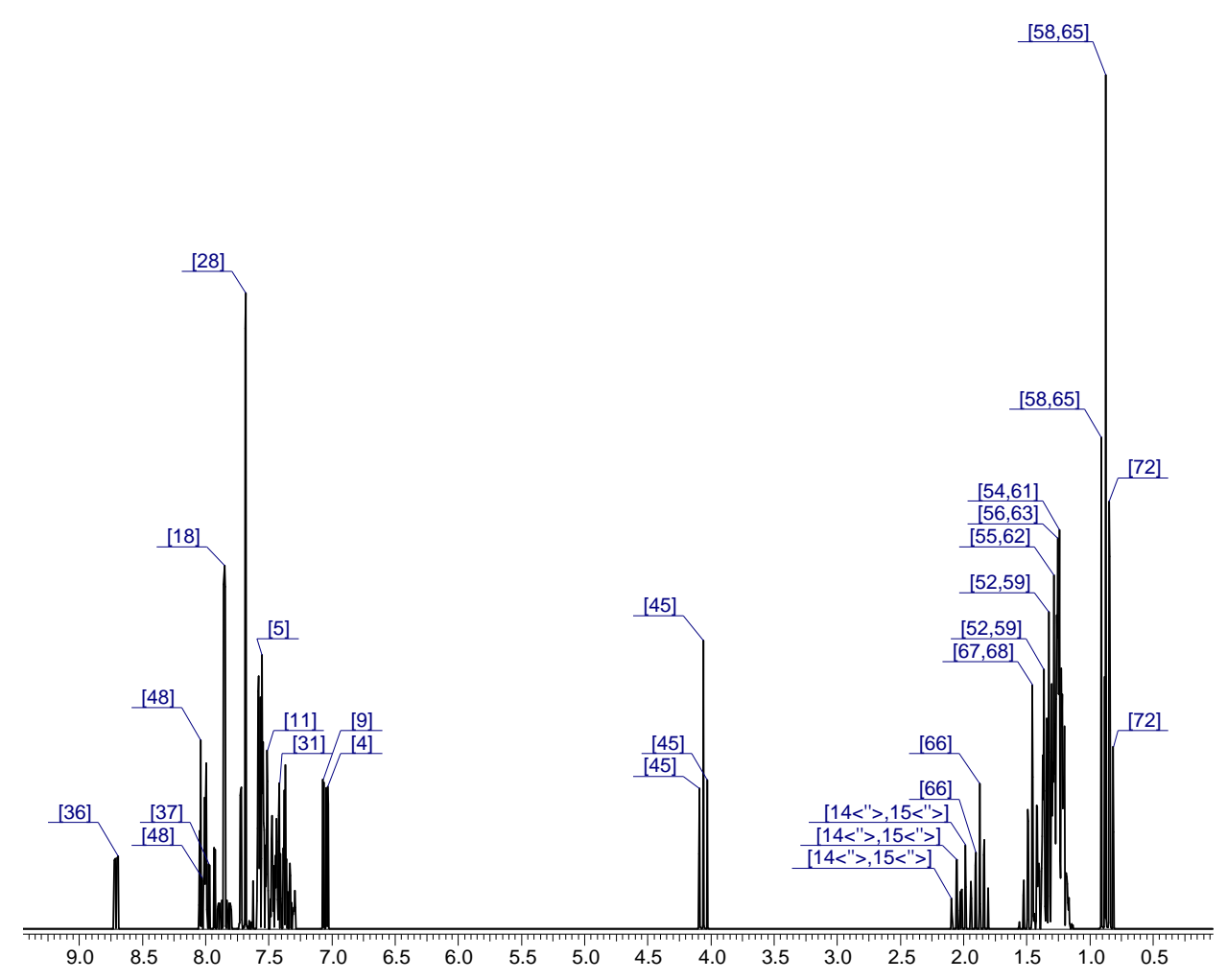

Figura 43 - Espectro de RMN ${ }^{1} \mathrm{H}$ simulado

Tabela 5 - Identificação dos deslocamentos químicos do copolímero.

\begin{tabular}{|c|c|c|c|}
\hline Região & Prótons & $\begin{array}{c}\text { Deslocamentos } \\
\text { químicos } \\
\text { simulados }\end{array}$ & $\begin{array}{c}\text { Deslocamentos } \\
\text { químicos } \\
\text { observados }\end{array}$ \\
\hline \multirow{6}{*}{1} & $58,72,65$ & $0,82-0,91$ & $0,77-0,90$ \\
\hline & $52-57$ & \multirow{3}{*}{$1,15-1,56$} & \multirow{3}{*}{$1,09-1,72$} \\
\hline & $59-64$ & & \\
\hline & $66-71$ & & \\
\hline & 14,15 & $1,80-2,09$ & $1,82-2,09$ \\
\hline & 45 & $4,03-4,09$ & $4,01-4,12$ \\
\hline \multirow{2}{*}{2} & Anéis Benzênicos & $7,03-8,05$ & $7,25-8,39$ \\
\hline & 36 & 8,72 & 9,02 \\
\hline
\end{tabular}


A Figura 44 mostra o espectro de $\mathrm{RMN}{ }^{1} \mathrm{H}$ do material de partida 5,7-dibromo8-oxioctil-quinolina (quinolina), através dela e da Tabela 6 podemos identificar e confirmar alguns picos característicos da quinolina. Alguns desses picos estão presentes no copolímero, como é o caso do pico 4,3 ppm e do pico em aproximadamente 9,0 ppm.

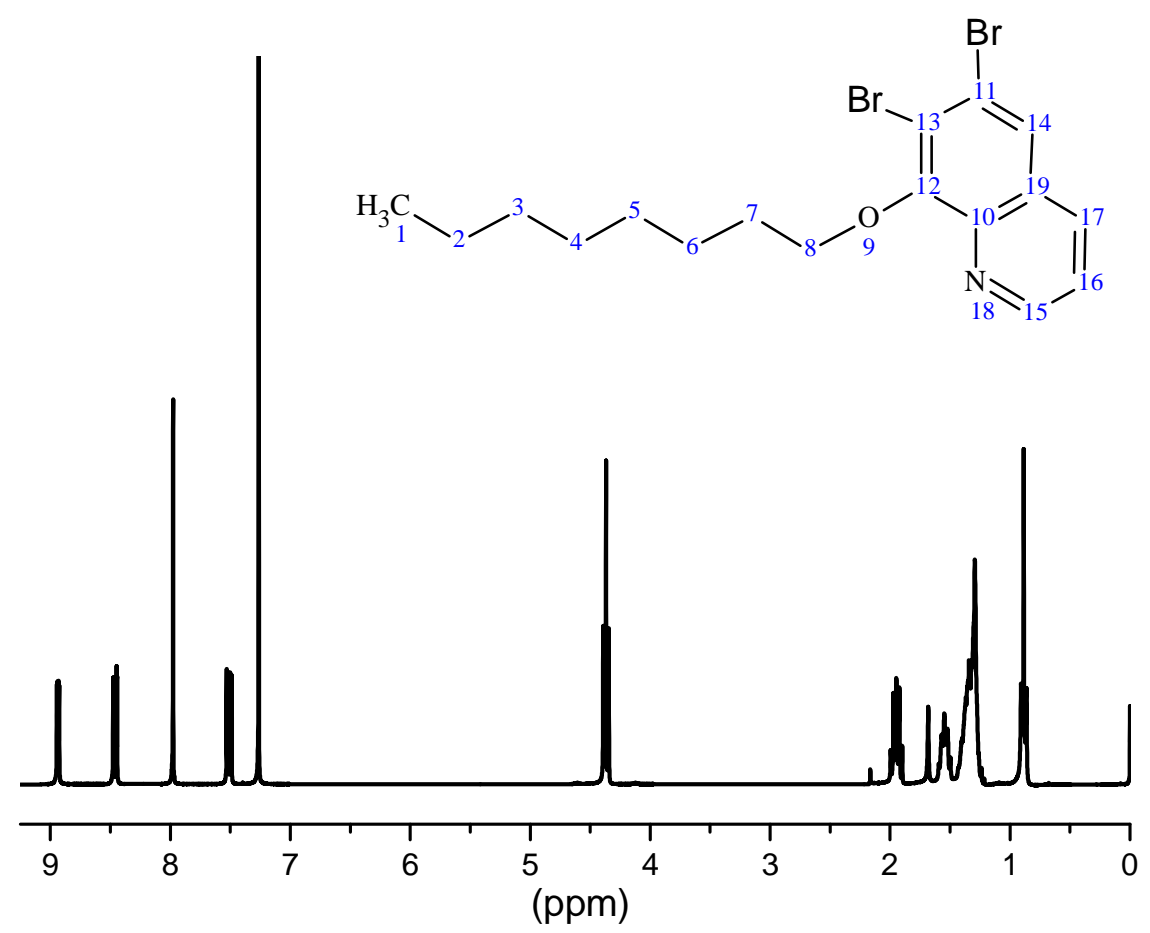

Figura 44 - Espectro de $\mathrm{RMN}^{1} \mathrm{H}(200 \mathrm{MHz})$ do material de partida 5,7-dibromo-8-oxioctil-quinolina.

Tabela 6 - Identificação dos deslocamentos químicos do 5,7-dibromo-8-oxioctilquinolina.

\begin{tabular}{|c|c|}
\hline $\begin{array}{c}\text { Deslocamento } \\
\text { químico }\end{array}$ & Prótons \\
\hline 0,88 & 1 \\
\hline $1,94-1,29$ & 2 ao 7 \\
\hline 4,36 & 8 \\
\hline $8,01-7,26$ & 16 e 17 \\
\hline 8,44 & 14 \\
\hline 8,98 & 15 \\
\hline
\end{tabular}




\subsubsection{Espectroscopia no infravermelho}

A Figura 45 mostra os espectros de infravermelho dos copolímeros PFN01, PFN02 e PFN10. Eles possuem bandas de vibrações nas mesmas regiões, porém para os copolímeros PFN02 e PFN10 o espectro é um pouco mais resolvido, os picos são mais nítidos e possuem uma intensidade maior que as do PFN01, podendo assim facilitar as suas identificações.

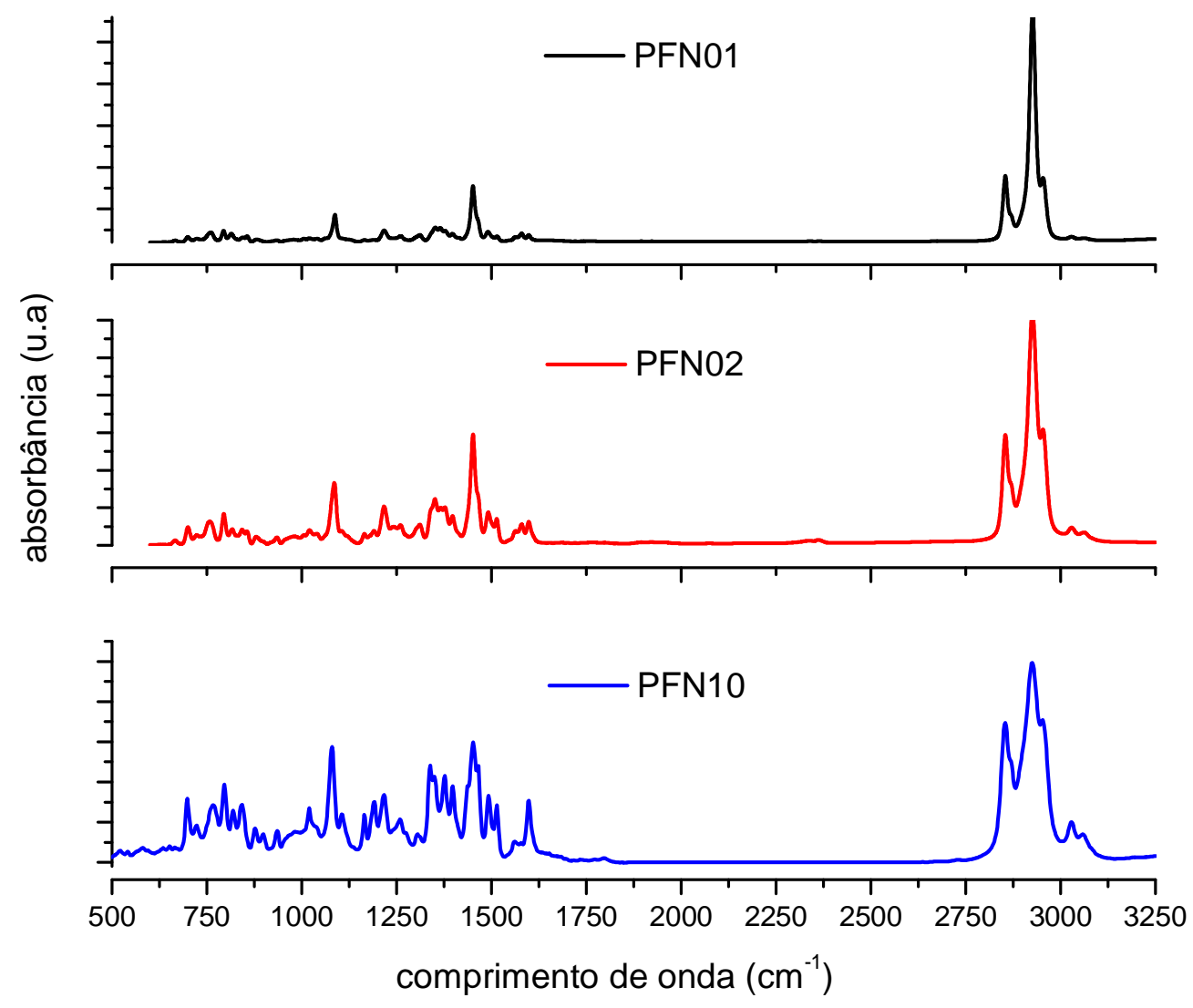

Figura 45 - Espectro de infravermelho dos copolímeros.

Para facilitar as análises o espectro do copolímero PFN10 foi separado em duas regiões. Na região 1 entre 2500 e $3200 \mathrm{~cm}^{-1}$ (Figura 46) é possível ver a banda de intensidade alta em $2926 \mathrm{~cm}^{-1}$ que é atribuída à ligação $\mathrm{C}-\mathrm{H}$ dos grupos $\mathrm{CH}_{2} \mathrm{e}$ $\mathrm{CH}_{3}$ e a banda em $2854 \mathrm{~cm}^{-1}$ que pode ser atribuída a ligação $\mathrm{C}-\mathrm{H}$ nos anéis aromáticos. 


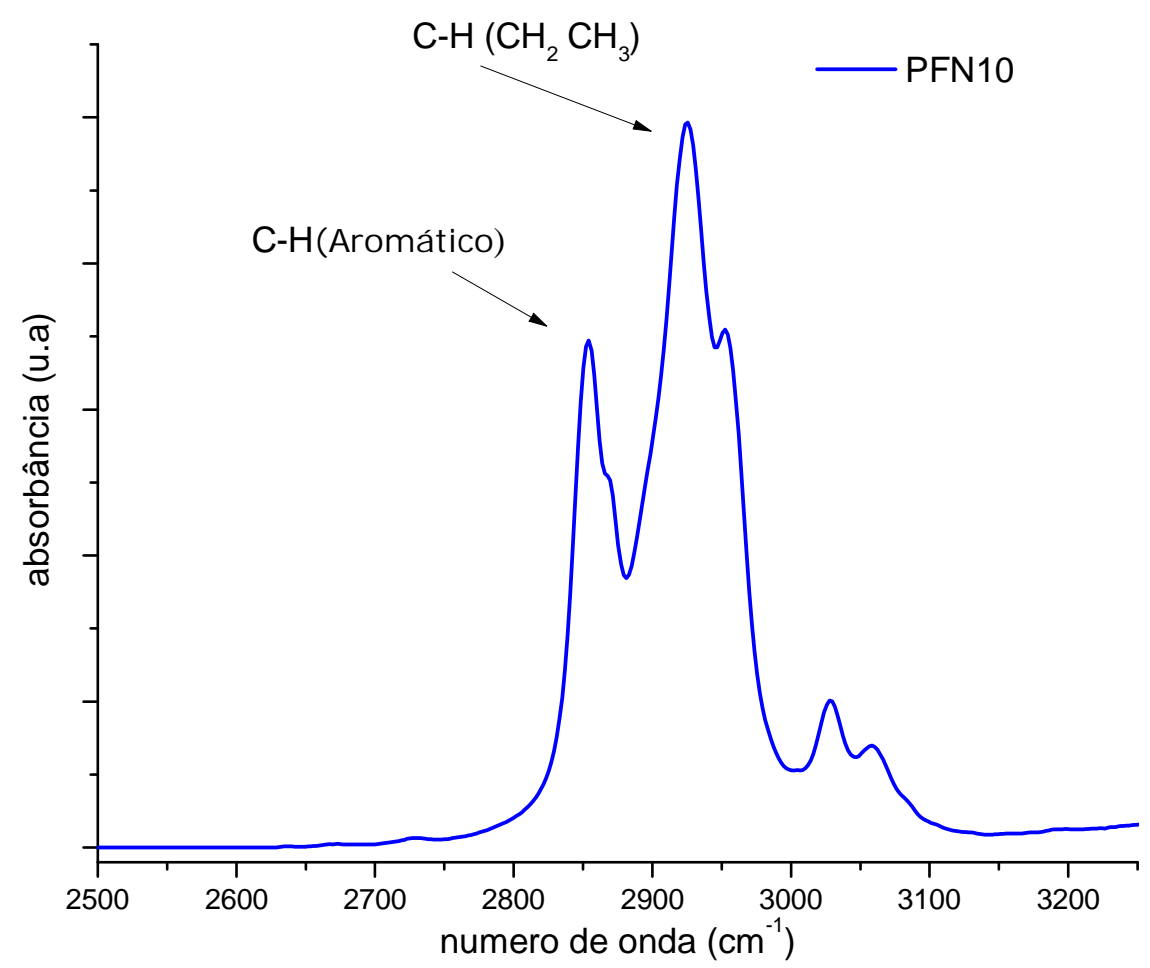

Figura 46 - Espectro de infravermelho do copolímero PFN10 (Região 1).

A Figura 47 e a Figura 48 mostram os espectros de infravermelho da Região 2 entre 600 e $2000 \mathrm{~cm}^{-1}$, bem como a identificação de alguns picos. Nesta região não foi possível observar bandas que pudessem caracterizar os materiais de partida, aqueles com grupos halogenados ou borônicos, cujas absorções correspondentes a ligação B-O deveriam aparecer entre 1330 e $1350 \mathrm{~cm}^{-1}$, , o que é positivo, pois demonstra que o processo de síntese eliminou esses grupos das terminações de cadeias. 


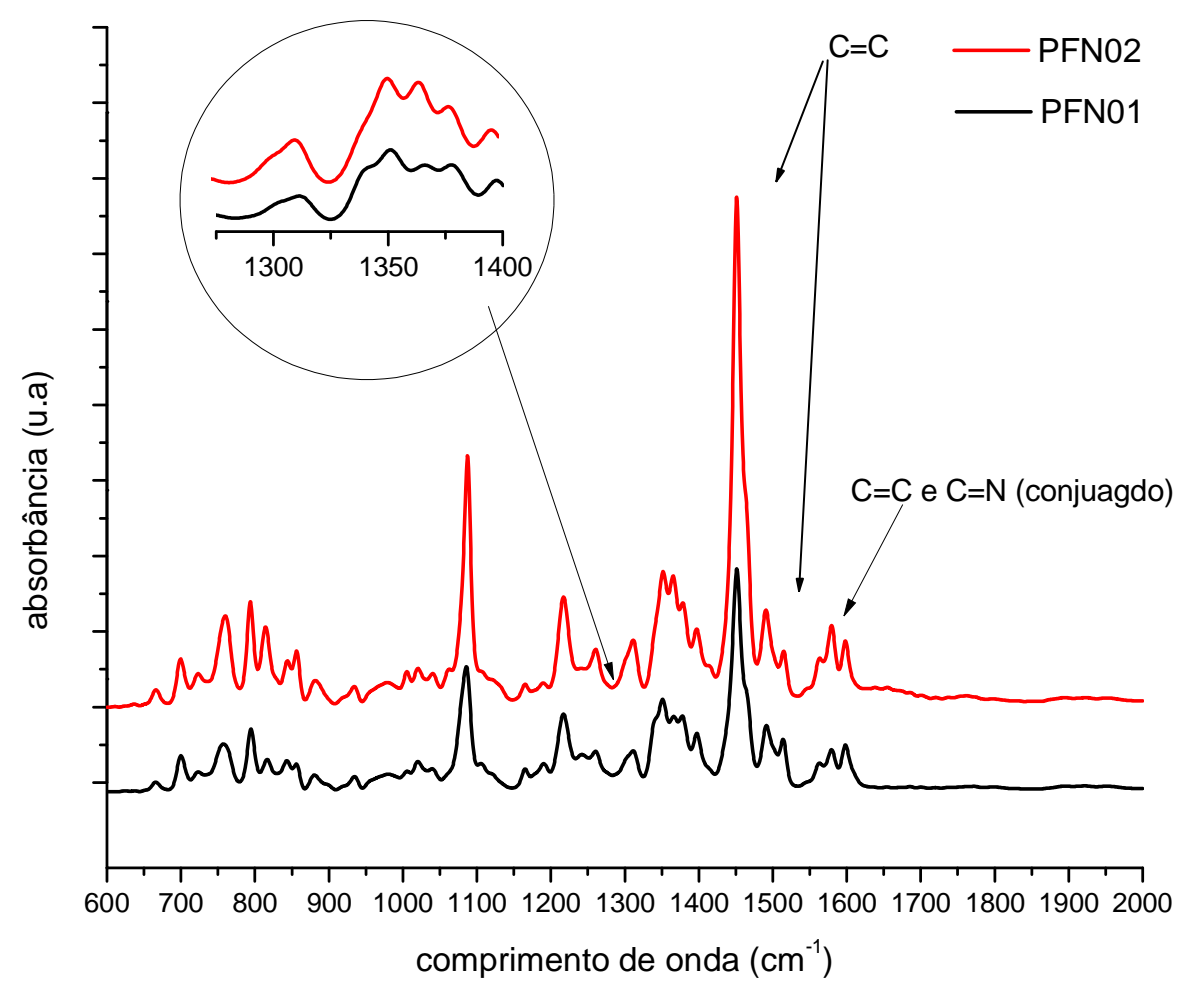

Figura 47 - Espectro de infravermelho dos copolímeros PFN01 e PFN02 (Região 2).

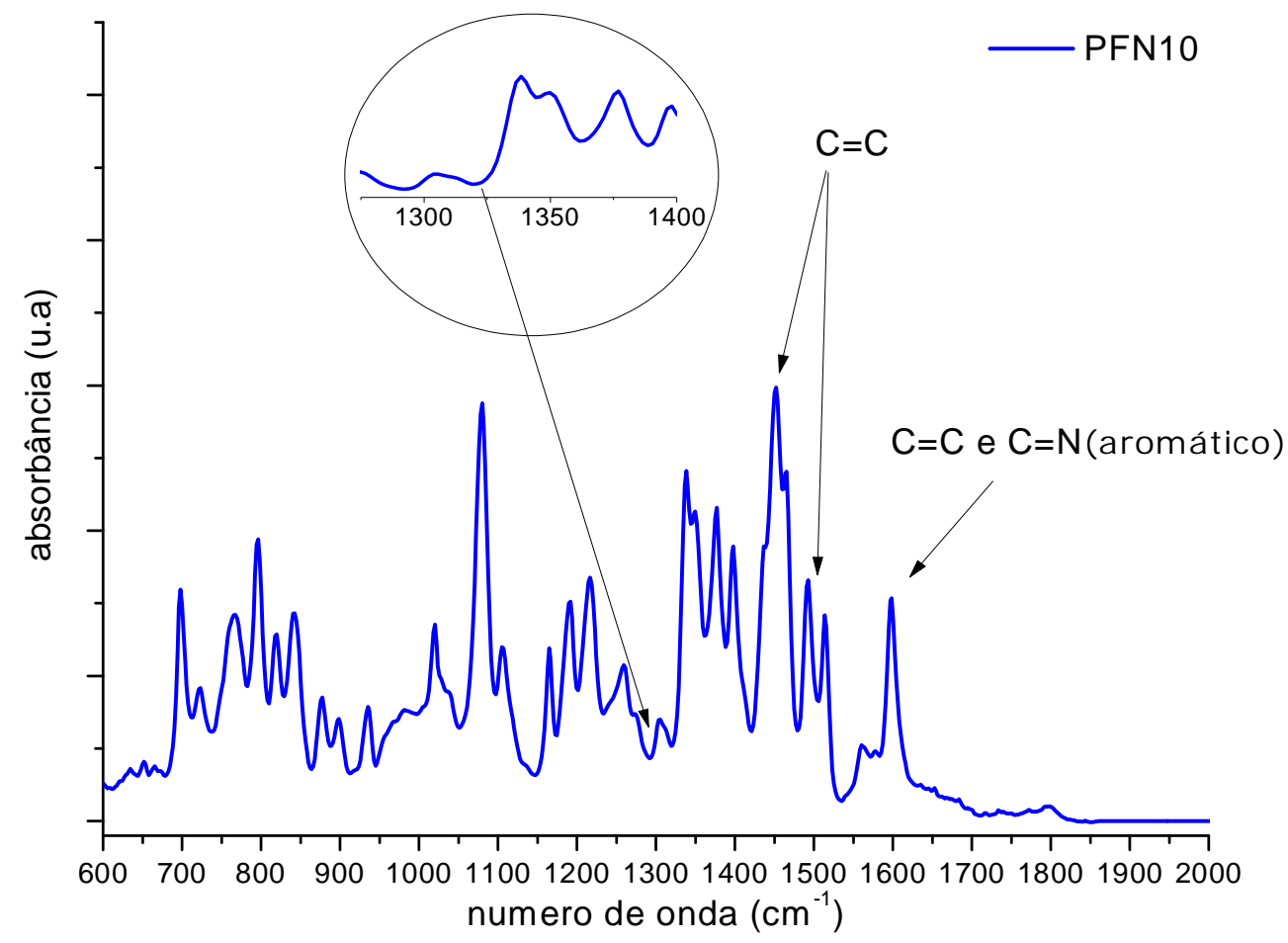

Figura 48 - Espectro de infravermelho do copolímero PFN10 (Região 2). 


\subsubsection{Análises de EDX}

Análises de EDX foram realizadas a fim de se observar alguns elementos químicos presentes na estrutura dos copolímeros. A Figura 49 e a Figura 50 apresentam as imagens de EDX dos copolímeros PFN02 e PFN10, respectivamente. Através desses espectros foi possível comprovar a ausência ou a baixíssima presença de cloro, bromo e boro, sinalizando mais uma vez que o processo de eliminação de grupos borônicos e halogenados das terminações das cadeias foi realizado com sucesso.

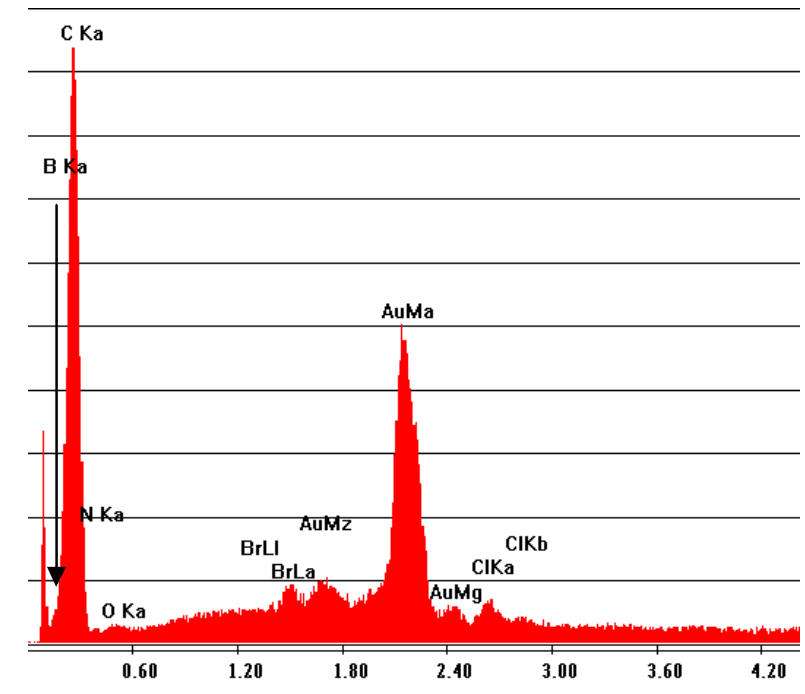

Figura 49 - Imagem de EDX do copolímero PFN02.

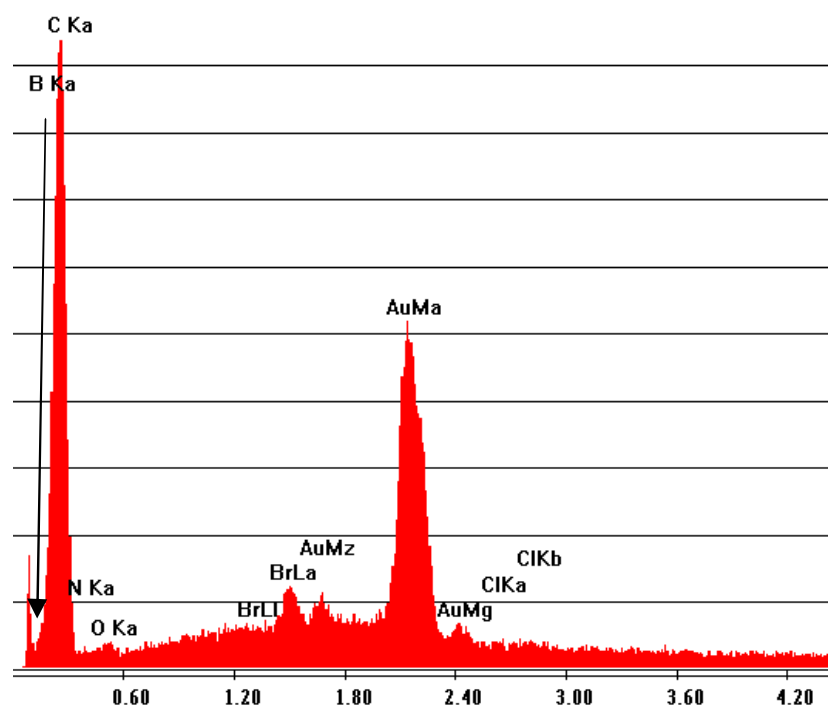

Figura 50 - Imagem de EDX do copolímero PFN10. 
A Tabela 7 apresenta a quantificação em porcentagem dos elementos químicos presentes na estrutura dos copolímeros.

Tabela 7 - Quantificação dos elementos químicos na estrutura dos copolímeros.

\begin{tabular}{|c|c|c|c|c|c|c|}
\hline Copolímero & $\mathbf{C}(\%)$ & $\mathbf{N}(\%)$ & $\mathbf{O}(\%)$ & $\mathbf{B r}(\%)$ & $\mathbf{C l}(\%)$ & $\mathbf{B}(\%)$ \\
\hline PFN02 & 90,29 & 3,11 & 1,92 & 3,35 & 1,33 & 0,00 \\
\hline PFN10 & 86,21 & 5,90 & 4,11 & 3,78 & 0,00 & 0,00 \\
\hline
\end{tabular}

Por esses dados apresentados, é possível também confirmar mais uma vez a ausência de compostos borônados pela baixa porcentagem de moléculas de oxigênio, já que esses compostos só existem na estrutura na forma de $\mathrm{B}(\mathrm{OH})_{2}$.

\subsubsection{Análise Termogravimétrica (TGA)}

A Figura 51 mostra a análise termogravimétrica dos copolímeros sintetizados, sendo que a faixa de temperatura na análise foi de $25^{\circ} \mathrm{C}$ a $800{ }^{\circ} \mathrm{C}$, temperatura suficiente para degradar os copolímeros.

A partir de $260^{\circ} \mathrm{C}$ os copolímeros PFN01 e PFN02 começaram a se degradar, sendo que o PFN02 apresentou dois patamares, quando a partir de $260^{\circ} \mathrm{C}$ uma parte do material começa a se decompor e termina em $386^{\circ} \mathrm{C}$, começando assim a outra parte a se degradar e ao atingir $485^{\circ} \mathrm{C}$ o copolímero se degrada por completo, ficando esse valor $60^{\circ} \mathrm{C}$ mais elevada que a da degradação total do PFN01 que foi de $425^{\circ} \mathrm{C}$.

Uma possível explicação para o copolímero PFN01 não ter apresentado os mesmos patamares de degradação do PFN02, está relacionada às sínteses envolvidas, pois para o copolímero PFN01 não houve a adição do cloreto benzalcônio e teve um tempo menor de reação, o que acabou culminando também num baixo rendimento, como já foi comentado anteriormente. Além disso, os valores de massa molar mostram também que este material apresenta, de forma geral, cadeias menores quando comparado ao PFN02 e ao PFN10. 
O copolímero PFN10 apresentou patamar de degradação inicial por volta de $330^{\circ} \mathrm{C}$, cerca de $70^{\circ} \mathrm{C}$ a mais que o inicio da degradação dos copolímeros PFN01 e PFN02, e tendo a sua temperatura final de degradação por volta de $565^{\circ} \mathrm{C}, 140{ }^{\circ} \mathrm{C}$ mais elevada que a temperatura de degradação final do PFN01 e $80{ }^{\circ} \mathrm{C}$ que a do PFN02, demonstrando uma melhora nas propriedades térmicas dos materiais e comprovando mais uma vez o aumento das massas molares desses copolímeros.

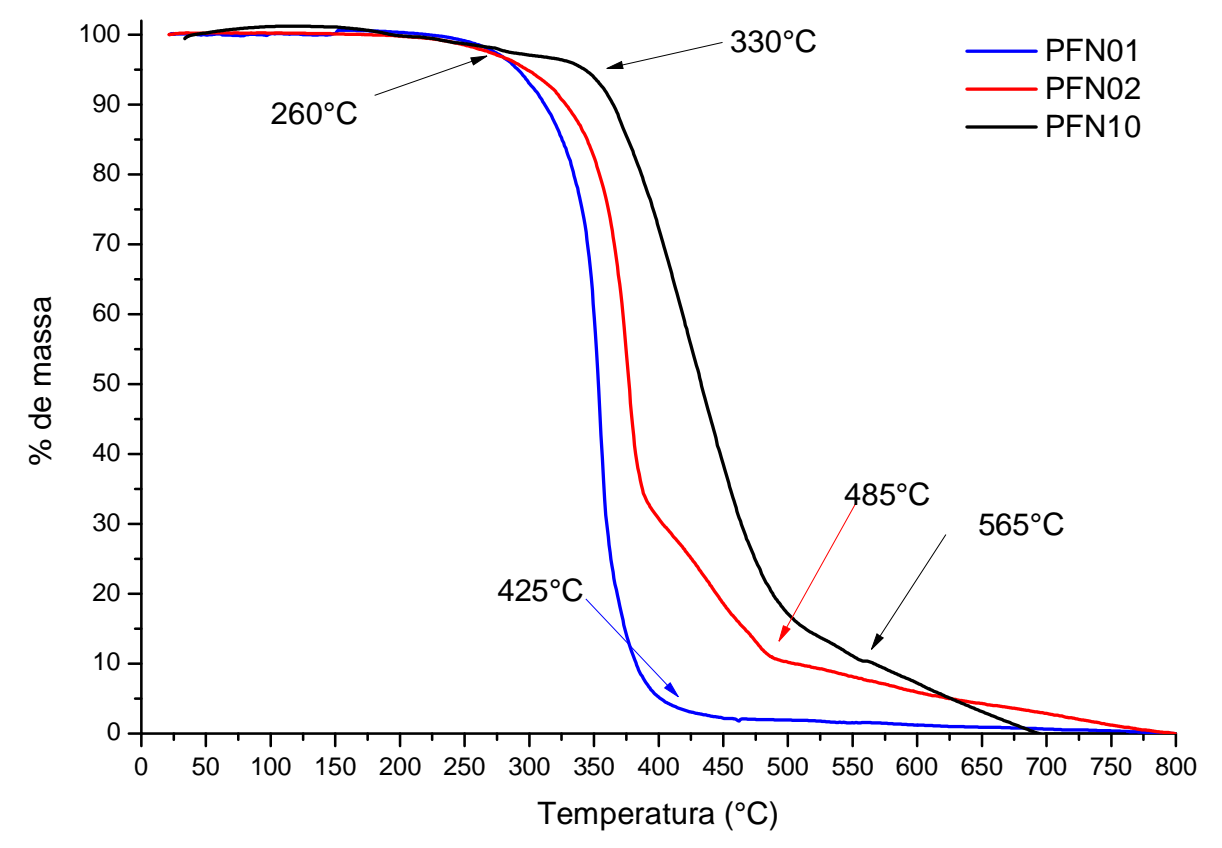

Figura 51 - TGA dos copolímeros PFN01, PFN02 e PFN10.

Derivando-se as curvas do gráfico apresentado na Figura 51 é possível obter e analisar as taxas de degradação máxima de cada copolímero. Esses novos gráficos de derivada de TGA são mostrados na Figura 52.

Como é possível observar, o copolímero PFN10 apresentou uma temperatura de degradação máxima por volta de $425^{\circ} \mathrm{C}$, cerca de $72{ }^{\circ} \mathrm{C}$ mais elevada que a do PFN01 e $50^{\circ} \mathrm{C}$ se comprado ao PFN02. 


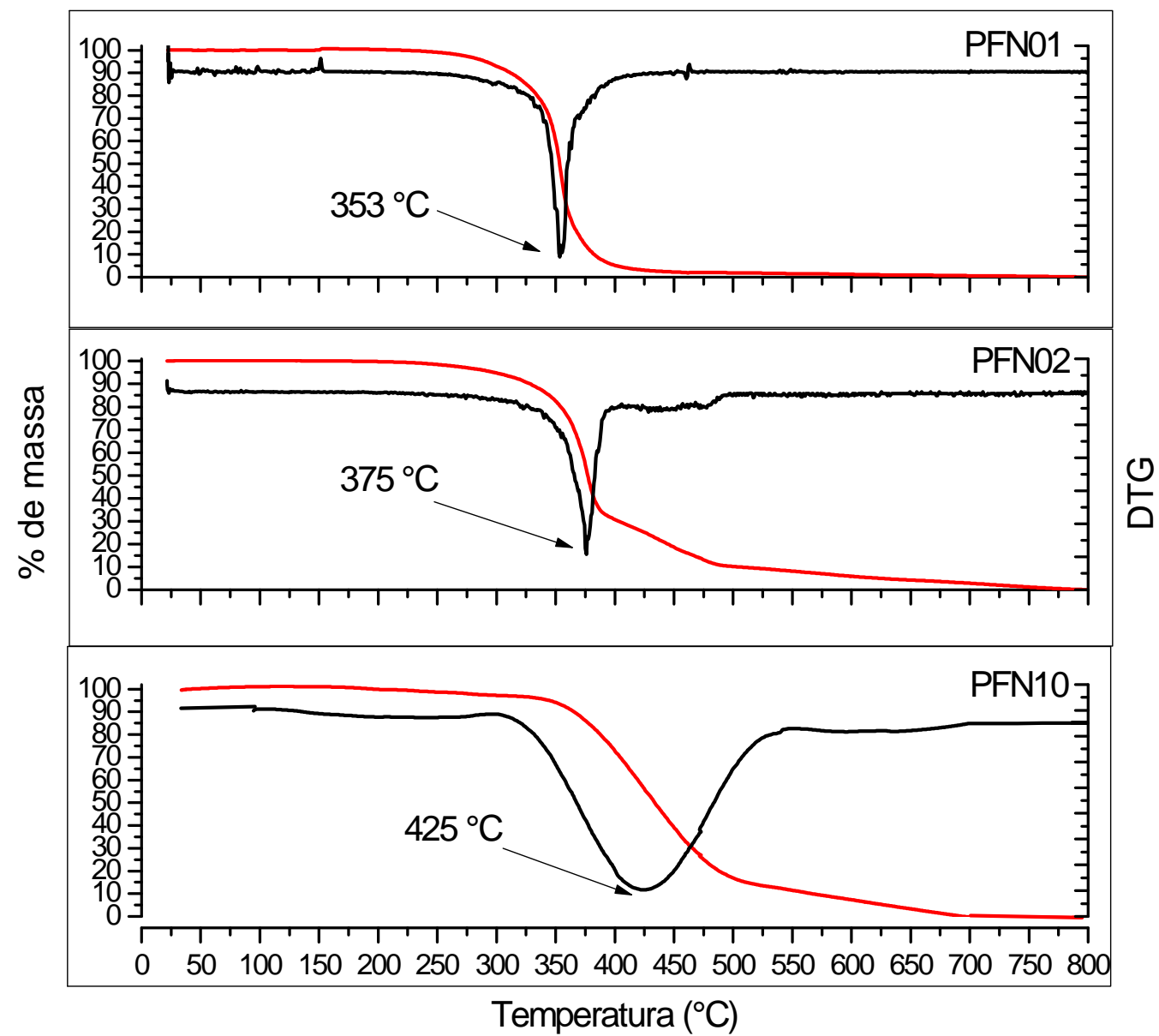

Figura 52 - Derivada dos gráficos de TGA dos copolímeros PFN01, PFN02 e PFN10 respectivamente.

\subsubsection{Análise de Calorimetria diferencial exploratória (DSC)}

A Figura 53 mostra o gráfico de DSC dos copolímeros PFN02 e PFN10, onde é possível observar através da inflexão das suas curvas as temperaturas de transição vítrea $\left(T_{g}\right)$.

$A T_{g}$ do PFN10 fica por volta de $28^{\circ} \mathrm{C}$, cerca de $50^{\circ} \mathrm{C}$ mais elevada que a $T_{g}$ do PFN01 que é de $-21^{\circ} \mathrm{C}$. Essa diferença nas temperaturas de transições vítreas também pode ser explicada pelo aumento da massa molar do PFN10 e pelo aspecto físico dos materiais, visto que a temperatura a ambiente o PFN02 já havia ultrapassado a sua $T_{g}$ ficando com aspecto pastoso e o PFN10 sólido já que sua $T_{g}$ é mais elevada, sendo ela acima da temperatura ambiente. 


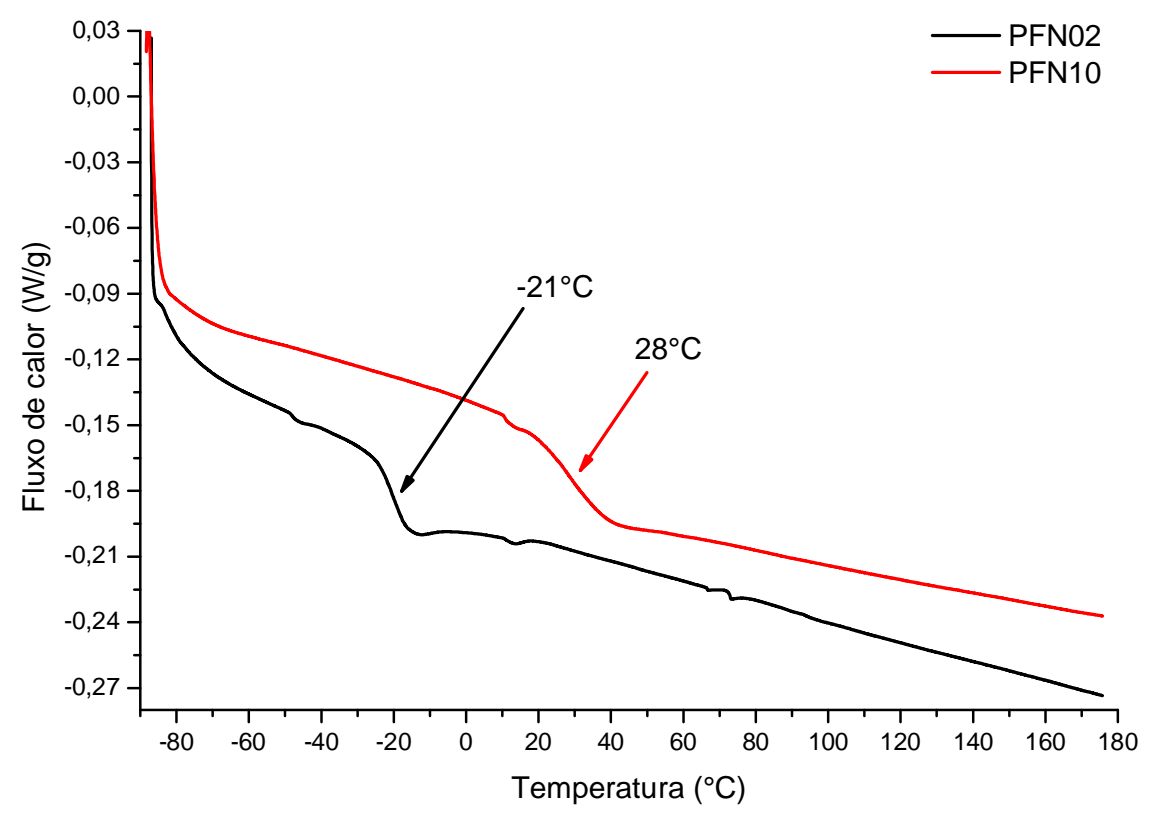

Figura 53 - medidas de DSC dos copolímeros PFN01 e PFN10.

\subsubsection{Espectroscopia de absorção no UV-Vis}

A Figura 54 mostra o espectro de absorbância no Uv-Vis dos copolímeros PFN01, PFN02 e PFN10.

É possível notar que para uma mesma concentração molar dos copolímeros $\left(5,0 \times 10^{-5}\right)$, o copolímero PFN02 possui uma maior intensidade de absorbância em relação ao PFN01, porém os comprimentos de onda nos pontos de picos máximos são os mesmos para ambos os copolímeros encontrando-se em 245 nm e 314 nm. Já para o PFN10, é possível notar um deslocamento nos picos de máxima absorção, sendo eles em $263 \mathrm{~nm}$ e $330 \mathrm{~nm}$, deslocamento esse relacionado a um aumento na massa molar, visto pelo seu aspecto sólido em relação aos outros copolímeros sintetizados. 


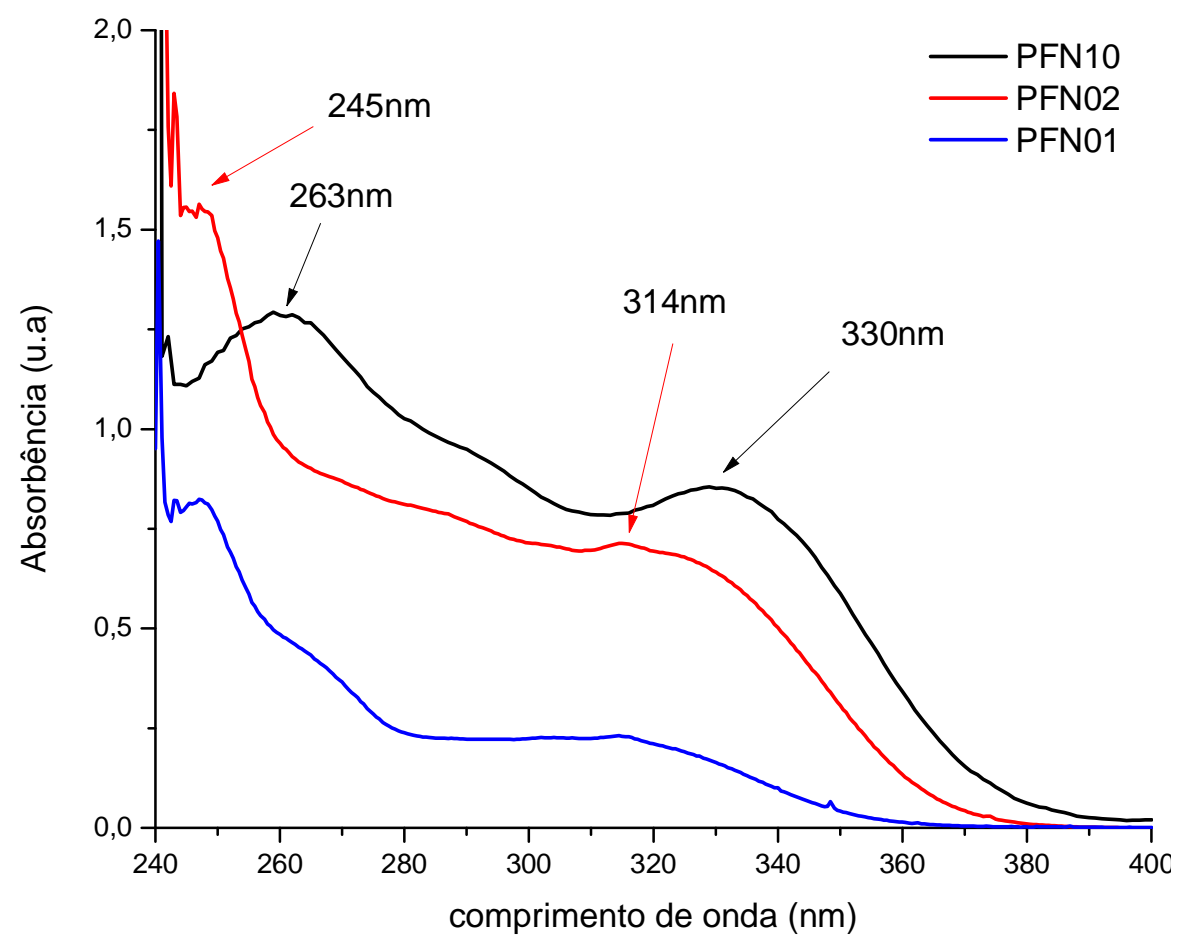

Figura 54 - Espectro de absorbância no Uv-Vis dos copolímeros PFN1, PFN2 e PFN10 nas mesmas concentrações molares $\left(5,0 \times 10^{-5}\right)$.

Traçando-se retas tangentes à curva no ponto de maior inclinação e da linha base e tomando-se o ponto de intersecção dessas retas pode ser obtido o comprimento de onda ou a energia associada, $E=\frac{h c}{\lambda}$, correspondente ao gap óptico dos copolímeros. Foram determinados então para o PFN01 um gap óptico de 3,46eV (358 nm), para o PFN02 3,35eV (370 nm) e para o PFN10 3,27eV (379 nm), valores esses que podem também ser explicados pelo aumento da massa molar, resultando na diminuição dos gaps ópticos.

A Figura 55 apresenta o gráfico de absorção no UV-Vis variando-se as concentrações dos copolímeros PFN02 e PFN10. Pode-se notar que ambos os copolímeros apresentaram valores de máximos de picos na mesma região dos apresentados na Figura 54, tendo apenas como diferença a diminuição de suas intensidades de absorção relacionada à diminuição da concentração da solução. 


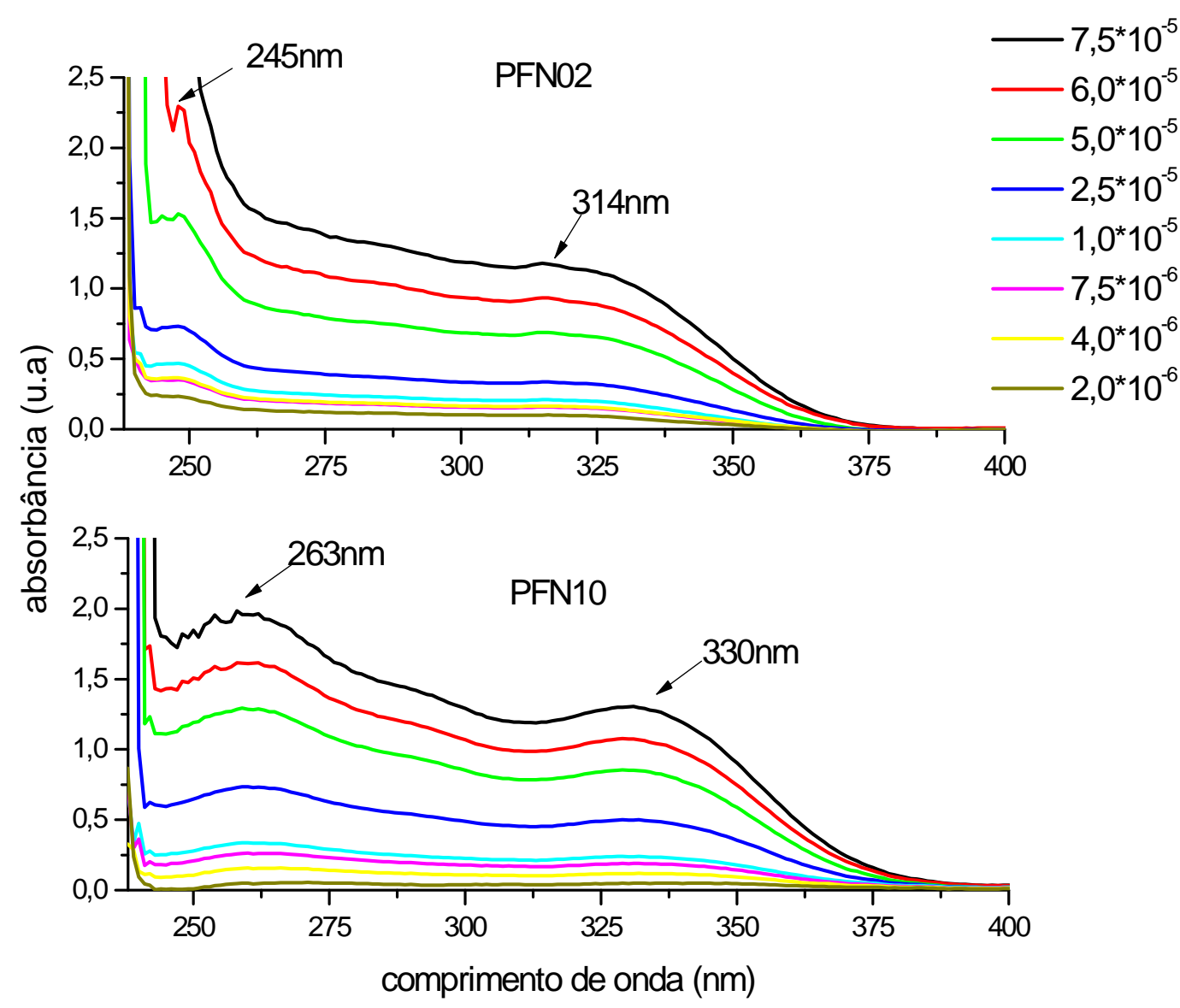

Figura 55 - Espectros de absorção no UV-Vis dos copolímeros PFN2 e PFN10 em diferentes concentrações.

O gráfico da Figura 56 faz uma correlação entre os valores de picos de intensidade de absorbância e a concentração em 314 nm para os copolímeros PFN01 e PFN02 e em 330 nm para o PFN10.

É possível notar para as soluções mais concentradas uma maior intensidade de absorção. O PFN10 tem um coeficiente angular maior do que os demais copolímeros, mostrando que pequenas variações em sua concentração resultaram em variação maior na intensidade de absorção, comparado aos demais copolímeros. 


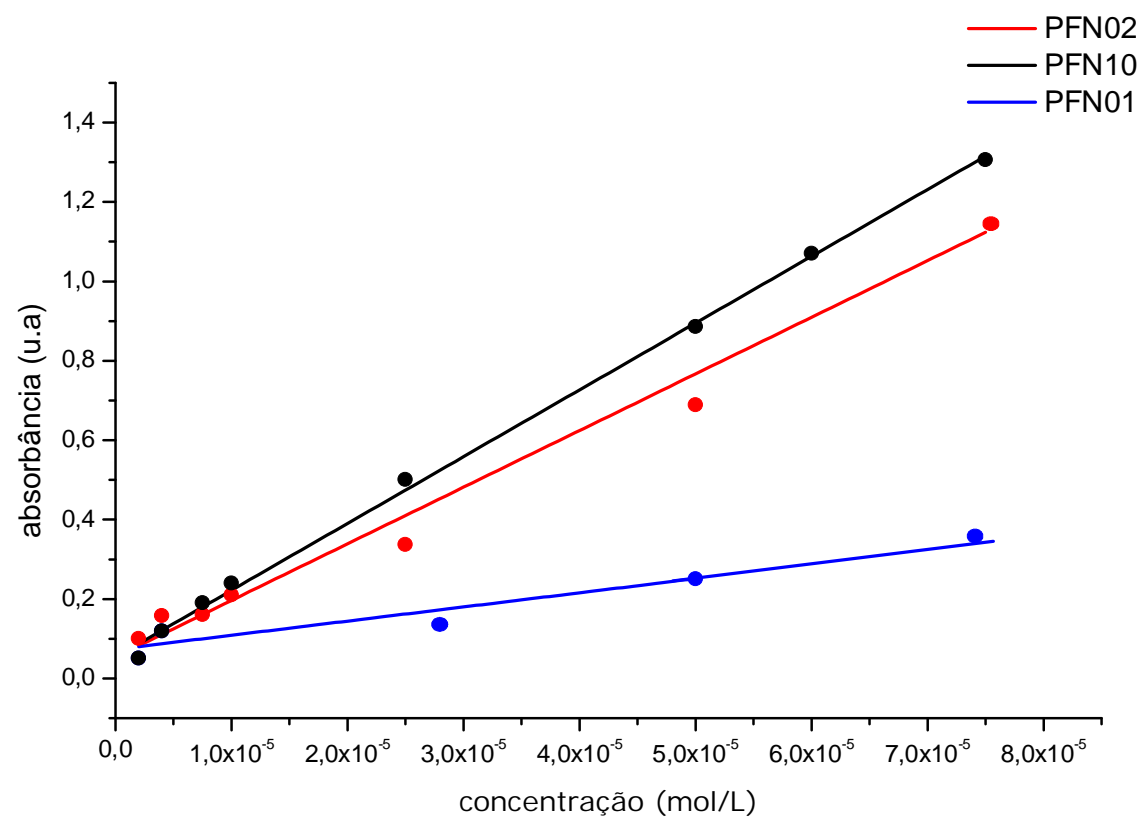

Figura 56 - Variação da intensidade da absorbância Vs. variação da concentração molar, para o pico de 314nm (PFN01 e PFN02) e para o pico de 330nm (PFN10).

A Figura 57 apresenta a comparação dos espectros de absorbância no UVVis dos materiais de partida, 5,7-dibromo-8-oxioctil-quinolina (quinolina) e o 9,9Dioctil-2,7-dibromofluoreno (fluoreno), com os copolímeros PFN02 e PFN10 na concentração de $5,0 \times 10^{-5}$.

É possível verificar que os picos de máximos na região de $330 \mathrm{~nm}$ (PFN10) e 314 nm (PFN02) apresentam um deslocamento em relação aos picos de máximos dos espectros de absorção dos materiais de partida. Podemos notar também que em comprimentos de onda maiores em relação aos picos máximos os copolímeros apresentam o mesmo perfil de absorção da quinolina, havendo também um alargamento na região de absorção, abrangendo toda a região de absorção do fluoreno. 


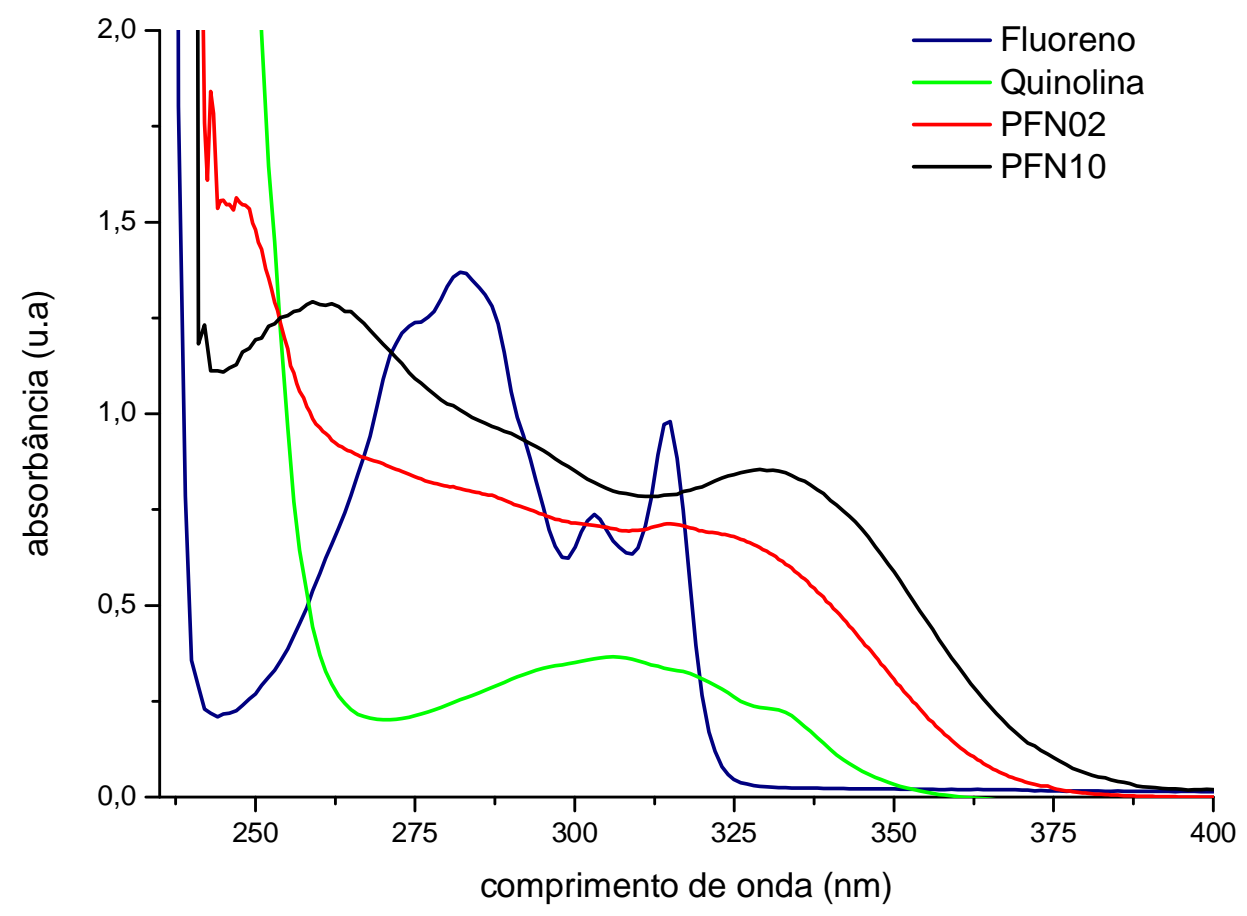

Figura 57 - Gráfico comparativo e absorbância no UV-Vis dos materiais de partida com os copolímeros PFN02 e PFN10.

\subsubsection{Espectroscopia de fluorescência}

A Figura 58 mostra o espectro de fluorescência para os comprimentos de onda de excitação de $314 \mathrm{~nm}$ para os copolímeros PFN01 e PFN02 e de $330 \mathrm{~nm}$ para o copolímero PFN10, ambos estão na mesma concentração $\left(1,0 \times 10^{-5} \mathrm{~mol} / \mathrm{L}\right)$. Nota-se que o pico máximo de emissão é de $419 \mathrm{~nm}$, sendo o mesmo para ambos os materiais apenas como diferença na intensidade. PFN10 apresentou um pico de intensidade de emissão bem maior que os demais. 


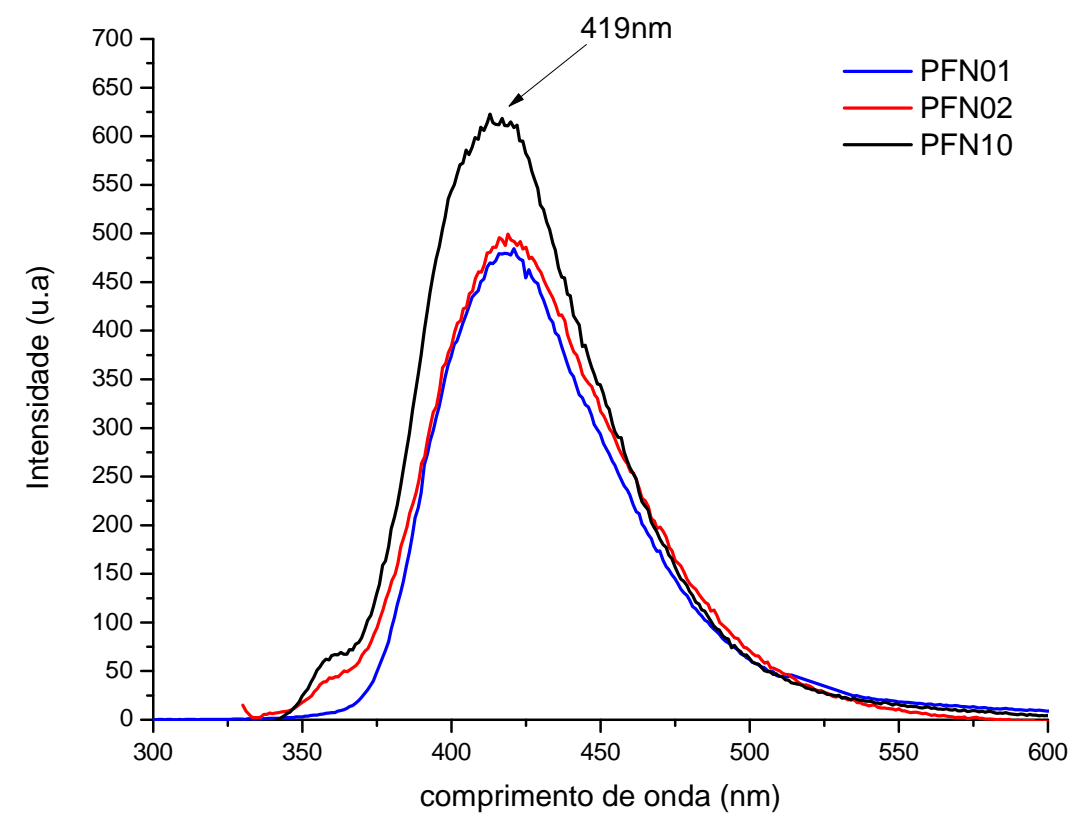

Figura 58 - Espectro de fluorescência dos copolímeros PFN01 e PFN02 excitado em 330nm e do PFN10 excitado em 315nm nas mesmas concentrações $\left(1,0 \times 10^{-5}\right)$.

Excitando os copolímeros nas mesmas concentrações $\left(5,0 \times 10^{-5}\right)$ em $245 \mathrm{~nm}$ (Figura 59), comprimento de onda correspondente ao menor comprimento de onda de absorção apresentado pelo espectro de absorção no Uv-vis (Figura 54), foi possível obter o espectro de emissão com o mesmo máximo em 419 nm e novamente com diferença nos valores de intensidade.

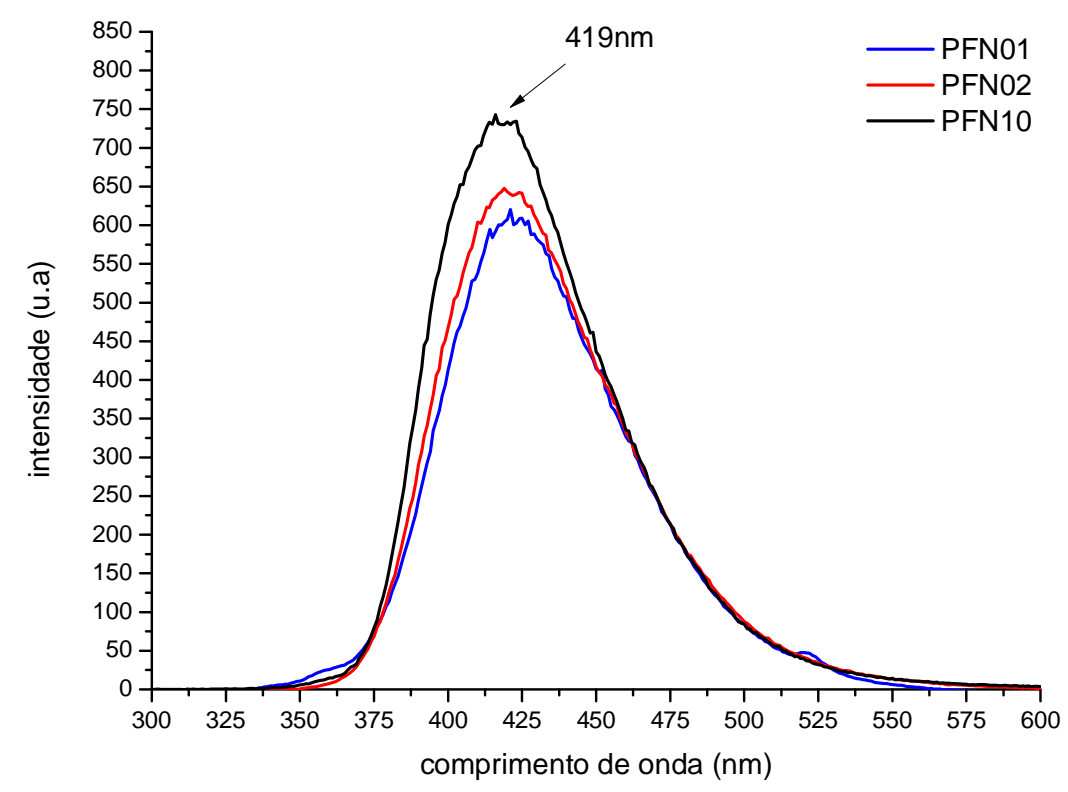

Figura 59 - Espectro de fluorescência dos copolímeros excitados em $245 \mathrm{~nm}\left(5,0 \times 10^{-5} \mathrm{~mol} / \mathrm{l}\right)$. 
Variando-se o comprimento de onda de excitação foi possível notar que para comprimentos de onda maiores, a intensidade de emissão é aumentada, porém a região de emissão continua no mesmo comprimento de onda (419 nm), como pode ser observado na Figura 60 e Figura 61.

A Figura 60 mostra o copolímero PFN02 a $2,5 \times 10^{-5} \mathrm{~mol} / \mathrm{L}$ e a Figura 45 , o PFN10 a $1,0 \times 10^{-5} \mathrm{~mol} / \mathrm{L}$, ambos excitados em diferentes comprimentos de onda, dentro das regiões dos seus espectros de absorção do UV-Vis.

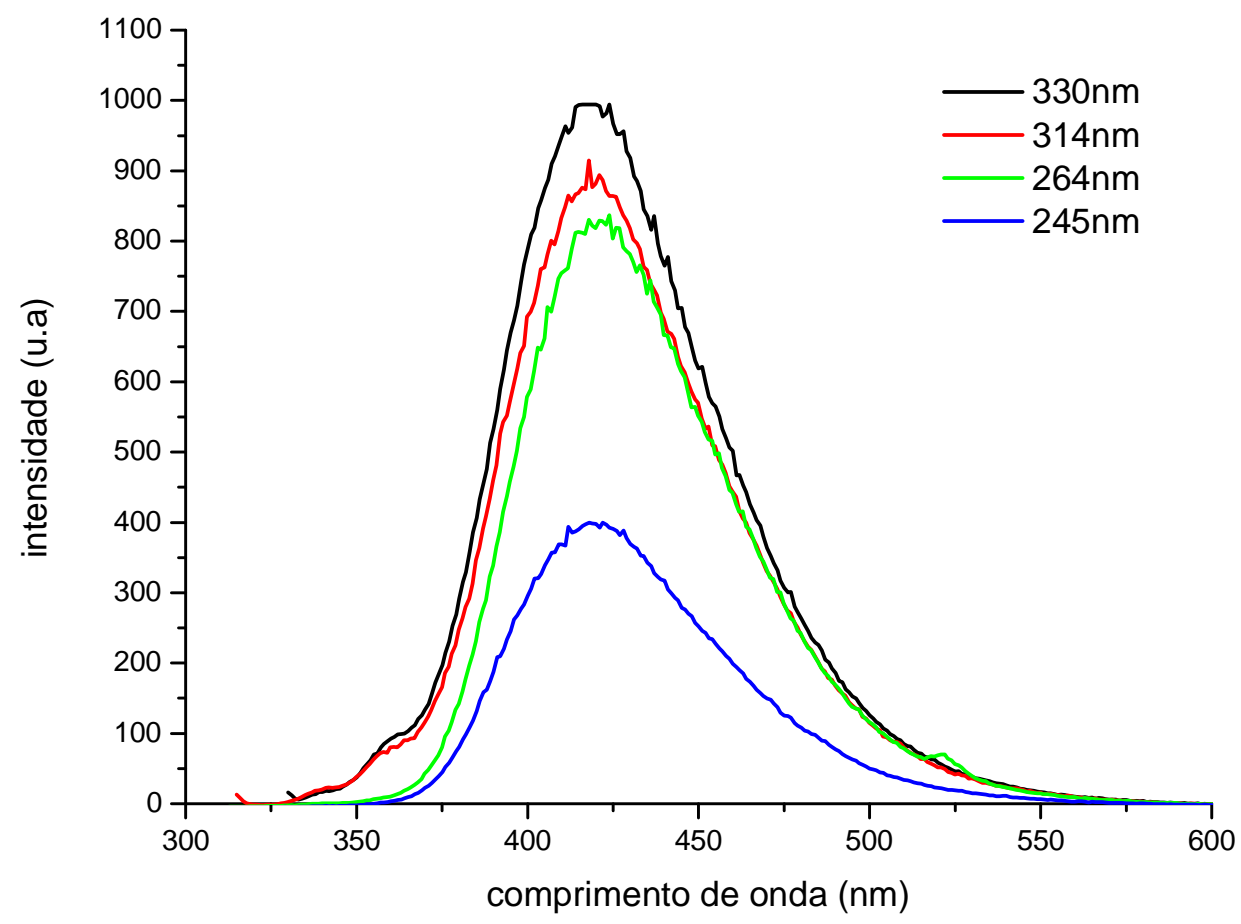

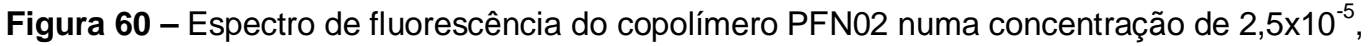
variando o comprimento de onda de excitação. 


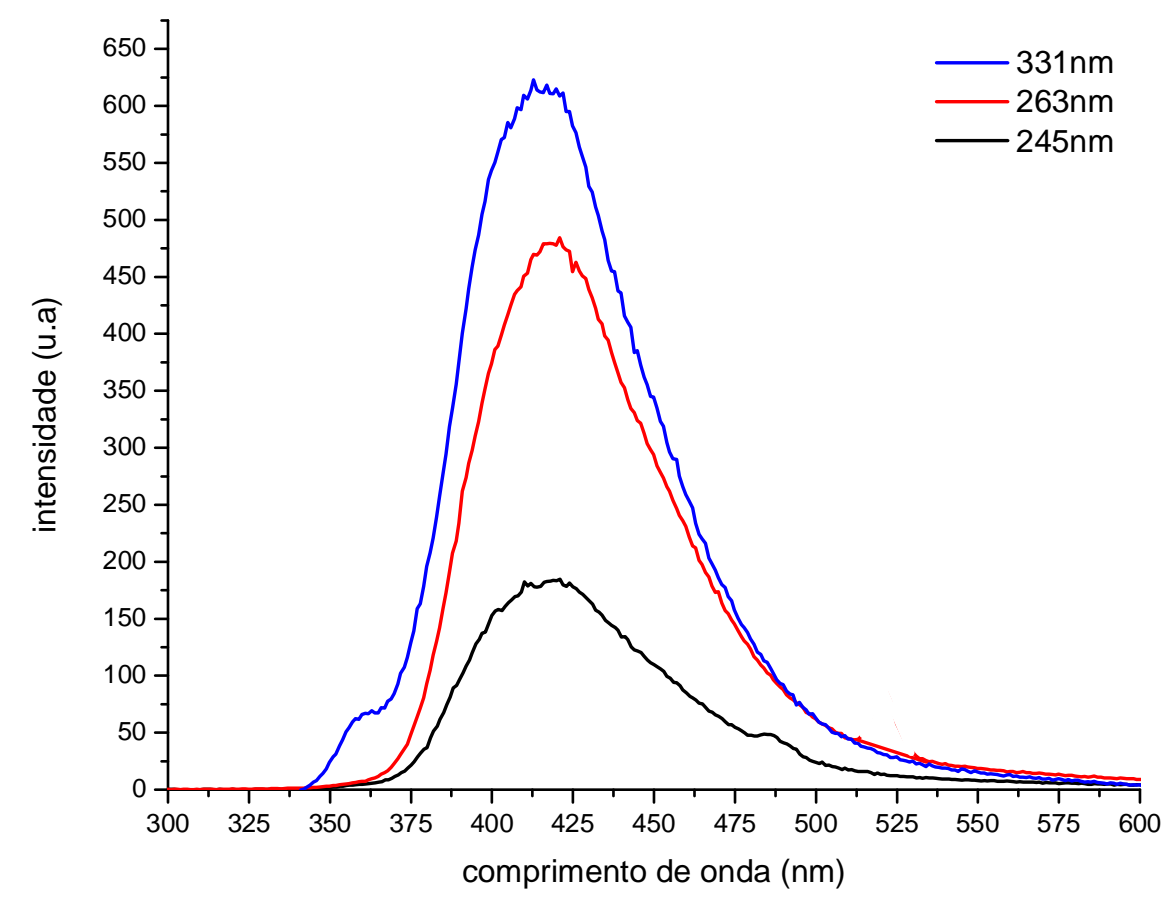

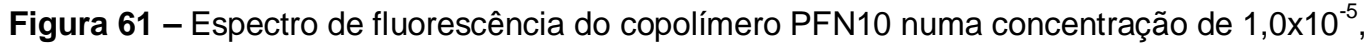
variando o comprimento de onda de excitação.

Alterando-se as concentrações dos copolímeros PFN02 e PFN10 e excitando em 245nm obtivemos o seguinte gráfico mostrado na Figura 62. Através desse gráfico, pode-se concluir que assim como na absorção no UV-Vis, a intensidade da emissão também é aumentada com o aumento da concentração, e os copolímeros continuam emitindo no mesmo comprimento de onda de $419 \mathrm{~nm}$. 


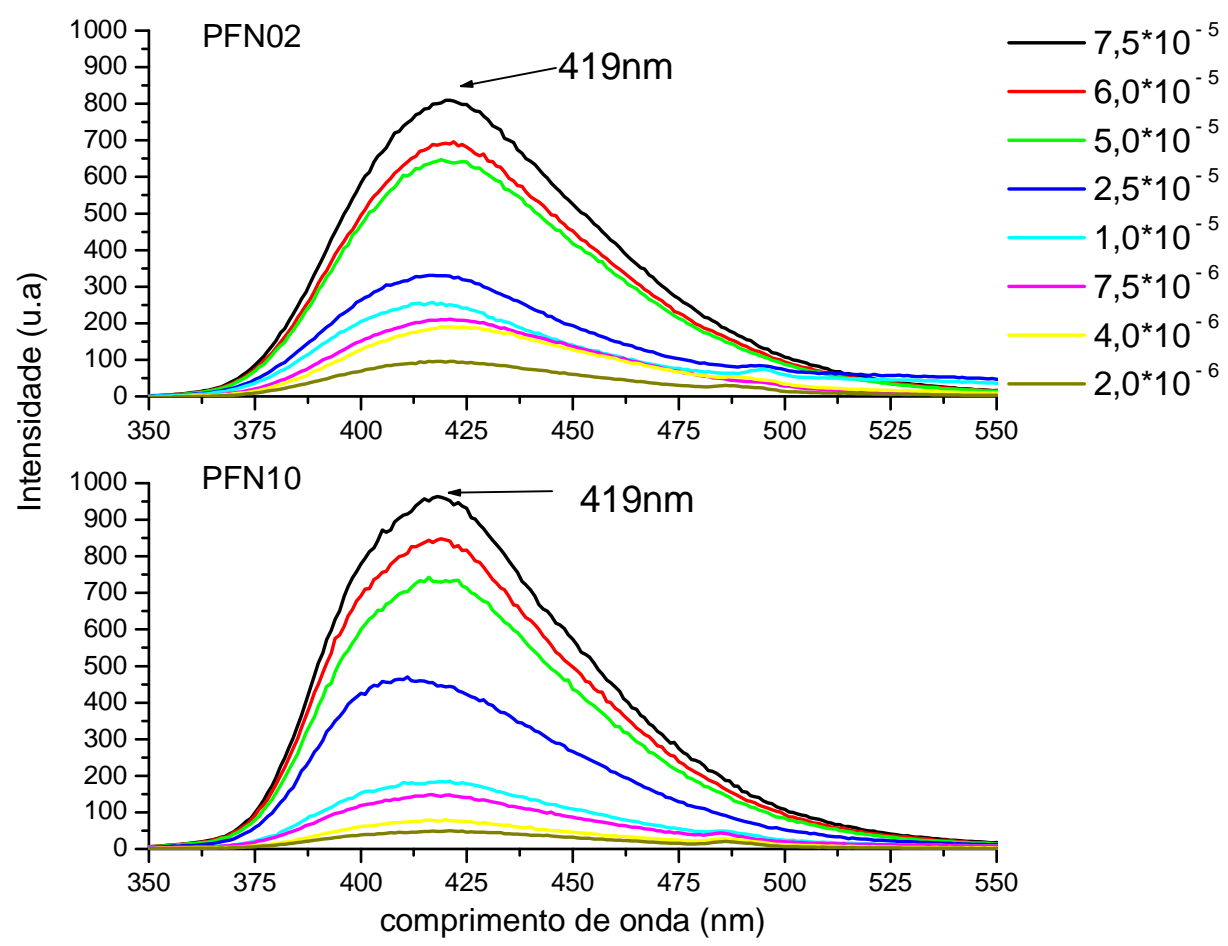

Figura 62 - Espectro de fluorescência dos copolímeros PFN02 e PFN10 em diferentes concentrações.

A Figura 63 mostra o gráfico que relaciona a concentração com a variação da intensidade para os copolímeros PFN02 e PFN10, podendo ser comprovado que o aumento da concentração aumenta também a intensidade de emissão. $O$ copolímero PFN10 apresentou um coeficiente angular um pouco maior, sendo assim mais sensível a variações na concentração, e melhor emissor quando comparado ao PFN02.

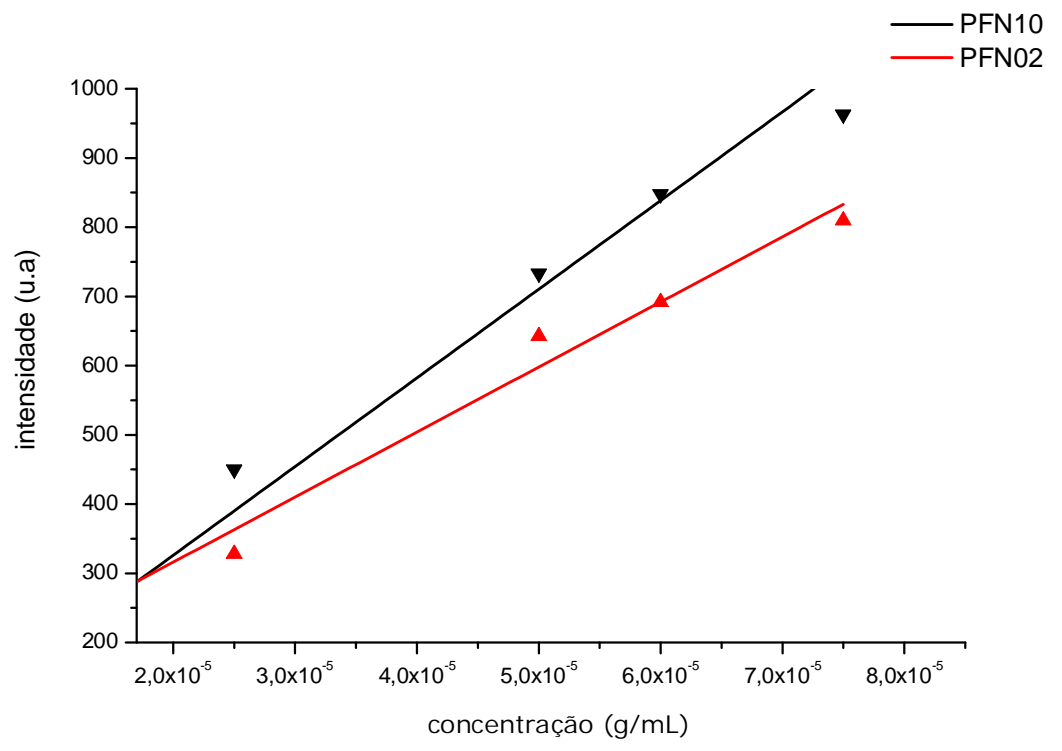

Figura 63 - Variação da intensidade de emissão vs. variação da concentração para os copolímeros. 
Na Figura 64 é mostrada uma comparação dos espectros dos materiais de partida, 5,7-dibromo-8-oxioctil-quinolina (quinolina) e 9,9-Dioctil-2,7-dibromofluoreno (fluoreno), com os copolímeros sintetizados. Pode-se observar os picos de emissão característicos para cada material; Para a quinolina o pico de emissão ficou em 325 $\mathrm{nm}$, para o fluoreno esse ponto de máxima intensidade é em $415 \mathrm{~nm}$, valor esse bem próximo ao dos copolímeros. Para ambos os materiais os comprimentos de onda de excitações foram de $330 \mathrm{~nm}, 314 \mathrm{~nm}$ e $245 \mathrm{~nm}$. As variações desses comprimentos de onda de excitação tiveram apenas influência no valor de intensidade, mantendo-se os picos máximos de emissão para cada material constante.

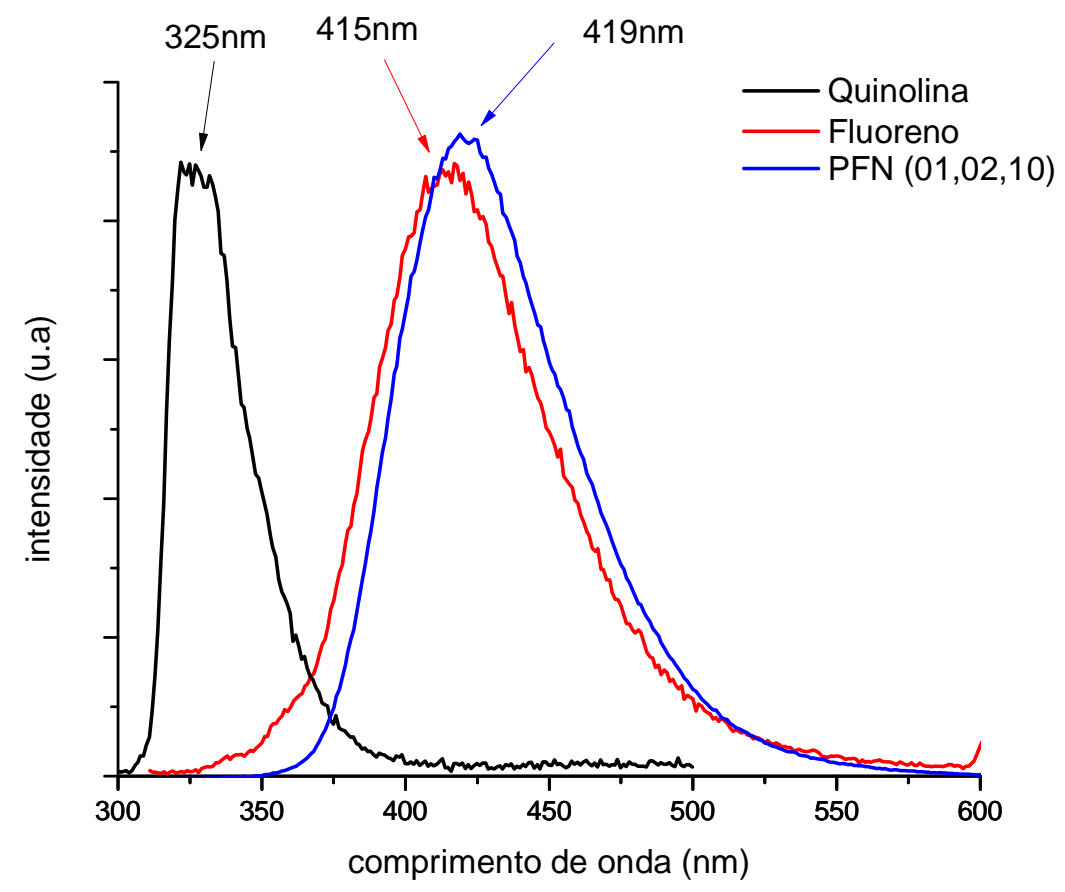

Figura 64 - Espectro de fluorescência dos materiais de partida e dos copolímeros.

O gráfico da Figura 65 apresenta os espectros de absorção e de emissão dos copolímeros, onde podemos ver em um único gráfico as regiões de absorção e de emissão, podemos observar que excitando os copolímeros em qualquer ponto de máximo de absorção entre $245 \mathrm{~nm}$ e $330 \mathrm{~nm}$, ele vai possuir apenas um único ponto de emissão de fluorescência na região de 419nm. 


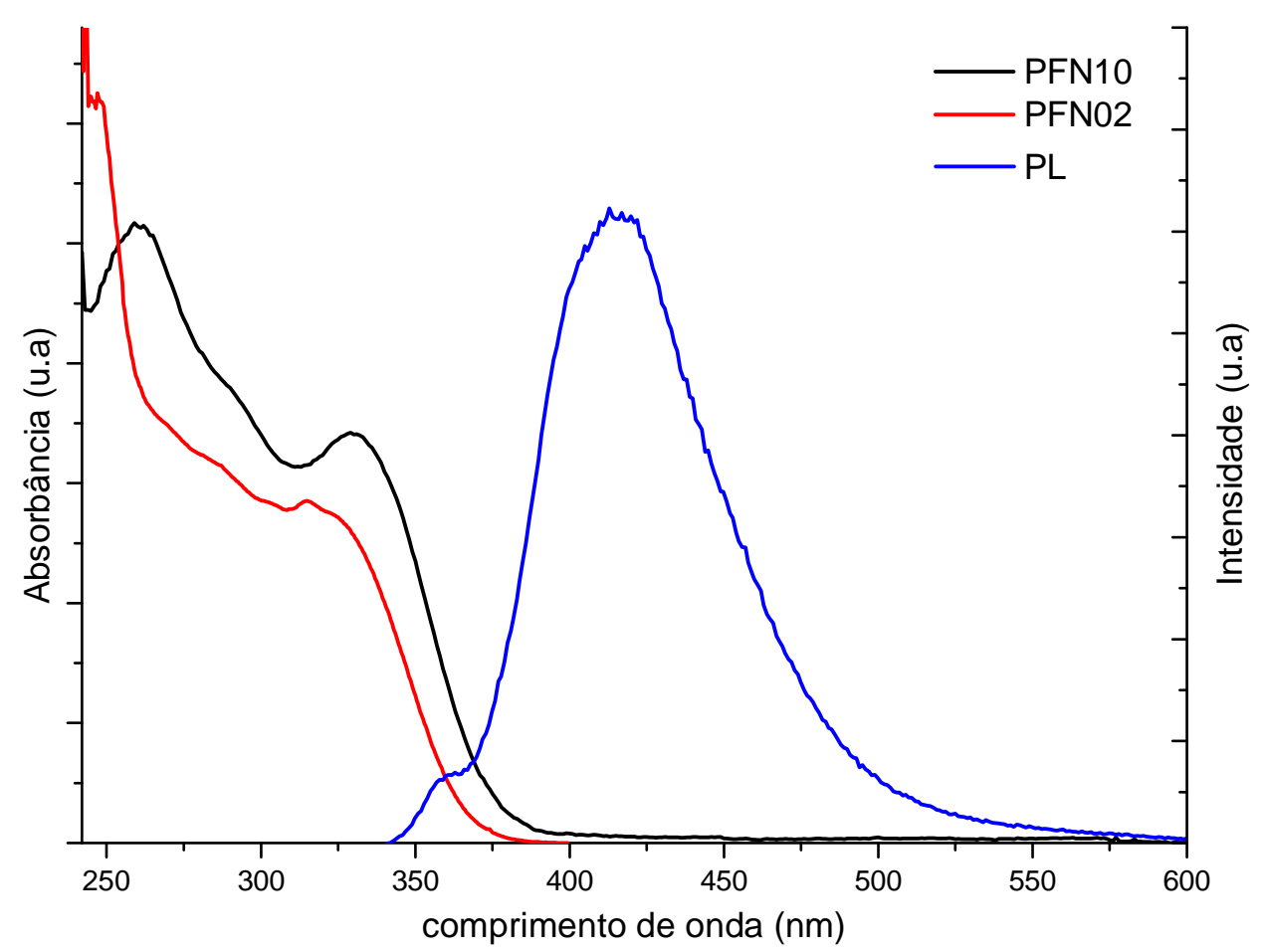

Figura 65 - Espectro de absorção e fluorescência no UV-Vis dos copolímeros.

\subsubsection{Rendimento Quântico}

O rendimento quântico foi calculado comparando os resultados de emissão de uma substância com rendimento quântico conhecido. No caso, foi utilizado o sulfato de quinina $\left(\left(\mathrm{C}_{20} \mathrm{H}_{24} \mathrm{~N}_{2} \mathrm{O}_{2}\right)_{2} \cdot \mathrm{H}_{2} \mathrm{SO}_{4} \cdot 2 \mathrm{H}_{2} \mathrm{O}\right)$ (Figura 66).

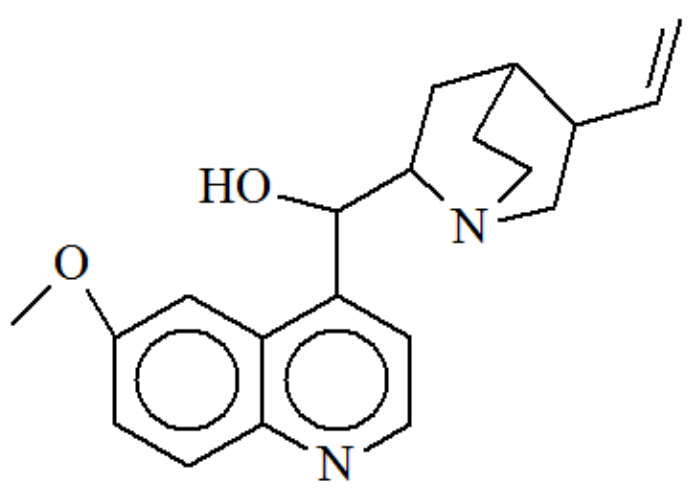

Figura 66 - Estrutura química da quinina. 
É conhecido o rendimento quântico do sulfato de quinina $(0,546)$, cujo valor é determinado em soluções em concentrações menores do que $10^{-4} \mathrm{~mol} / \mathrm{L}$ em solução de $\mathrm{HCl}-1,0 \mathrm{~N}$, excitado a $365 \mathrm{~nm}$ a $25^{\circ} \mathrm{C}^{67}$.

Através da eq. (1), relaciona-se as propriedades de rendimentos quânticos, respostas emissivas e índice de refração de duas substâncias, o que permite a determinação do rendimento quântico de uma substância desconhecida.

$$
Q x=\mathrm{Qr}^{*}\left(\mathrm{D}_{\mathrm{x}} / \mathrm{D}_{\mathrm{r}}\right)^{*}\left(\mathrm{n}_{\mathrm{x}}^{2} / \mathrm{n}_{\mathrm{r}}^{2}\right)
$$

eq. (1) - Formula para o cálculo de rendimento quântico.

$\mathrm{Na}$ equação $1, Q, D$ e $\mathrm{n}$ são o rendimento quântico, a resposta do equipamento no caso a área dos gráficos de emissão e o índice de refração, respectivamente, os índices $r$ e $x$ estão relacionados à referência e à amostra, respectivamente.

A Figura 67 mostra os espectros de emissão do sulfato de quinina para uma concentração de $1,0 \times 10^{-5}$ excitado em $365 \mathrm{~nm}$, cuja área do gráfico $\left(D_{r}\right)$ é 35828 .

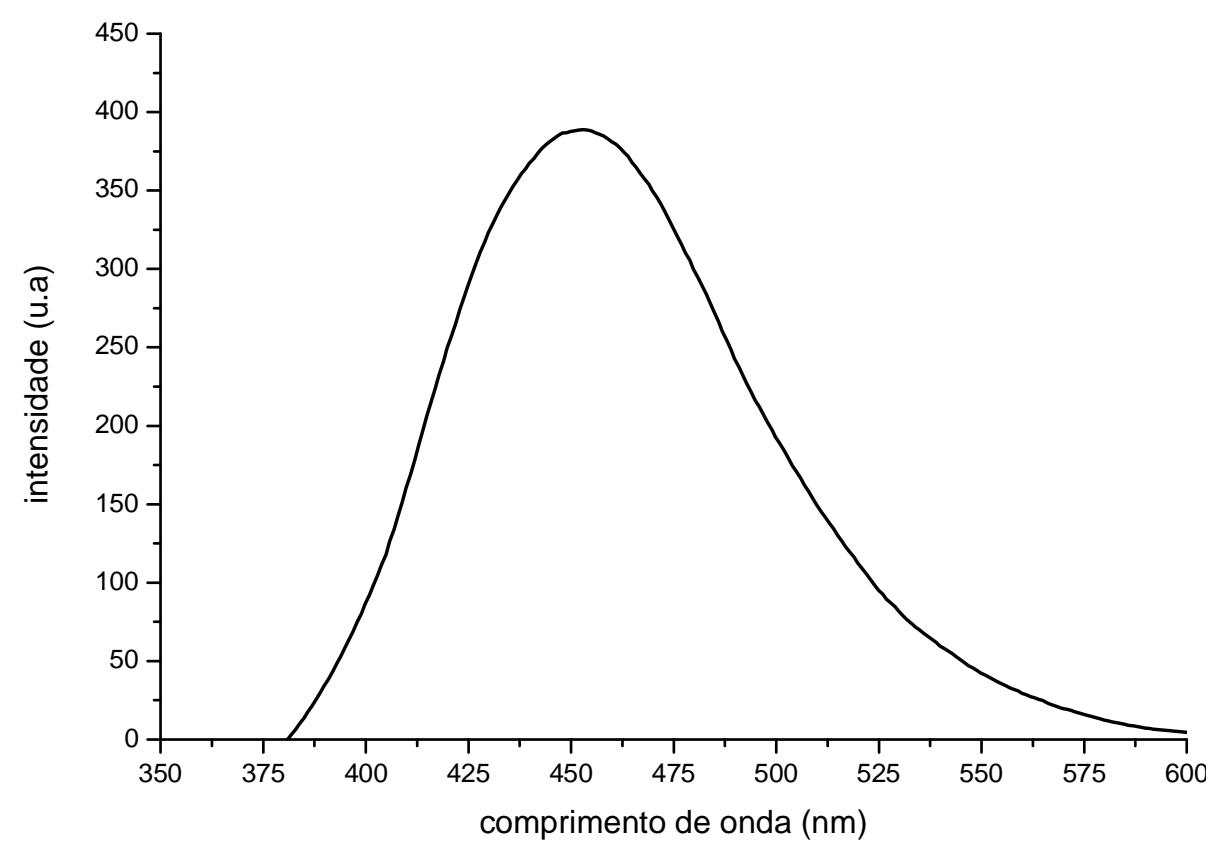

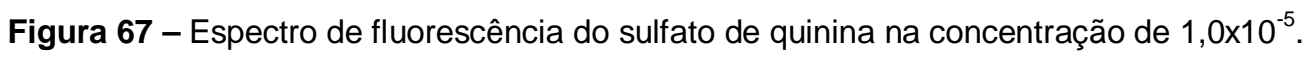


Os outros valores de $D_{x}$ foram obtidos calculando-se as áreas de cada copolímero apresentado no gráfico da Figura 68, os copolímeros estão na concentração de $1,0 \times 10^{-5} \mathrm{~mol} / \mathrm{L}$, sendo os copolímeros PFN01 e PFN02 excitados em 314nm e o PFN10 excitado em $330 \mathrm{~nm}$.

Para o copolímero PFN01 a área calculada foi $D_{x 01}=36847$, PFN02 $D_{\times 02}=39238$ e PFN10 $D_{x 10}=47118$.

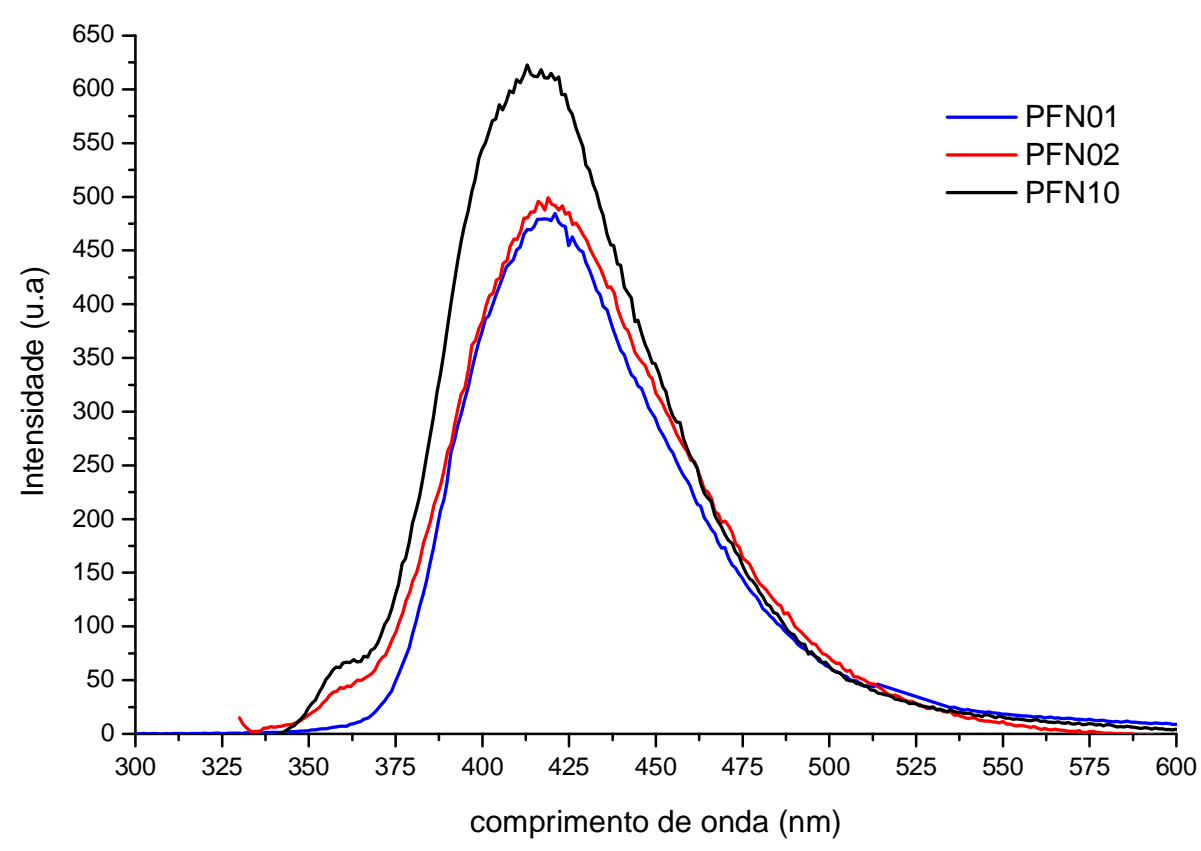

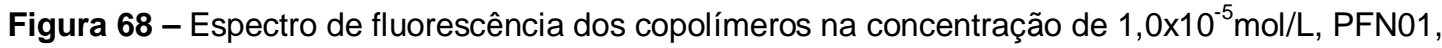
PFN02 excitado em 314nm e PFN10 em 330nm.

Com os valores de $D_{x}$ de cada copolímero e sabendo que os parâmetros de $n_{x}$ e $\mathrm{n}_{\mathrm{r}}$ são respectivamente, o índice de refração do clorofórmio $(1,446)$ e o índice de refração da água destilada $(1,3525)^{67}$, e utilizando a eq.(1) foi possível achar os rendimentos quânticos de cada material.

A Tabela 8 apresenta os rendimentos quânticos calculados para os copolímeros PFN01 $\left(Q_{\times 01}\right)$, PFN02 $\left(Q_{\times 02}\right)$ e PFN10 $\left(Q_{\times 10}\right)$.

Tabela 8 - Tabela de valores dos rendimentos quânticos calculados.

Copolímero

Rendimento Quântico

\begin{tabular}{ll}
\hline PFN01 & $64 \%$ \\
\hline PFN02 & $68 \%$ \\
\hline PFN03 & $82 \%$ \\
\hline
\end{tabular}




\subsubsection{Voltametria Cíclica}

Os copolímeros PFN02 e PFN10 sintetizados e estudados neste trabalho apresentam processos de oxidação e redução irreversíveis, Figura 69.

No voltagrama, observam-se dois picos de redução um em -0,94 V e outro em $-1,58 \mathrm{~V}$ e o pico oxidação um em $1,17 \mathrm{~V}$, já para o PFN10 os picos de redução são -0,60V e -1,60V e 1,17V para oxidação.

Os primeiros picos de redução dos copolímeros, -0,94V para o PFN02 e -0,60V para o PFN10 estão relacionado a presença da quinolina, que tem como principal função o transporte de elétrons e consequentemente atuando de forma a diminuir o gap do copolímero.

Uma maneira de se estipular os valores de energias HOMO e LUMO e consequentemente o valor de gap do material é através das medidas de potencial de redução e oxidação respectivamente, obtidos através das análises de voltametria cíclica. Pegando-se então o primeiro valor onde ocorre uma variação na passagem de corrente tanto para os potencias de redução quanto para oxidação.

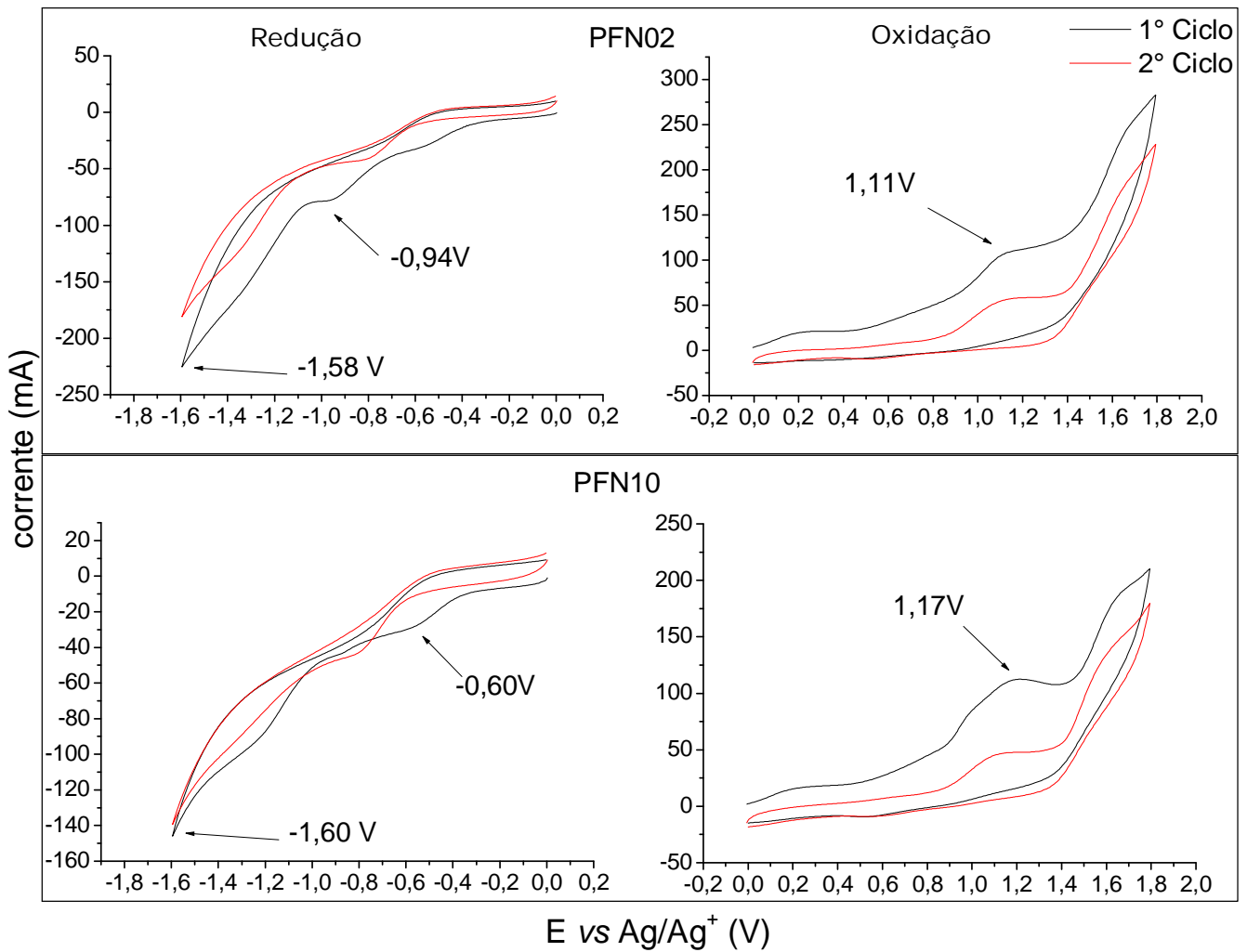

Figura 69 - voltametria cíclica dos copolímeros PFN02 e PFN10. 
Para conseguirmos achar os valores de HOMO e LUMO, devemos ainda assumir um eletrodo padrão como referência no caso o eletrodo de calomelano saturado (SCE), portanto devemos somar aos valores de oxidação e redução um fator de 4,7 eV, a soma desse valor já convertendo os valores em Volt fornecido pelos voltagramas para $\mathrm{eV}^{64,68}$.

Feito os cálculos chegamos aos valores de HOMO e LUMO e o gap (LUMOHOMO) para cada copolímero apresentados na Tabela 9.

Tabela 9 - Valores de HOMO, LUMO e gap calculados através dos dados de voltametria cíclica.

\begin{tabular}{cccc} 
Copolímero & $\mathrm{HOMO}(\mathrm{eV})$ & $\mathrm{LUMO}(\mathrm{eV})$ & gap $(\mathrm{eV})$ \\
\hline PFN02 & 3,76 & 5,81 & 2,05 \\
PFN10 & 4,10 & 5,87 & 1,77 \\
\hline
\end{tabular}

Podemos notar uma diminuição no valor de gap, fato esse que pode ser explicado pelo aumento da massa molar com um consequente aumento da concentração de quinolina. 


\subsection{Caracterização dos PLEDS}

\subsubsection{Microscopia óptica do filmes}

Para a construção de um dispositivo eficiente foi necessário que o filme depositado seja uniforme, e para isso foram feitas as análises de microscopia ótica dos filmes de ITO (Figura 70), dos filmes de PEDOT:PSS e dos copolímeros que haviam acabado de ser depositados, pelo método de spin-coating descrito nas seções 3.3.3.5 e 3.3.3.6.

Figura 70 - Microscopia ótica do ITO sobre Vidro, com aumento de 500X (menor divisão $2 \mu \mathrm{m}$ ).

Pela Figura 70 é possível notarmos em alguns pontos, defeitos do filme de ITO sobre o Vidro. Esses defeitos podem influenciar as outras deposições subseqüentes como a do PEDOT:PSS e diminuir a eficiência e o rendimento dos dispositivos.

A Figura 71 mostra a deposição da camada de PEDOT:PSS sobre ITO, e como podemos observar as falhas no ITO induziram algumas falhas na deposição do PEDOT:PSS também. 
Figura 71 - Microscopia óptica do filme de PEDOT sobre ITO, com aumento de 500X (menor divisão $2 \mu \mathrm{m})$.

A Figura 72 mostra o filme do copolímero da PFN02 depositado sobre ITO. Nela pode-se observar que em algumas regiões não houve deposição e em outras a deposição não foi uniforme, visto que mesmo após a deposição ainda era possível ver o ITO.

Figura 72. Microscopia óptica do filme do copolímero PFN2 sobre ITO aumento de 500X (menor divisão $2 \mu \mathrm{m})$.

A Figura 73 mostra a deposição do Copolímero PFN2 sobre o substrato, onde já havia sido depositado o PEDOT:PSS (Figura 71). A deposição não foi uniforme como podemos notar pela presença dos pontos alaranjados. 


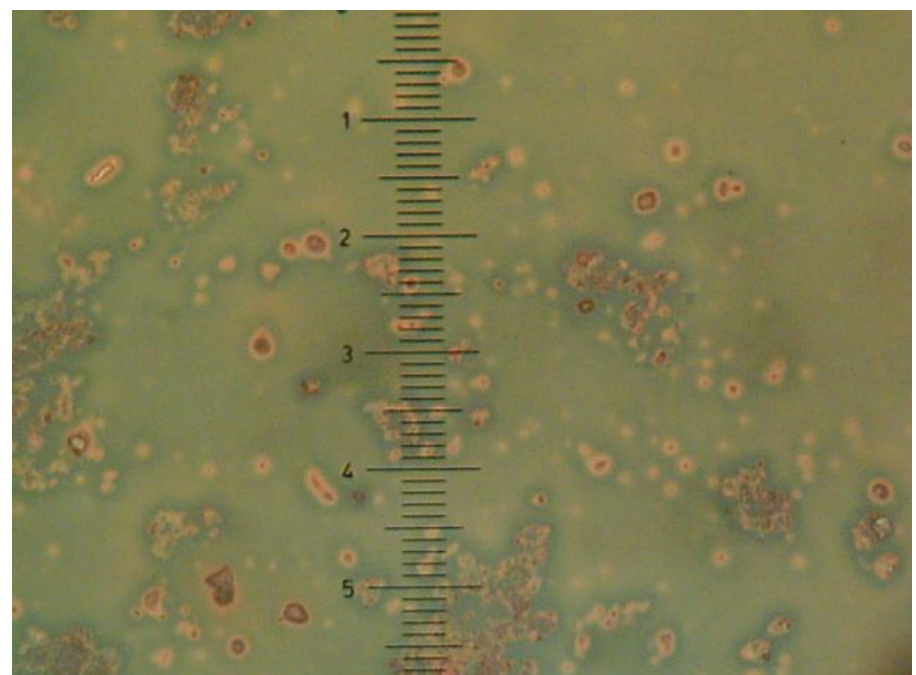

Figura 73. Microscopia óptica do filme do copolímero PFN2 dobre PDOT/ITO/Vidro, aumento de 1000X (menor divisão 1 $\mu \mathrm{m}$ ).

Parte do problema dessa deposição está no estado físico do copolímero, visto que ele é um sólido pastoso, tendendo, então, a formar um filme mais instável, com deformação devida a escoamento em temperatura relativamente baixa. Para melhorar o aspecto do filme depositado foram acrescentados 10 e $20 \%$ de PVK ao total de copolímero na solução e as microscopias óticas desses filmes são mostradas nas Figura 74 e Figura 75.

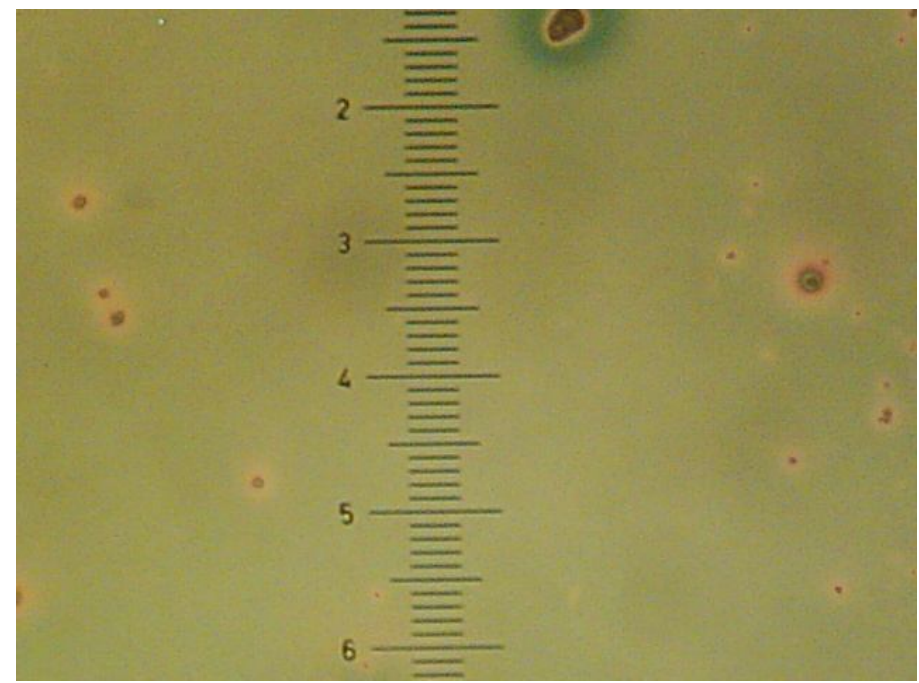

Figura 74 - Microscopia óptica do filme do copolímero PFN2 com 10\% de PVK sobre PDOT/ITO/Vidro, aumento de 1000X (menor divisão 1 $\mu \mathrm{m}$ ). 
Figura 75. Microscopia óptica do filme do copolímero PFN2 com 20\% de PVK dobre PDOT/ITO/Vidro, aumento de 500X (menor divisão $2 \mu \mathrm{m}$ ).

Através das microscopias dos filmes contendo a blenda do copolímero com $10 \%$ e $20 \%$ de PVK, foi obtido um filme mais uniforme porém ainda existe alguns pontos com defeitos e esses pontos podem ser atribuídos as falhas de deposição do filme de PDOT:PSS sobre ITO, cujos defeitos vão sendo transferidos para as deposições sucessivas.

\subsubsection{Espessura dos filmes}

Usando o perfilometro Alpha Step 500 foram obtidos os dados das medidas de espessuras dos filmes. Foram feitas três medidas de espessura em cada região da lâmina, sendo as médias dessas medidas apresentadas na Tabela 10.

Tabela 10 - Tabela com as medidas de espessuras dos filmes finos.

\begin{tabular}{|c|c|}
\hline Filme & Espessura $(\mathbf{n m})$ \\
\hline ITO & 130,0 \\
\hline PEDOT:PSS & 53,8 \\
\hline Alumínio & 500,0 \\
\hline
\end{tabular}

\begin{tabular}{|c|c|}
\hline Copolímeros & $\begin{array}{c}\text { Espessura } \\
\text { (nm) }\end{array}$ \\
\hline PFN02 & 40,2 \\
\hline PFN10 & 20,9 \\
\hline PFN10+10\% de PVK & 25,3 \\
\hline
\end{tabular}




\subsubsection{Espectroscopia de absorção no UV-Vis em filme}

A Figura 76, mostra o gráfico de absorbância no UV-Vis em filme, contendo o copolímero PFN02 puro e com diferentes concentrações de PVK. É possível notar o surgimento de um ombro para os filmes com PVK e a diferença entre as duas concentrações utilizadas é percebida por um pequeno deslocamento desse ombro para comprimento de ondas maiores quando a quantidade de PVK é maior.

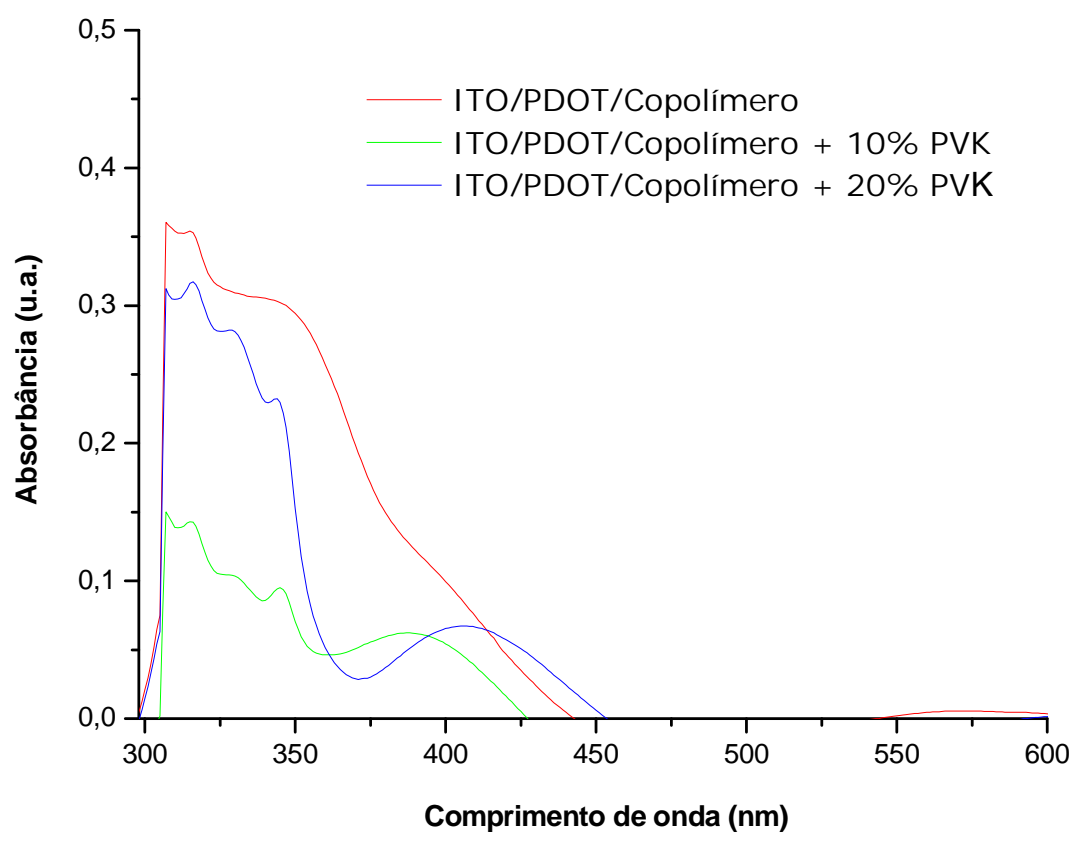

Figura 76 - Espectro de absorbância no UV-Vis em filme. 


\subsubsection{Caracterização elétrica dos PLEDS}

\subsubsection{PLED com o copolímero PFN02 como camada ativa.}

A Figura 77 mostra o esquema de polarização utilizado para o teste dos dispositivos.

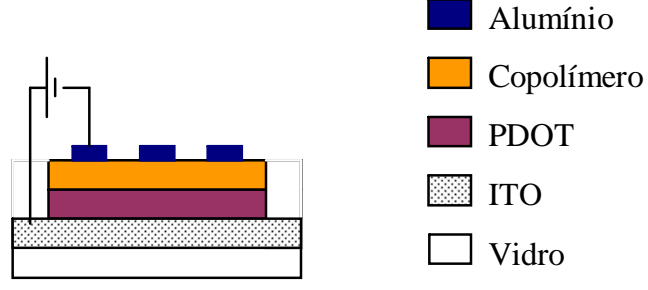

Figura 77 - Esquema de testes elétricos.

A Figura 78 mostra o gráfico de corrente vs. tensão dos dispositivos testados. Esse gráfico corresponde aos dispositivos sem tratamento superficial do ITO com UV-Ozônio, com o copolímero puro e com diferentes concentrações de PVK. Através destes gráficos é possível notar que com a presença do PVK há uma diminuição na tensão de limiar (tensão de condução) de 6,55 V para o copolímero puro para 5,1 V para o copolímero com 10\% em massa de PVK e para $4,8 \mathrm{~V}$ para $20 \%$ em massa de PVK.

A Tabela 11 apresenta a variação das tensões de limiar das curvas mostradas na Figura 78 , nela podemos concluir que a adição de $20 \%$ em massa de PVK não teve influência significativa na diminuição da tensão de limiar dos dispositivos. 


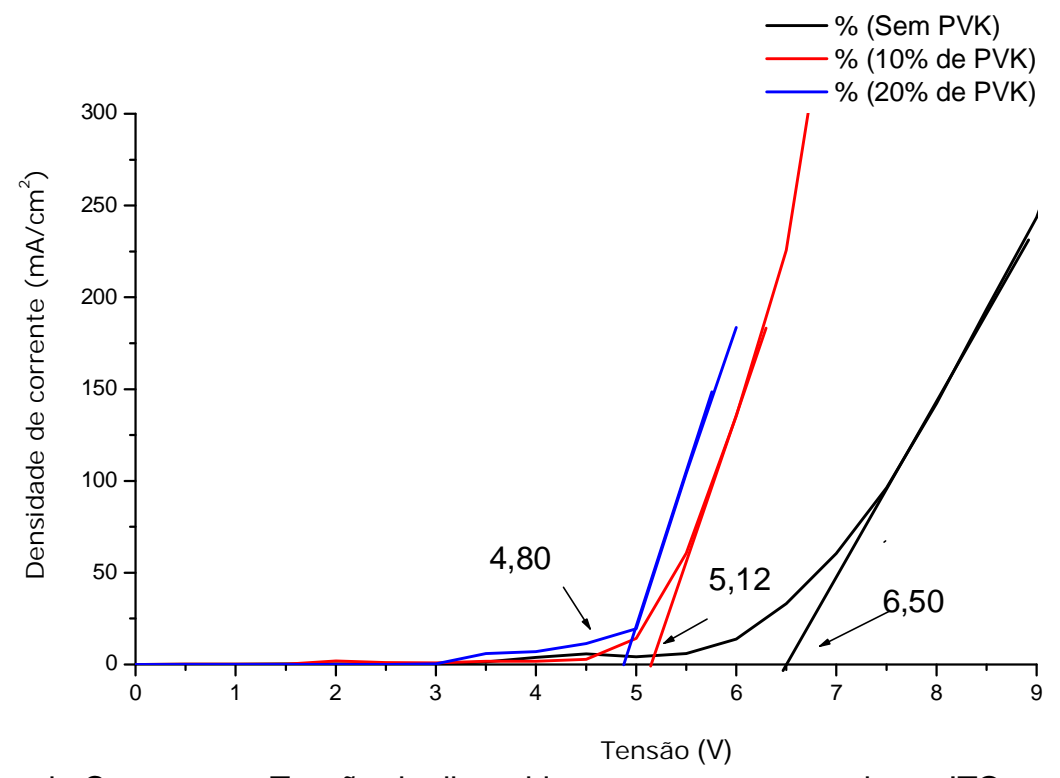

Figura 78 - Curva de Corrente vs. Tensão do dispositivo sem tratamento sobre o ITO, com o copolímero PFN02 puro, com 10\% e 20\% em massa de PVK.

Tabela 11 - Variação das tensões de limiar do dispositivo sem tratamento, variando a quantidade de PVK.

\begin{tabular}{|c|c|c|}
\hline Sem PVK & $10 \%$ de PVK & 20\% de PVK \\
\hline$(6,50 \pm 0,47) \bigvee$ & $(5,12 \pm 0,04) \mathrm{V}$ & $(4,8 \pm 0,30) \mathrm{V}$ \\
\hline
\end{tabular}

A Figura 79 mostra o gráfico de corrente vs. tensão do copolímero puro e com $10 \%$ e $20 \%$ de PVK com tratamento de limpeza sobre o ITO. Pelo gráfico podemos notar a exemplo do gráfico da Figura 78 uma diminuição na tensão de limiar quando comparada com o copolímero puro e com PVK, porém essa diminuição foi bem menos significativa, mostrando que o tratamento superficial só teve influência no dispositivo com o copolímero puro, sem nenhuma quantidade PVK, o que pode ser creditado à influência da melhora da qualidade superficial do filme nas propriedades elétricas do dispositivo.

Podemos notar também que o aumento da quantidade de PVK para valores maiores de $10 \%$ não tem influência significativa na diminuição da tensão de limiar (Tabela 12). 


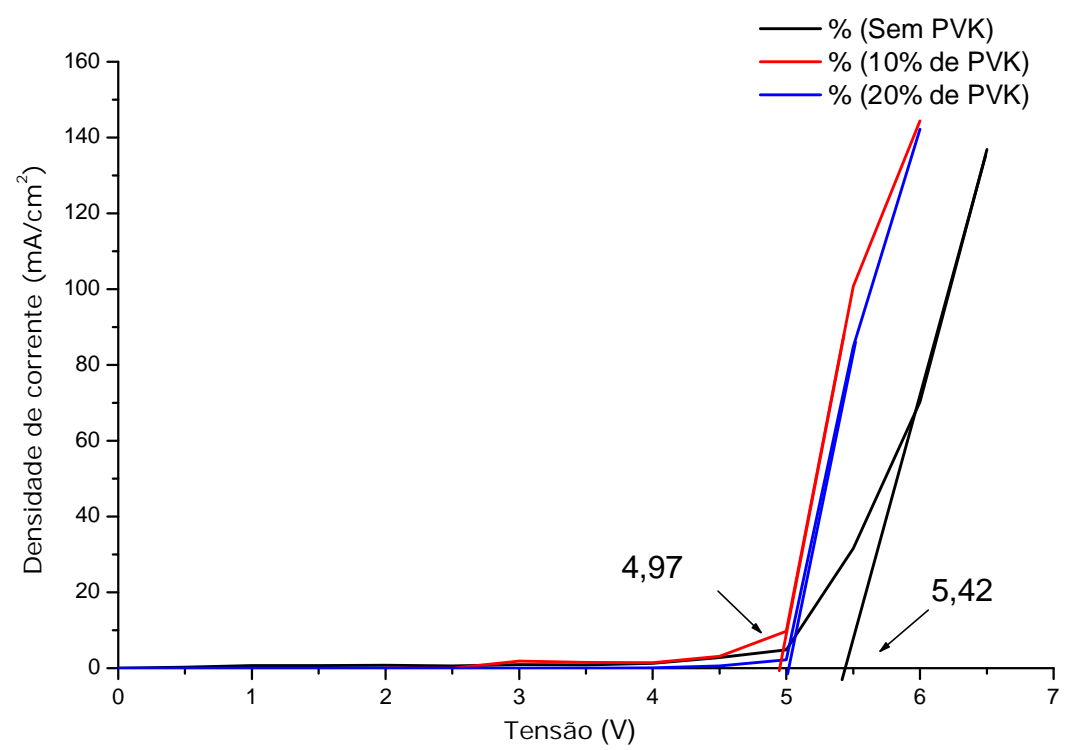

Figura 79 - Curva de Corrente vs. Tensão do dispositivo com tratamento sobre o ITO, com o copolímero PFN02 puro, com $10 \%$ e $20 \%$ em massa de PVK.

Tabela 12 - Variação das tensões de limiar do dispositivo com tratamento, variando a quantidade de PVK.

\begin{tabular}{|c|c|c|}
\hline Sem PVK & 10\% de PVK & 20\% de PVK \\
\hline$(5,7 \pm 0,40) \bigvee$ & $(4,97 \pm 0,20) \bigvee$ & $(4,9 \pm 0,30) \bigvee$ \\
\hline
\end{tabular}

Fixando a densidade de corrente em $150 \mathrm{~mA} / \mathrm{cm}^{2}$ e traçando uma reta até o cruzamento dela com as curvas do diodo podemos comparar as tensões de operação dos dispositivos, como mostrado na Figura 80. Os copolímeros com a presença do PVK tem uma tensão de trabalho bem menor do que a do copolímero puro. 


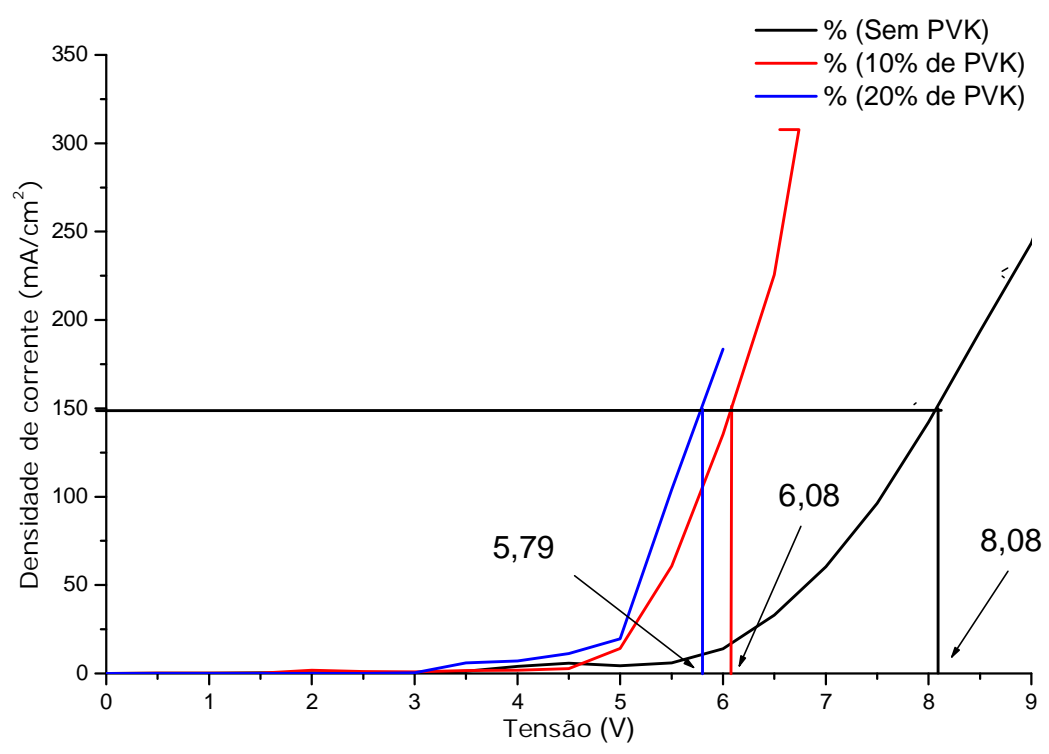

Figura 80 - Curva de Corrente vs. Tensão para comparação da tensão de operação do copolímero sem tratamento do ITO, puro, com $10 \%$ e $20 \%$ em massa de PVK.

A Figura 81 mostra o gráfico de corrente vs. tensão do copolímero puro com e sem tratamento, com a adição de um ETL, Alq 3 .

Podemos notar que o tratamento, mais uma vez não teve influência significativa na redução da tensão de limiar, ficando os dois dispositivos com essa tensão próxima de $5,2 \mathrm{~V}$, se comparamos esses dados com dos outros dispositivos apresentados na Figura 78 e na Figura 79, notamos que a adição do ETL ( $\left.\mathrm{Alq}_{3}\right)$ também não tem influência na diminuição da tensão de limiar dos dispositivos.

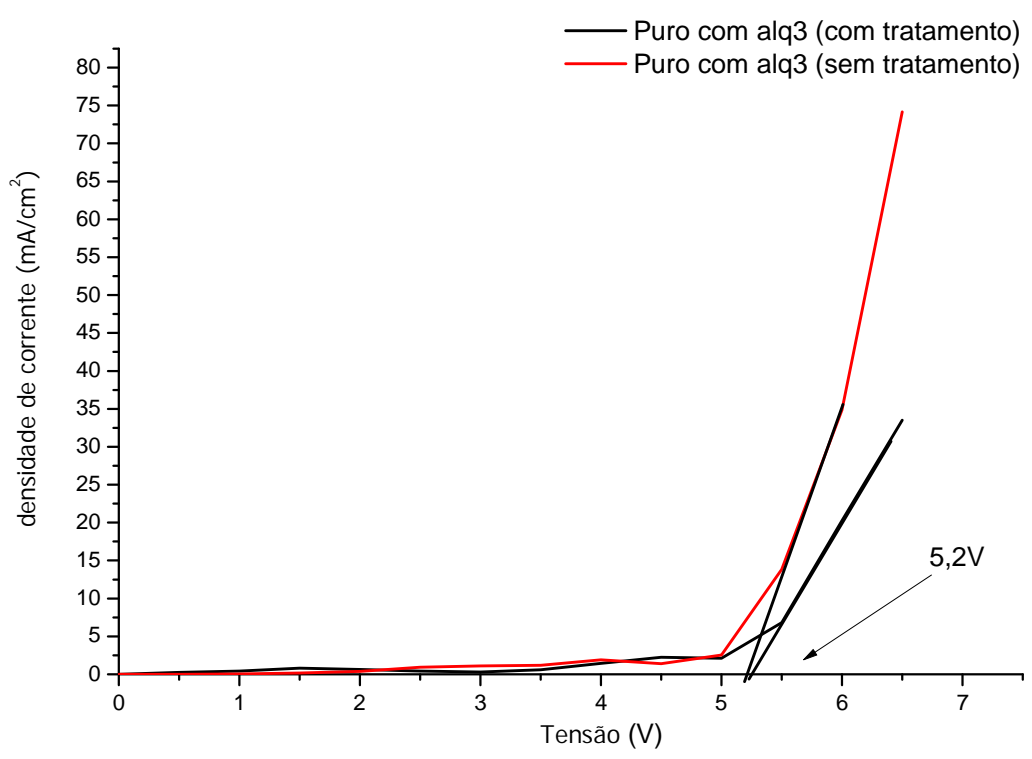

Figura 81 - Curva de Corrente vs. Tensão com e sem tratamento sobre o ITO com ETL. 
Através do gráfico da Figura 82 pode-se obter o pico de emissão do dispositivo quando aplicadas tensão de $20 \mathrm{~V}$ e corrente de $20 \mathrm{~mA}$, obtendo-se assim o seu comprimento de onda característico. Pelo gráfico podemos ver que esse comprimento de onda fica em torno de $550 \mathrm{~nm}$, o que o enquadra segundo o espectro eletromagnético apresentado na Figura 83 na cor verde-claro, é possível notar também que o dispositivo possui emissão em todo o espectro visível de radiação eletromagnética.

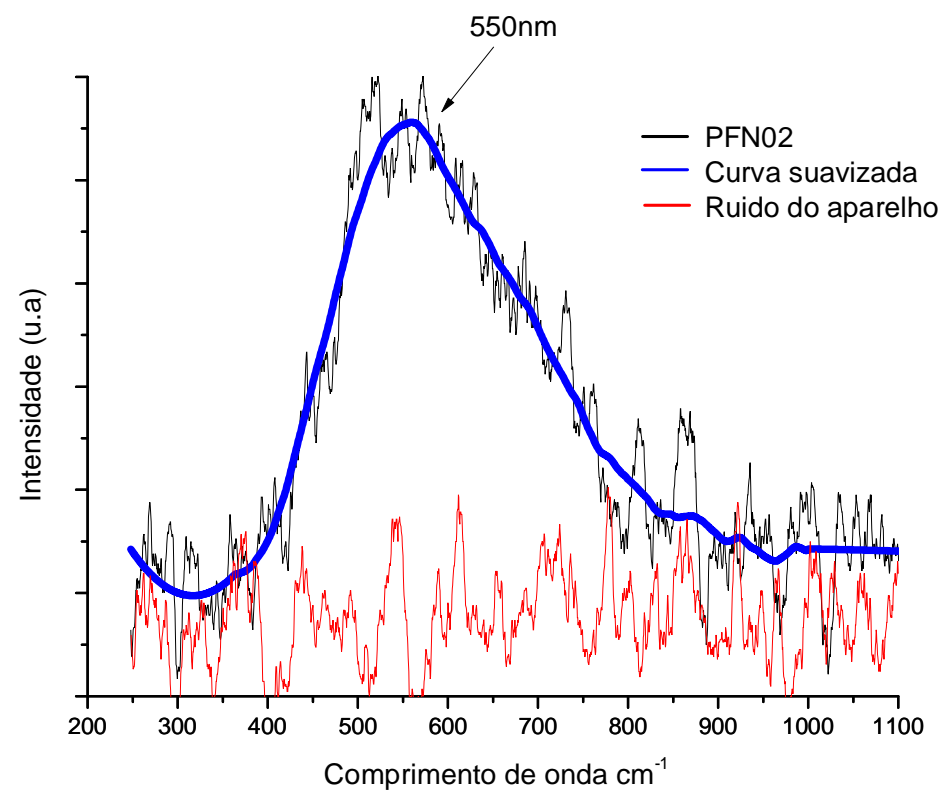

Figura 82 - Espectro de EL do PLED - ITO/PEDOT/PFNO2/AI.

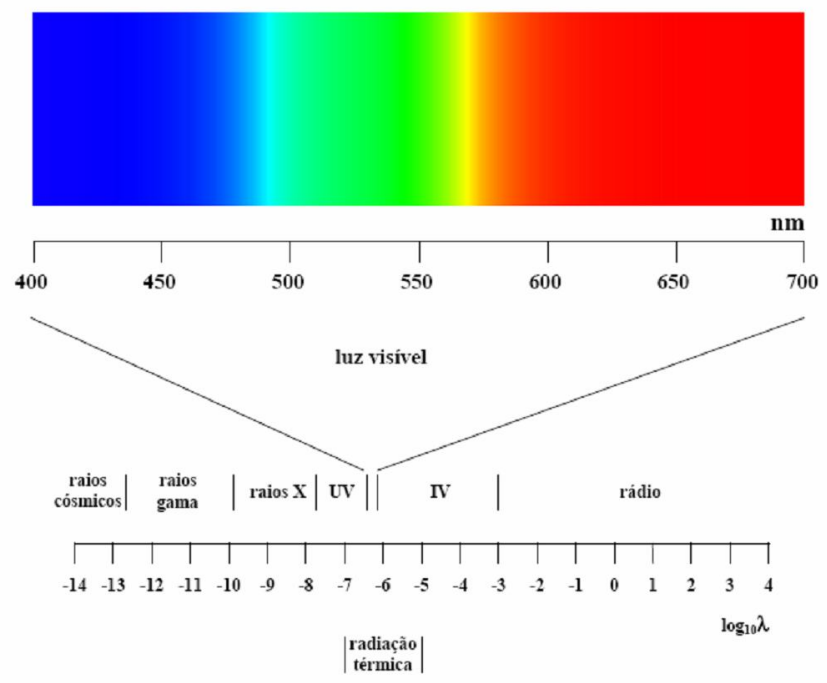

Figura 83 - Espectro eletromagnético mostrando as faixas de comprimento de onda de alguns tipos de onda eletromagnética e a banda correspondente à luz visível. 


\subsubsection{PLED com o copolímero PFN10 como camada ativa.}

A Figura 84 mostra as curvas características do PLED com o copolímero PFN10 como camada ativa, com tratamento superficial sob o ITO e com $10 \%$ em massa de PVK, constantes essas estabelecidas com base nos resultados já obtidos e discutidos na seção anterior (4.2.4.1).

Esse dispositivo apresentou uma tensão de limiar próxima a $8,5 \mathrm{~V}$, tensão essa bem superior aos dos dispositivos fabricados com o copolímero PFN02. Porém esse novo dispositivo se comportou de forma mais estável, sendo possível obter um registro fotográfico mostrado na Figura 85, apesar do dispositivo não ter sido preparado em atmosfera inerte e nem ter sido selado para evitar a oxidação.

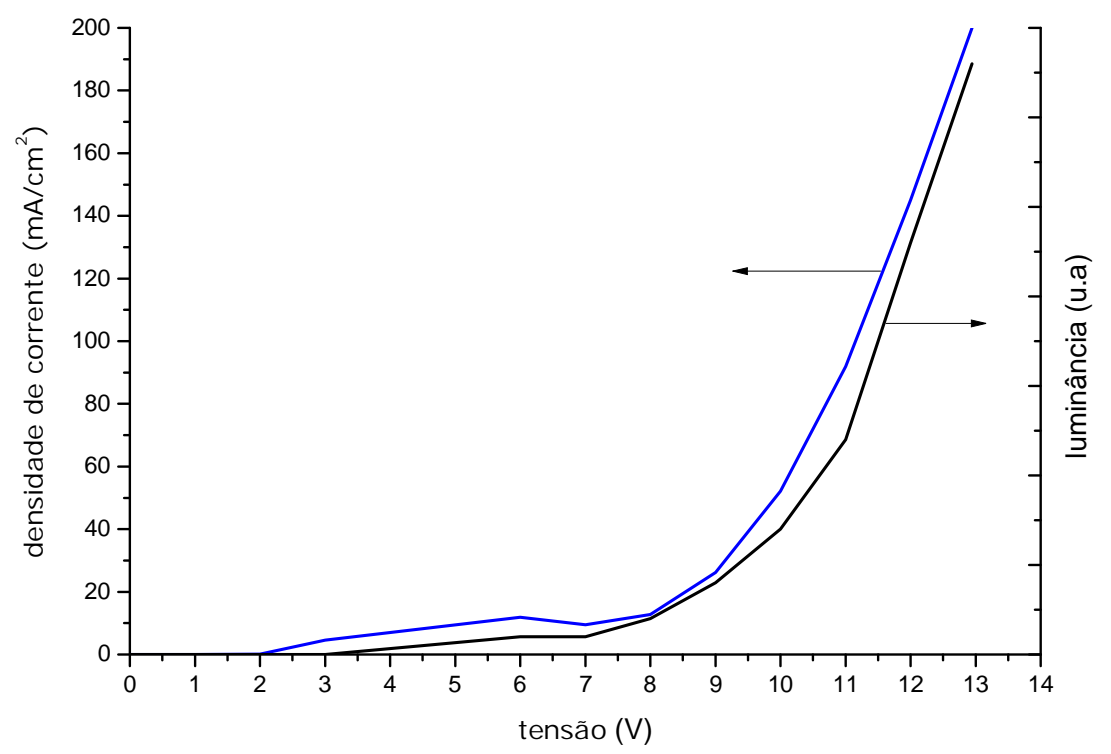

Figura 84 - Curva característica densidade de corrente vs. tensão e de Luminância do PLED ITO/PEDOT/PFN10/AI. 


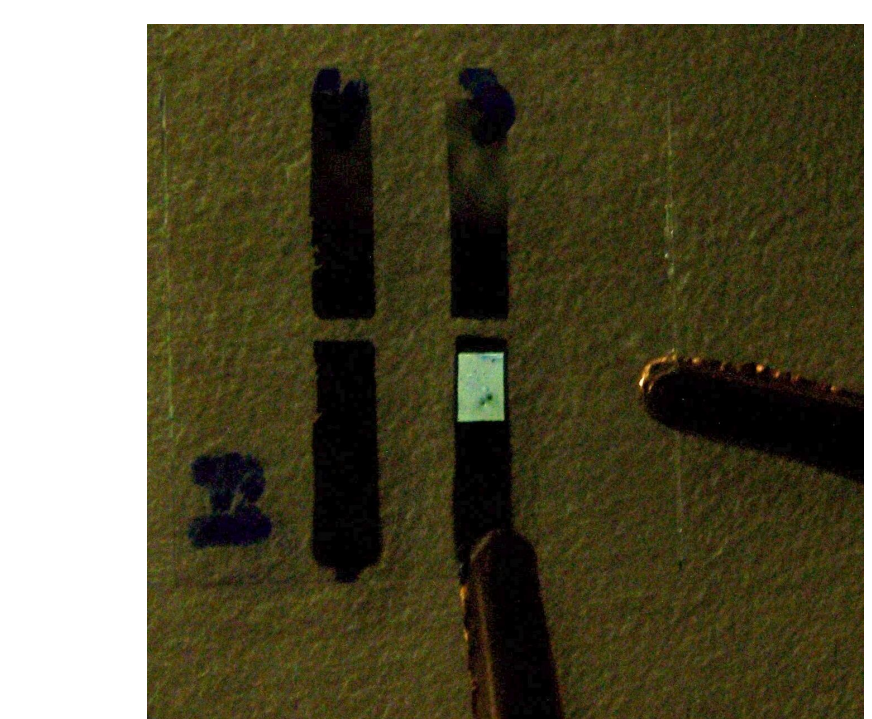

Figura 85 - Registro fotográfico do dispositivo ITO/PDOT/PFN10/Al.

A Figura 86 mostra o espectro de eletroluminescência do dispositivo quando aplicada uma tensão de $15 \mathrm{~V}$ e uma corrente de $20 \mathrm{~mA}$. Nela pode-se observar que o seu maior pico de emissão ocorre em 550 nm, mesmo pico apresentado para os dispositivos com o copolímero PFN02 como camada ativa.

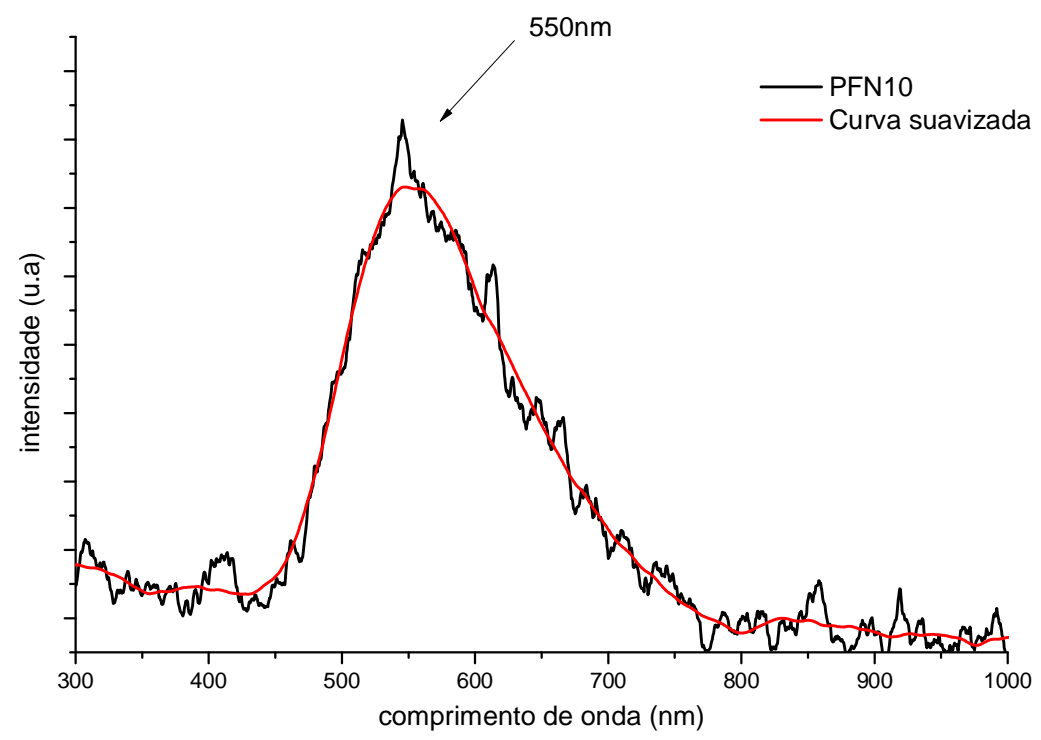

Figura 86 - Espectro de EL do PLED - ITO/PEDOT/PFN10/AI. 
Através desse dispositivo foi também obtido as coordenadas $\mathrm{CIE} x=0,2835$ e $y=0,4736$, coordenadas essas utilizadas para localizar os pontos no diagrama de cromaticidade mostrado na Figura 87.

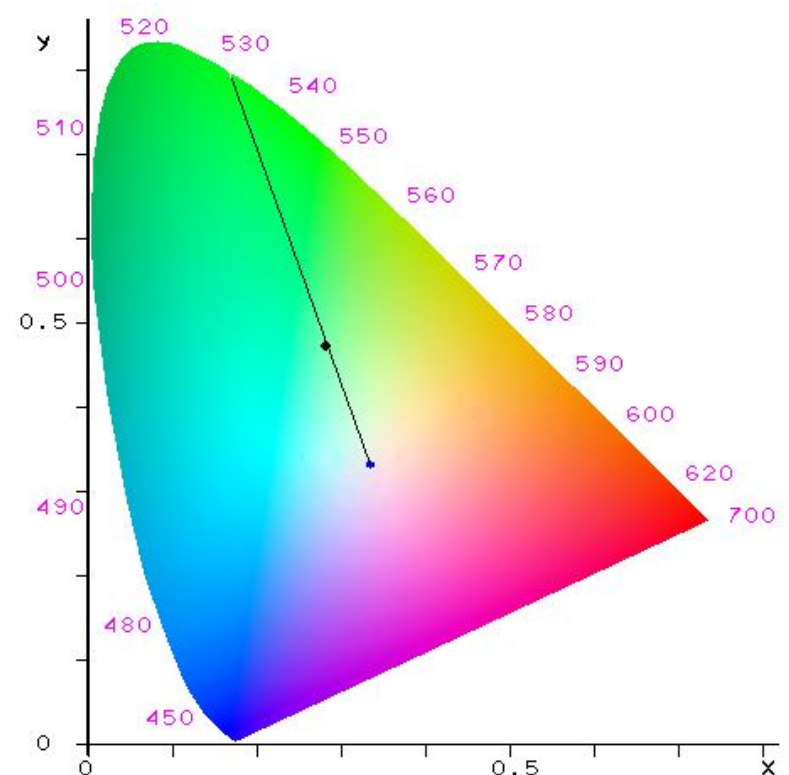

Figura 87 - Diagrama de Cromaticidade com as coordenadas $x$ e y da EL do dispositivo ITO/PEDOT/PFN10/Al. 


\section{CONCLUSÕES}

O presente trabalho teve como finalidade o estudo de um novo copolímero que tivesse boas propriedades semicondutoras para a aplicação na construção de PLEDS.

Através de uma modificação na rota de síntese por acoplamento de Suzuki com a inclusão de um agente transferidor de fases o cloreto de benzalcônio e um maior controle do sistema de refluxo é possível obter copolímeros com rendimento próximos a $90 \%$ e com maiores massas molares, comprovada pelos resultados de GPC.

Os copolímeros PFN01 e PFN02 possuíam picos de absorbância nas regiões de 245 e $314 \mathrm{~nm}$ tendo apenas como diferença a variação da intensidade dos picos sendo os seus gaps ópticos 3,46 e 3,35eV respectivamente, já para o PFN10 os picos de absorção foram deslocados sendo eles nas regiões de 263 e 330nm apresentando um gap óptico $3,27 \mathrm{eV}$. Com relação ao pico de emissão ambos os copolímeros emitem na mesma região de $419 \mathrm{~nm}$, havendo um deslocamento para o vermelho quando comparado com os materiais de partida 9,9-Dioctil-2,7dibromofluoreno e 5,7-dibromo-8-oxioctil-quinolina, possuindo rendimentos quânticos utilizando o sulfato de quinina como referência de aproximadamente $64 \%$ para o PFN01, 68\% para PFN02 e 82\% para o copolímero PFN10.

Através das análises de infravermelho e de EDX não foi possível comprovar a existência de vibrações de grupos boronados e halogenados na estrutura, o que é bastante satisfatório, já que a presença destes grupos na estrutura seriam impurezas não desejáveis que poderiam atuar como armadilhas de elétrons prejudicando o futuro desempenho dos dispositivos.

A análise de TGA forneceu a temperatura inicial de degradação dos copolímeros, em torno de $260^{\circ} \mathrm{C}$ para PFN01 e PFN02 e em torno de $330^{\circ} \mathrm{C}$ para o PFN10, o que para a aplicação em dispositivos eletrônicos é mais do que suficiente. Através destas análises foi também possível concluir que a modificação na rota de Suzuki teve efeito, visto que houve diferenças nas curvas de degradação dos copolímeros sintetizados, o que pode levar que crer que na síntese do copolímero PFN01 além de um menor rendimento comprado com o PFN02 e PFN10 teve uma 
temperatura onde ocorre a maior degradação inferior, comprovando mais uma vez a diferença nas massas molares.

Dados de GPC mostram uma diferença de aproximadamente $50{ }^{\circ} \mathrm{C}$ nas temperaturas de transição vítrea entre os copolímeros PFN02 $\left(-21^{\circ} \mathrm{C}\right)$ e PFN10 $\left(20^{\circ} \mathrm{C}\right)$.

Dados de voltametria cíclica comprovam a influência da quinolina na estrutura dos copolímeros de forma a reduzir o gap, comprovando também a sua influência relacionado ao aumento da massa molar

Quanto a montagens dos dispositivos foi observado um problema com relação ao filme fino do copolímero PFN02 depositado, devido ao seu estado físico, isso foi resolvido com a adição de $\mathrm{PVK}$, que fez com que o filme ficasse mais sólido e tendo uma melhor deposição e com menos desfeitos, como pode ser constatado pelas imagens de microscopia ótica, a diferença entre 10 e 20\% em massa de PVK pouco foi notada, ficando então como padrão para as próximas construções a proporção de $10 \%$.

Através das curvas Corrente vs. Tensão, pode-se chegar a conclusão que o uso de um ETL, no caso $\circ \mathrm{Alq}_{3}$, para esses dispositivos se tornaram totalmente dispensáveis comprovando a ação injetora de elétrons da quinolina presente na estrutura do copolímero.

Montado os PLEDS foi obtido as curvas de diodo e o espectro de emissão de luz do dispositivo. Pelas curvas de diodo é possível observar as tensões de limiar e as tensões de operação de cada dispositivo. Os dispositivos sem PVK apresentaram tensões de limiar em torno de 6,5 V, e o copolímero PFN02 com 10\% e com 20\% em torno de 5,1 e 4,9V respectivamente, o que pode-se chegar a conclusão também que quantidades maiores de $10 \%$ pouco influenciam no desempenho dos dispositivos.

Apesar dos dispositivos montados com o copolímero PFN10 apresentarem uma maior tensão de limiar comparado aos dispositivos montados como o PFN02, estes se comportaram de forma mais estável e possuindo uma emissão de luz constante em toda a região ativa dos dispositivos. O dispositivo tem emissão em praticamente todo o espectro visível, porém com um pico de emissão máximo em torno do comprimento de onda de $550 \mathrm{~nm}$. 


\section{REFERÊNCIAS BIBLIOGRÁFICAS}

Pope M.; Kallmann H.P.; Magnante P. Electroluminescence in organic crystals. J.Chem.Phys, 1963, 38 2042-2043p.

2 FINCHER C. R.; PEEBLES D. L.; HEEGER A. J.; DRUY M. A.; MATSUMURA Y.; SHIRAKAWA $H$. and IKEDA S. Anisotropic optical properties of pure and doped polyacetylene. Solid State Communications, 1978, v. 27, 489-494 p.

3 CHIANG C. K.; FICHER C.R.; PARK Y. W.; HEEGER A. J.; SHIRAKAWA H.; LOUIS, E. J.; GAU S.C.; MACDIARMID A.G. Electrical Conductivity in doped Polyacetylene. Phys. Rev. Lett. 1977, v.39, p. 1098.

4 PARTRIDGE R. H. Electroluminescence from polyvinylcarbazole films: 3. Electroluminescent devices. Polymer, 1983, v.24, 748 p.

5 TANG C.W.; VANSLYKE S.A.; Organic electroluminescent diodes. Appl. Phys. Lett. 1987, 51, 913 p.

6 BURROUGHES J. H.; JONES C. A.; FRIEND R. H. Polymeric semiconductor devices. Synthetic Metals, 1989, v.28, 735-745 p.

7 BURROUGHES J. H.; BRADLEY D. D. C., BROWN A. R., MARKS R. N., MACKAY K., FRIEND R. H., BURNS P. L., HOLMES A. B. Light-emitting diodes based on conjugated polymers. Nature, 1990, 347, 539-541 p.

8 DAI L.; WINKLER B.; DONG L.; TONG L.; MAU A. W. H. Conjugated Polymers for Light-Emitting Applications. Adv. Mater. 2001, 13, 915-925 p.

9 SALLEO A. Charge transport in polymeric transistors. Materials Today, 2007, 10, 38-45 p.

10 INZELT G.; PINERI M.; SCHULTZE J.W.; VOROTYNTSEV M.A.; Electron and proton conducting polymers: recent developments and prospects. Electrochimica Acta. 2000, 45, 2403-2421 p.

11 AKCELRUD L. Electroluminescent polymers. Progress in Polymer Science, Prog. Polym. Sci, 2003, 28, 875-952 p.

12 BERNTSEN A.; CROONEN Y.; LIEDENBAUM C.; SCHOO H.; VISSER R.; VLEGGAAR J.; WEIJER P. Stability of polymer LEDs. Optical Materials, 1998, v.9, $125-133$ p.

13 OLIVEIRA H. P. M.; COSSIELLO R. F.; ATVARS T. D. Z.; AKCELRUD L. Dispositivos poliméricos eletroluminescentes. Química. Nova, 2006, 29, 277-286 p. 
14 CALLISTER W. D. Ciências e Engenharia de Materiais: Uma Introdução. 5ed. Rio de Janeiro, LTC.

15 FRIEND, R.H. Semiconductor device physics of conjugated polymers. Sol. Stat. Phys. 1995, 49, 1 p.

16 GLOGAUER, A. Síntese e caracterização fotofísica de dois copolímeros eletroluminescentes: um completamente conjugado e outro multibloco tendo como unidade cromófora o fluoreno-vinileno-fenileno. Dissertação de mestrado, Universidade Federal do Paraná, Paraná, 2004.

17 DEUS J. F. Dispositivos Poliméricos emissores de luz branca. Tese de doutorado, Universidade Federal do Paraná, Paraná, 2008.

18 FRIEND R. H.; et al. Electroluminescence in Conjugated Polymers. Nature, 1999, 397, 121-128 p.

19 C.A.M. Borges, Processos radiativos e não radiativos em polímeros conjugados emissores de luz, Dissertação de Mestrado, Instituto de Física de São Carlos. São Paulo, 2001.

20 MIYAURA N.; SUZUKI A. Palladium-Catalyzed Cross-Coupling Reactions of Organoboron Compounds Chem. Rev. 1995, 95, p. 2457-2483 p.

21 SUZUKI A. Recent advances in the cross-coupling reactions of organoboron derivatives with organic electrophiles, 1995-1998. Journal of Organometallic Chemistry, 1999, 576, 147-168 p.

KOTHA S.; LAHIRI K.; KASHINATH, D. Recent applications of the SuzukiMiyaura cross-coupling reaction in organic synthesis. Tetrahedron, 2002, 58, 9633-9695 p.

YAMAMOTO T.; MORITA A.; MUYAZAKI Y.; MARUYAMA T.; WAKAYAMA H.; ZHOU Z-H.; NAKAMURA Y.; KANBARA T.; SASAKI S.; KUBOTA K.; Preparation of pi-conjugated poly(thiophene-2, 5-diyl), poly( p-phenylene), and related polymers using zerovalent nickel complexes. Linear structure and properties of the pi-conjugated polymers. Macromolecules, 1992, 25, 1214-1223 p.

24 ACKERMANN M.; BERGER S. Wittig reactions of moderate ylides with heteroaryl substituents at the phosphorus atom. Tetrahedron, 2005, 61, 6764-6771 p.

MORATTI S. C.; CERVINI R.; HOLMES A. B.; BAIGENT D. R.; FRIEND R. H. Hight Eletron affinity polymers for LEDs, Synthetic Metals, 1995, 71, $2117-$ $2120 \mathrm{p}$. 
27 GURAM A. S.; WANG X.; BUNEL E. E.; FAUL M. M.; LARSEN R. D.; MARTINELLI M. J. New Catalysts for Suzuki-Miyaura Coupling Reactions of Heteroatom-Substituted Heteroaryl Chlorides. Journal of Organometallic Chemistry, 2007, 72, 5104-5112 p.

ASSAKA A. M. Síntese e caracterização de copolímeros conjugados contendo fluoreno para aplicações em dispositivos Eletro - ópticos. Tese de Doutorado, Universidade Federal do Paraná, Paraná, 2006 Tuning in Bis-Dipolar Diphenylamino-Endcapped Oligoarylfluorenes. Chemistry of materials, 2005, 17, 5032-5040p.

INBASEKARAN M.; WU W.; WOO E. P. Process for preparing conjugated polymers US Patent 5777070 - july, 1998.

JANG S. H.; TAI T. B.; KIM M. K.; HAN J. W.; KIM Y.; SHIN S. C.; YOON Y. J.; KWON S. K.; LEE S. G. Synthesis and Physical Properties of Decylbithiophene End-Capped Oligomers Based on Naphthalene, Anthracene and Benzo[1,2-b:4,5-b']dithiophene. Bull. Korean Chem. Soc, 2009, 30 (3), 618-622 p.

PARKER C.A. Photoluminescence of Solutions. 1968, Amsterdam: American Elsevier

BANGCUYO C. G.; RAMPEY-VAUGHN M. E.; QUAN L. T.; ANGEL S. M.; SMITH M. D.; BUNZ U. H. F. Quinoline-Containing, Conjugated Poly(aryleneethynylene)s: Novel Metal and $\mathrm{H}^{+}$responsive Material. Macromolecules, 2002, 35, 1563-1568 p.

ZHANG X.; SHETTY A.S.; JENEKHE S.A. Electroluminescence and photophysical properties of polyquinolines. Macromolecules, 1999, 32, 7422-7429 p.

NORRIS, S. O.; STILLE, J. K. Synthesis and solution properties of phenylated polyquinolines. Utilization of the Friedlander reaction for the synthesis of aromatic polymers containing 2,6-quinoline units in the main chain. Macromolecules, 1976, 9, 496-505 p.

STILLE, J. K. Polyquinolines. Macromolecules, 1981, 14, 870-880 p.

37 SCHULER T. E.; WANG S. H.; ONMORI R. K.; POSSIDONIO S. Synthesis and characterization of semiconductor polymers having different phenylenevinylene conjugation lengths. Journal of Materials Science, 2008, 43, 541$545 p$. segmentos de vinilcarbazol e derivados de estireno, Tese de Doutorado, Universidade de São Paulo, São Paulo, 2006. 
NEHER D. Polyfluorene Homopolymers: Conjugated Liquid-Crystalline Polymers for Bright Blue Emission and Polarized Electroluminescence. Macromol Rapid Commun, 2001, 22, 1365-1385 p.

LÉVESQUE I. et al. Organic tunable electroluminescent diodes from polyfuorene derivatives. Synthetic Metals, 2001, 122 79-81 p.

KANG J.; Jo J.; YOUNGEUN J.; LEE S. Y., KEIVANIDIS P. E.; WEGNER G.; YOON D. Y. Time-resolved photoluminescence study of low-energy emission mechanisms in oligofluorene and polyfluorene films. Polymer, 2008, 49, 5700-5704 p.

LECLERC M. Polyfluorenes: Twenty Years of Progress. Journal of Polymer Science: Part A: Polymer Chemistry, 2001, 39, 2867-2873 p.

SCHERF U.; LIST E.J.W. Semiconducting Polyfluorenes - Towards Reliable Structure-Property Relationships. Advanced Materials, 2002, 14, 477-487 p.

KLAERNER G.; MILLER R. D. Polyfluorene Derivatives: Effective Conjugation Lengths from Well-Defined Oligomers. Macromolecules, 1998, 31, 2007-2009 p.

YOSHINO K. et al. Electrical and Optical Properties of Poly(3,4-

dialkylthiophene). J. Phys. Soc. Jpn. 1989, 58, 1320-1324 p.

FUKUDA M.; SAWADA K.; YOSHINO K. Fusible Conducting Poly(9alkylfluorene) and Poly(9,9-dialkylfluorene) and Their Characteristics.. J. Appl. Phys Jpn. 1989, 28, 1433-1435 p.

GRAZULEVICIUSA J. V.; STROHRIEGLB P.; PIELICHOWSKIC J.; PIELICHOWSKIC K.; Carbazole-containing polymers: synthesis, properties and applications. Prog. Polym. Sci. 2003, 28, 1297-1353 p.

JANUSIK M. M.; SANETRA J.; PALMER H.; BOGDAŁ D.; GONDEK E.; KITYK I. $\mathrm{V}$. Absorption spectra of poly- $\mathrm{N}$-vinylcarbazole derivatives by experiment and simulation. European Polymer Journal, 2004, 40, 799-804 p.

KHALIFA M. B.; VAUFREY D.; BOUAZIZI A.; TARDY J.; MAAREF H. Hole injection and transport in ITO/PEDOT/PVK/Al diodes. Materials Science and Engineering, 2002, 21, 277-282 p.

D'ANGELO P.; BARRA M.; CASSINESE A.; MAGLIONE M. G.; VACCA P.; MINARINI C.; RUBINO A. Electrical transport properties characterization of PVK (poly N-vinylcarbazole) for electroluminescent devices applications. Solid-State Electronics, 2007, 51, 123-129 p. 
51 SANETRA J.; ARMATYSB P.; CHRZASZCZB R.; PIELICHOWSKIB J.; BARTAC P.; NIZIOL S. Light Emitting diodes of the multilayer structures with modified PVK polymers. Synthetic Metals, 1999, 102, $1115 \mathrm{p}$.

LIN H. C.; TSAI C. M.; LIN J. T. S.; THOMAS J. K.R. Novel red and white PLED devices consisting of PVK blended with blue-emitting fluorene derivatives and carbazole dopants. Synthetic Metals, 2006, 156, 1155-1160 p.

ATVARS T. D.Z.; MARTELLI C. Espectroscopia de Luminescência.

Disponível em www.chemkeys.com; acessado 11 de maio 2009.

54 BIANCHI R. F. Estudo das propriedades eletrônicas e ópticas de filmes e dispositivos poliméricos. Tese de doutorado, Universidade de São Paulo, São Carlos, 2002.

SEDRA A. S.; SMITH K. S. Diodos, em Microeletrônica. 4ª Edição. Makron Books Ltda, São Paulo, 1998.

BRÜTTING W.; BERLEB S.; MÜCKL A. G. Devices physics of molecular light-emitting diodes based on molecuar materials. Organic electronics, 2002, 2, 1-36p.

57 HUNGA L. S.; CHEN C. H. Recent progress of molecular organic electroluminescent materials and devices. Materials Science and Engineering, 2002, 39, 143-222 p.

$\mathrm{KOCH}$ N. Organic Electronic Devices and Their Functional Interfaces. Chem. Phys. Chem. 2007, 8, 1438-1455p.

FRIEND R.; BURROUGHES J.; SHIMODA T. Polymer diodes. Phys. Word, 1999, 12 (6), 35-40 p. A.;JENEKHE S. A. Electron Transport Materials for Organic Light-Emitting Diodes. Chem. Mater. 2004, 16, 4556-4573p.

JAISWAL M.; MENON R. Polymer electronic materials: a review of charge transport. Polymer International,2006, 55, 1371-1384p.

CACIALLI, F. et al. Surface and bulk phenomena in conjugated polymers devices. Synthetic Metals, 2000, 109, 7-11 p.

PERES L. O.; ERRIEN N.; FAULQUES E.; ATHALIN H.; LEFRANT S.; MASSUYEAU F.; WERY J.; FROYER G.; WANG S. H. Synthesis and characterization of a new alternating copolymer containing quaterphenyl and fluorenyl groups. Polymer, 2007, 48, 98-104 p. 
64 JAREM R. G.; PERES L. O.; FERNANDES M. R.; GRUBER J.; NART F. C. One-step electrochemical synthesis of pure poly(2,5-dicyano-p phenylenevinylene) films. J Solid State Electrochem, 2004, 8, 122-126p.

SCHULER T. E, Síntese e caracterização de copolímeros randômicos poli[bis-(fenilenovinileno)-stat- (1,8-bis-(2,6-dioximetano-1,4fenilenovinileno) -ioxioctano)-1,4-fenileno)] e aplicação em diodos emissores de luz orgânicos, Dissertação de mestrado, Universidade de São Paulo, São Paulo, 2008.

66 SANTOS E. R. Estudos de tratamentos superficiais em substratos de óxidos transparentes condutivos para a fabricação de dispositivos poliméricos eletroluminescentes, Tese de doutorado, Universidade de São Paulo, São Paulo, 2008.

DEMAS J. N.; CROSBY G. A.; The Measurement of Photoluminescence Quantum Yields, Journal of Physical Chemistry, 1971, 75, 991-1024 p.

68 FERNANDES M. R. Síntese e caracterização espectroscópica de materiais para eletrônica molecular, Tese de doutorado, Universidade de São Paulo, São Carlos, 2002. 